University of Nebraska - Lincoln

DigitalCommons@University of Nebraska - Lincoln

$1-1998$

\title{
Chemical Information on Tank Supernatants, Cs Adsorption From Tank Liquids Onto Hanford Sediments, and Field Observations of Cs Migration From Past Tank Leaks
}

\author{
R. J. Serne \\ Pacific Northwest National Laboratory \\ John M. Zachara \\ Pacific Northwest National Laboratory, john.zachara@pnl.gov \\ D. S. Burke \\ Pacific Northwest National Laboratory
}

Follow this and additional works at: https://digitalcommons.unl.edu/usdoepub

Part of the Bioresource and Agricultural Engineering Commons

Serne, R. J.; Zachara, John M.; and Burke, D. S., "Chemical Information on Tank Supernatants, Cs Adsorption From Tank Liquids Onto Hanford Sediments, and Field Observations of Cs Migration From Past Tank Leaks" (1998). US Department of Energy Publications. 283.

https://digitalcommons.unl.edu/usdoepub/283

This Article is brought to you for free and open access by the U.S. Department of Energy at DigitalCommons@University of Nebraska - Lincoln. It has been accepted for inclusion in US Department of Energy Publications by an authorized administrator of DigitalCommons@University of Nebraska - Lincoln. 
PNNL-11495

UC-510

Chemical Information on Tank Supernatants, Cs Adsorption From Tank Liquids Onto Hanford Sediments, and Field Observations of Cs Migration From Past Tank Leaks
R. J. Serne
J. M. Zachara
D. S. Burke

January 1998

Prepared for

the U. S. Department of Energy under Contract DE-ACO6-76-RLO 1830

Pacific Northwest National Laboratory Richland, Washington 99352

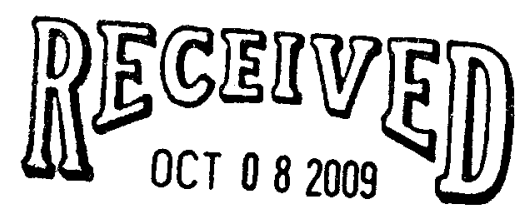

EDMC 


\section{DISCLAIMER}

This report was prepared as an account of work sponsored by an agency of the United States Government. Neither the United States Government nor any agency thereof, nor any of their employees, makes any warranty, express or implied, or assumes any legal liability or responsibility for the accuracy, completeness, or usefulness of any information, apparatus, product, or process disclosed, or represents that its use would not infringe privately owned rights. Reference berein to any specific commercial product, process, or service by trade name, trademark, manufacturer, or otherwise does not necessarily constitute or imply its endorsement, recommendation, or favoring by the United States Government or any agency thereof. The views and opinions of authors expressed herein do not necessarily state or reflect those of the United States Government or any agency thereof. 


\section{DISCLAIMER}

Portions of this document may be illegible electronic image products. Images are produced from the best available original document. 


\section{EXECUTIVE SUMMARY}

Borehole gamma-logging profiles beneath the SX-Tank Farm suggest that contamination from Cs-137 extends to at least a depth of $40 \mathrm{~m}(130 \mathrm{ft})$, and may extend even deeper. What is presently not known is the pathway that $\mathrm{Cs}-137$ has taken to reach these depths. In this report we provide an analysis of the chemistry of tank supernates with emphasis on the REDOX waste stream disposed in SX tanks, Cs chemistry in aqueous solutions and adsorption properties onto minerals, available data on Cs adsorption onto Hanford sediments, and information on Cs migration from other Hanford tank leaks that have been studied. The data in this report was used to help guide the vadose zone transport analysis of the SX Tank Farm presented in a companion report, Ward et al. (1997). The goal of the vadose zone transport modelling is to attempt to explain the depth and extent of the Cs-137 plume under the SX Tank farm, specifically in the vicinity of the greatest leak, near the SX-109 Tank as inferred from the gamma logs (DOE 1996).

In solution $\mathrm{Cs}$ is present as the monovalent cation and shows very little tendency to form aqueous complexes with inorganic or organic ligands. Cs is expected to adsorb primarily onto selective minerals that have unique adsorption sites. The small $\mathrm{Cs}^{+}$ion is accommodated on these frayed edge and interlayer sites. Adsorption within the interlayers often leads to collapse of the layers such that the $\mathrm{Cs}^{+}$ion is effectively trapped and not readily exchangeable by all other common cations. The degree of adsorption is thus only moderately dependent on the types and high concentrations of other cations in leaking tank liquors.

As the Pu separations processes improved over the years the quantity of inert salts added to tanks decreased and a significant reduction in the volume of high radioactivity waste per unit of $\mathrm{Pu}$ production resulted. This economically attractive decrease in unit volume of waste per unit of $\mathrm{Pu}$ production increased the fission product concentrations in waste and thus increased the heat generation from radioactive decay. The liquid level in self-boiling tanks was continually changing so that level measurements were not useful to assure no leaks occurred. We found that the REDOX liquid chemical composition varied significantly from its original state with time largely because of its high radioactivity content that created self-boiling conditions. Fresh REDOX waste had a chemical composition shown in Table 3.2 and was predominately a $4 \mathrm{M}$ sodium-nitrate-nitrite-aluminate-hydroxide solution. This composition was similar to other Hanford process wastes such as bismuth phosphate and PUREX waste liquids. But after self-boiling or other concentrating processes, the residual REDOX liquid exhibits a much higher ionic strength and perhaps higher basicity (free hydroxide content) in the range of 8-10 M Na and perhaps 0.5 to $1 \mathrm{M}$ free hydroxide. This chemical composition is beyond any for which sediment-contaminant adsorption studies have been performed. The comparison of the T-106 tank leak with SX Tank Farm leak(s) in terms of chemical composition of leaking liquid is not close enough to expect that the adsorption reactions between contaminants, especially $C s$ should be quantitatively similar. The chemical composition of the supernatant solution in T-106 at the time of the leak was much lower in dissolved $\mathrm{Na}, \mathrm{Al}$, and hydroxide content than the REDOX supernate. It is quite possible that 
the migration of Cs in SX tank liquors is larger than that observed for the T-106 tank leak.

REDOX solution chemistry exhibits much higher $\mathrm{Na}, \mathrm{Al}$ and hydroxide then solutions used in past Kd experiments. None of the available Kd tests, for Hanford sediments, or in general literature were run with liquids that contain more than $4 \mathrm{M}$ sodium and $\mathrm{pH}$ values were never above 12 (free hydroxide $\sim 0.01 \mathrm{M}$ ). The data that are available may be adequate to estimate Kd values for Cs in very fresh REDOX liquid that has not self-concentrated, but the data are not adequate to estimate $\mathrm{Kd}$ values for the higher ionic strength and higher $\mathrm{pH}$ solution that forms through self-boiling. Dependent upon when the SX tank leaks actually occurred, the chemical composition of the draining liquid would vary over a rather significant range. The extremely high $\mathrm{pH}$ condition might impact the $\mathrm{Cs}$ adsorption by dissolving bulk sediment or severely etch the selective mica minerals with their special frayed edge sites that likely perform most of the adsorption. About the only conclusion that can be offered, without empirical testing using such high ionic strength/high $\mathrm{Al}$ and high $\mathrm{pH}$ solutions, is that the $\mathrm{Cs} \mathrm{Kd}$ values could be lower than those reported in the available literature. As shown for the less concentrated T-106 liquid simulants, the Cs $\mathrm{Kd}$ value ranges from 0.5 to $12 \mathrm{ml} / \mathrm{g}$ across a range of solution compositions, with a more realistic $\mathrm{Kd}$ range of 2 to $6 \mathrm{ml} / \mathrm{g}$ for the simulant most representative of the tank liquor (see Table 4.3 Solution II).

The three extensive field studies of past tank leaks support the conceptual model that Cs is not as mobile as other contaminants and does not appear to migrate tens of meters from the tank bottoms over the time periods of a few years to up to about 30 years after suspected leak events. But as mentioned above, the REDOX metal or fission product bearing-waste composition found in SX tanks varies significantly from the bismuth phosphate-type wastes that were in tanks BX-102 and the combined bismuth phosphate and REDOX cladding wastes present in T-106 at the time of the leak, such that it may not be useful to compare Cs behavior between SX tank farms with these two field studies of leaks. On the other hand Raymond and Shdo (1966) did study two leaks from the SX tank farm approximately two years after the suspected leaks and their data show Cs migration of only a few meters over this period.

One can conclude from all this available information that $\mathrm{Cs}$ is not very mobile if the liquid in which it is being carried is more dilute than that in tank supernates and drainable liquid. The very leading edge of solution from a tank leak plume should interact and be diluted by the existing vadose zone sediment pore water such that there should be some retardation in Cs migration until the volume of leak plume water has had an opportunity to completely dominate the sediment pore water chemistry. The volume that may have leaked from any tank in the SX tank farm or other tank farms is smaller than the water that would be needed to completely control all the sediment above the water table, IF the flow path was not some isolated preferred pathline such as a fracture, clastic dike, open borehole or loosely consolidated annulus around the borehole. Regardless of the chemistry of the leaking tank liquor it is unlikely that the Cs in the leak plume could migrate all the way to the water table without significant adsorption occurring in sediments away from the tank bottom and closer to the water table, unless one of these preferred isolated paths were carrying the leaking solution. 
This does not rule out low concentrations (the very early leading edge of a breakthrough curve) of ${ }^{137} \mathrm{Cs}$ reaching the water table. The transport modeling described in Ward et al. (1997) further elaborates on this issue.

A few scoping studies were funded at the end of FY96 with the goals to get an indication on the adsorption tendencies of $\mathrm{Sr}$ and $\mathrm{Cs}$ from a solution with very high ionic strength, high $\mathrm{Na}$, high $\mathrm{Al}$ and high $\mathrm{OH}$ content and to see whether the high $\mathrm{OH}$ might significantly dissolve the existing sediment. Work was conducted over one month period. The scoping tests were not successful at bounding the probable fate of $\mathrm{Sr}$ and Cs radionuclides in REDOX waste tanks in the SX Tank Farm. The very high Al, Na and nitrate contents measured in the past were not sustained in our simulated tank liquor. The $\mathrm{Al}$ especially seems to remain reactive with time and elevated temperatures resulting in the precipitation of very fine grained (high surface area) material that has been identified as bayerite, an $\mathrm{Al}$ hydroxide. The measurement of the adsorption properties of $\mathrm{Sr}$ and $\mathrm{Cs}$ from the evolving REDOX solution was difficult. $\mathrm{Sr}$ is not soluble in the REDOX solution as long as Al precipitation is occurring. The literature review and past analytical measurements of tank waste phases also supports this conclusion. Cs is essentially soluble but upon contact with sediment and further precipitation of $\mathrm{Al}$ bearing material there appears to be a higher than expected sorption (Kd). The flow-through column Cs adsorption data corroborates the batch Kd tests. The observed Kd for Cs-137 in the range of 20 to $60 \mathrm{ml} / \mathrm{g}$ dependent on whether the solution is filtered or only gravity settled, is much larger than expected and appears to disagree with the values necessary to get the results of transport predictions to mimic gamma logging results of Cs in vadose zone sediments underlying the SX Tank Farm (see Ward et al. 1997).

If the $\mathrm{Al}$ precipitation is the key to the higher than expected $\mathrm{Cs}$ adsorption and if the $\mathrm{Al}$ in the REDOX liquor is rapidly removed by the sediments surrounding the tank, then perhaps the Cs $\mathrm{Kd}$ would be much lower beyond the zone of $\mathrm{Al}$ precipitation. Without more empirical adsorption data on REDOX solutions interacting with Hanford sediments with emphasis on the $\mathrm{Al}$ chemistry, all we can offer is that the Kd for Cs may be lower than the range determined in the scoping studies. It is clear that more resources and testing would be needed to better interpret the fate of cesium, strontium and other contaminants present in REDOX tank liquors.

Simple weight measurements of Hanford sediments after contact with the very high caustic REDOX solution showed no significant weight loss, but the possibility of significant dissolution with simultaneous reprecipitation of other phases is still possible. It seems certain that the high Al content in the REDOX solution does react with soil to precipitate $\mathrm{Al}$ hydroxide phase(s). At some point away from the tanks, the tank leak liquor would be expected to be "neutralized" by the sediments large buffering capacity to consume free hydroxide and one should see a re-precipitation of the silica and aluminum to form amorphous coatings/gel that could lower permeability as well as coprecipitate (physically trap) or adsorb other soluble components such as Cs. The precipitation of Al hydroxide was observed in all of the scouting tests and appears to enhance the adsorption of Cs. Thus it is difficult to say that the fate of Cs should follow a monotonically increasing adsorption (Kd) as the distance from 
the tank increases. It appears that the fate of $\mathrm{Cs}$ may be controlled by a complicated mix of parameters such as competing cations, $\mathrm{pH}$, and presence of fresh precipitates such as $\mathrm{Al}$ hydroxides. The net effect may cause the $\mathrm{Kd}$ to vary widely with increases and decreases as a function of distance from the tank.

Based on groundwater data presented in Caggiano (1996) there is no indication that matrix dissolution products (high $\mathrm{Si}, \mathrm{Al}$ and $\mathrm{pH}$ ) have reached the groundwater below $\mathrm{SX}$ tanks and further one might expect that massive dissolution would manifest itself in the near vicinity of the tanks as more porous material with perhaps copious gel-like coatings. It is possible that the high ${ }^{137} \mathrm{Cs}$ found by gamma spectral logging in several SX-tank farm boreholes at the 75foot level is an indication of how far the matrix dissolution impact has reached. If there was a significant accumulation of precipitated Al hydroxide in the 75-foot zone perhaps it would adsorb large amounts of $\mathrm{Cs}$ and appear as highly concentrated material in the gamma logs. This would imply a zone of reaction of about 20-25 feet below the tank bottoms.

More detailed and complete solution and solid (both sediment and reaction products) characterization of actual contaminated samples obtained from field sampling or laboratorygenerated samples after simulated tank liquor contacts clean sediments are required. Techniques such as inductively coupled plasma-mass spectrometry [ICP-MS], scanning electron microscopy [SEM-EDS], $x$-ray diffraction [XRD], high resolution transmission electron microscopy [HRTEM] and atomic force microscopy [AFM] would be needed to help interpret the complicated reactions expected when REDOX liquors contact Hanford sediments. 


\section{CONTENTS}

Executive Summary $\ldots \ldots \ldots \ldots \ldots \ldots \ldots \ldots \ldots \ldots \ldots \ldots \ldots \ldots$ iii

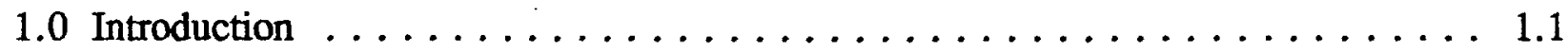

2.0 Cs Geochemistry $\ldots \ldots \ldots \ldots \ldots \ldots \ldots \ldots \ldots \ldots \ldots \ldots \ldots \ldots \ldots \ldots \ldots \ldots \ldots .1$

2.1 Cs Aqueous Geochemistry . . . . . . . . . . . . . 2.1

2.2 Cs Adsorption Mechanisms $\ldots \ldots \ldots \ldots \ldots \ldots \ldots \ldots \ldots .2$

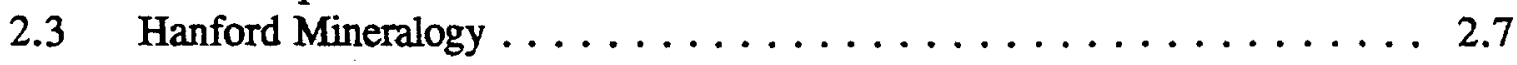

3.0 General REDOX Chemistry and SX Tank Farm History $\ldots \ldots \ldots \ldots . \ldots .1$

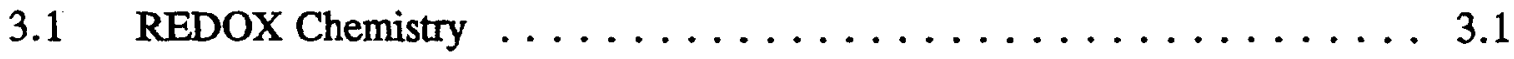

3.2 SX Tank Farm History $\ldots \ldots \ldots \ldots \ldots \ldots \ldots \ldots \ldots \ldots \ldots . \ldots \ldots \ldots$

3.3 Observed Cs Concentrations/Activities in Other Tanks . . . . . . 3.8

3.4 Section Summary $\ldots \ldots \ldots \ldots \ldots \ldots \ldots \ldots \ldots \ldots \ldots \ldots \ldots$

4.0 History of Cs Kd Values for Hanford Sediments [Based on Laboratory Studies] $\quad \ldots 4.1$

4.1 Bismuth Phosphate Waste Streams . . . . . . . . . . . . 4.1

$4.2 \quad$ T-106 Tank Simulants . . . . . . . . . . . . . 4.2

4.3 Miscellaneous Simulated Solutions . . . . . . . . . . . 4.3

4.4 Miscellaneous Actual Waste Streams $\ldots \ldots \ldots \ldots \ldots \ldots \ldots \ldots .7$

4.5 Section Summary $\ldots \ldots \ldots \ldots \ldots \ldots \ldots \ldots \ldots \ldots \ldots$

5. 0 Scoping Lab Tests on SX Tank Liquor Interactions with Hanford Sediments . . . 5.1

5.1 Summary of Past Sediment-Caustic Tank Liquor Interactions $\ldots \ldots \ldots 5.1$

5.2. Preparation of Simulated Tank Liquor $\ldots \ldots \ldots \ldots \ldots \ldots \ldots .3$

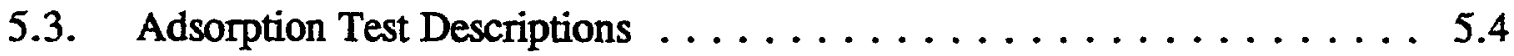

5.3.1. Batch Kd Tests . . . . . . . . . . 5.4

5.3.2 Flow Through Column Tests . . . . . . . . . 5.7

5.4. Sediment Dissolution Tests $\ldots \ldots \ldots \ldots \ldots \ldots \ldots \ldots . . \ldots$

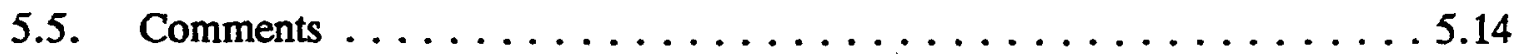

6.0 Field Observations of Cs Migration Underneath Hanford Disposal Facilities . . . . 6.1

6.1 Studies of Past Tank Leaks-Cs Data . . . . . . . . . . . 6.1 


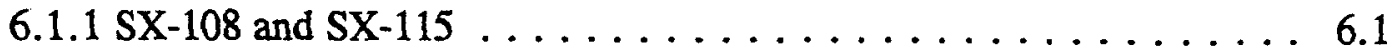

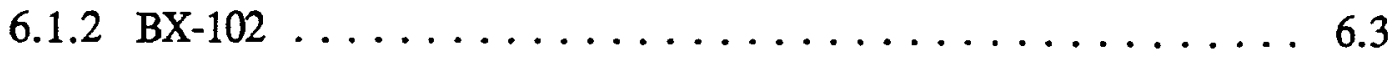

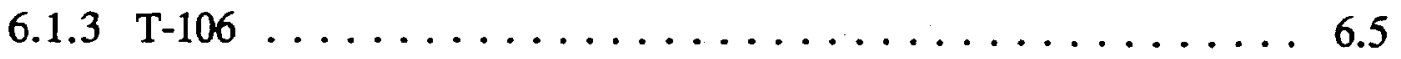

6.2 Cs Migration Underneath Various Liquid Disposal Facilities $\ldots \ldots \ldots 6.8$

6.3 Field Experiment - Sisson and Lu Test $\ldots \ldots \ldots \ldots \ldots \ldots .11$

6.4 Ammonia Discharges at Hanford $\ldots \ldots \ldots \ldots \ldots \ldots \ldots .12$

7.0 Conclusions and Recommendations $\ldots \ldots \ldots \ldots \ldots \ldots \ldots \ldots \ldots \ldots$

8.0 References $\ldots \ldots \ldots \ldots \ldots \ldots \ldots \ldots \ldots \ldots \ldots \ldots \ldots \ldots \ldots .1$

Appendix A. Details on Accessing the Tank Characterization Data Base $\ldots \ldots \ldots$ A.1 


\section{FIGURES}

2.1 Sorption Environments for $\mathrm{Cs}^{+}$Onto $2: 1$ Layer Silicates $\ldots \ldots \ldots \ldots \ldots 2.4$

2.2 General Stratigraphy of Sediments Underlying Hanford's 200 Areas . . . . . 2.8

2.3 Hanford and Ringold Formation Lithology and Stratigraphy at T Tank Farm

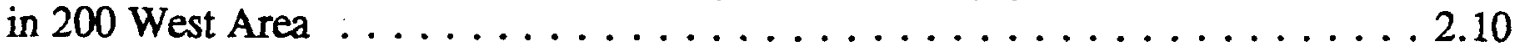

2.4 Mineralogy of Clay-Sized Particles in Hanford and Ringold Formations . . . . . 2.11

2.5 Types of Clays in Various Facies of Hanford and Ringold Formations . . . . . 2.11

3.1 Conceptual Structures of Al-Hydroxy Interlayered 2:1 Layer-Silicates

[From Barnhisel and Bertsch (1989)] . . . . . . . . . . . . . 3.17

$5.1{ }^{137} \mathrm{Cs}$ Breakthrough in SX Tank Simulant in Hanford Sediment . . . . . . 5.10

$5.2{ }^{137} \mathrm{Cs}$ Adsorbed in SX Sediment Column as a Function of Depth . . . . . . . 5.10

$5.3 \mathrm{pH}$ vs. Pore Volume in Effluent from Sediment Column $\ldots \ldots \ldots \ldots . \ldots 5.11$

\section{TABLES}

2.1 Stability Complexes for Various Metals with EDTA $\ldots \ldots \ldots \ldots \ldots \ldots .1$

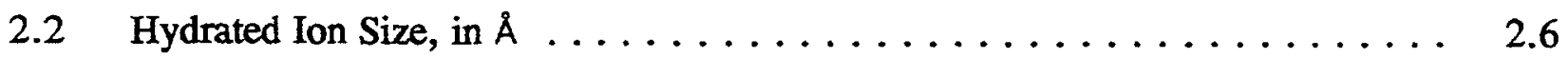

2.3. Representative Hanford/Ringold Formation Properties . . . . . . . . . . 2.9

3.1 Current Status of SX Tanks $\ldots \ldots \ldots \ldots \ldots \ldots \ldots \ldots \ldots \ldots \ldots \ldots$

3.2 Agnew's (1995) Estimated Chemical Composition of REDOX Wastes . . . . . . 3.5

3.3 Agnew's et al. (1996) Estimate of Supernate Compositions in SX-Tanks . . . . 3.6

3.4 Historical Analysis of Supernate Solutions in SX Tanks and Comparison to Agnew's Predicted Current Supernates in SX Tanks with Drainable Liquor . . . 3.7

3.5 Estimate of the Types of Waste Currently in Tanks Studied by Weiss and Schull . 3.9

3.6 Chemical/Radionuclide Composition of Supernate Liquid Tank T-106 . . . . . . 3.11 
3.7 Agnew Predictions of Chemical Composition of Waste in Tank T-106 in $1973 \ldots 3.12$

4.1 Kd Values (units $=\mathrm{ml} / \mathrm{g}$ ) for Cs Using 7 Hanford Sediments and Five Simulated Tank T-106 Liquors . . . . . . . . . . . . . . . . . 4.3

4.2 Description of Sediments Used in Kd Tests for T-106 Leak . . . . . . . . . . . 4.4

4.3 Chemical Composition of the Five Simulated T-106 Tank Liquors . . . . . . . 4.4

5.1 Composition of the Synthetic Tank Liquor Used by Shade (1974) _ . . . . . 5.2

5.2 Measured Composition of the Solution vs. Desired Composition If All Chemicals Had Dissolved . . . . . . . . . . . . . . . . . . 5.4

5.3 Unfiltered Kd Values [m1/g] for $\mathrm{Sr}$ and Cs From REDOX Liquor Contacting a Coarse Hanford Sand . . . . . . . . . . . . . . . . 5.5

5.4 REDOX Solution Chemical Composition After Contacting Sediment . . . . . . 5.6

5.5 Data From the Dissected Column $\ldots \ldots \ldots \ldots \ldots \ldots \ldots \ldots$

5.6 Net Weight Change in Sediment/Rxn Product Solids After Contacting REDOX

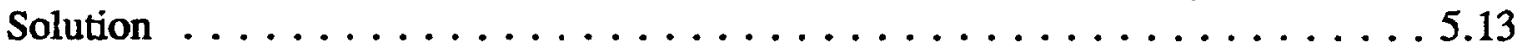

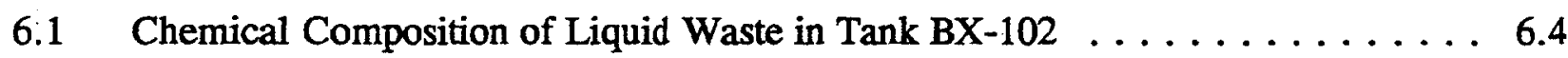




\subsection{INTRODUCTION}

One activity within DOE-RL's Vadose Zone Characterization Project has been conducted the DOE-Grand Junction Projects Office (GJPO). Individual boreholes are logged with gamma spectral analysis tools, and raw measurements are then analyzed and interpreted by the DOE-GJPO technical team. When the gamma spectral logging of boreholes surrounding all tanks in a particular Tank Farm have been completed, the results/interpretation are discussed in a specific Tank Farm Report. The first completed report is for the SX Tank Farm (DOE 1996).

Profiles of ${ }^{137} \mathrm{Cs}$ contamination beneath the SX-Tank Farm suggest that contamination from ${ }^{137} \mathrm{Cs}$ extends to at least a depth of $40 \mathrm{~m}(130 \mathrm{ft})$, and may extend even deeper. Supplemental information from past gross-gamma surveys also supports the observation that contamination has reached the full depth in a number of the drywells (boreholes). What is presently not known is the pathway that ${ }^{137} \mathrm{Cs}$ has taken to reach these depths. Did the ${ }^{137} \mathrm{Cs}$ move throughout the entire subsoil or did the leak intercept the borehole and move down the outside of the casing? Are there other explanations for the extent of the ${ }^{137} \mathrm{Cs}$ plume in the vadose (unsaturated) zone?

The interest in the Cs occurrence in some of the deepest dry wells surrounding SX tanks also lead to more attention being given to the chemical composition of the groundwater in wells surrounding the tank farm. It was found that some constituents such as nitrate, ${ }^{99} \mathrm{Tc}$, gross beta and tritium concentrations are above natural Hanford background levels in several wells in the SX environs. The RCRA monitoring program has also recently been flagged based on a higher than background specific conductance to go from the indicator monitoring level to a groundwater quality assessment level. As part of the RCRA process a groundwater monitoring assessment plan is required and a draft has been prepared (Caggiano 1996). The Phase I Assessment report is expected to be available in October 1997 and the lead author will be V. G. Johnson at PNNL. Much of the information presented in our report will be used to help determine whether the $S$ and SX tanks may be the source of these constituents in the aquifer at higher than background concentrations.

Herein we provide an analysis of the chemistry of tank supernates with emphasis on the REDOX waste stream disposed in SX tanks, Cs aqueous chemistry, available data on Cs adsorption onto Hanford sediments, and information on Cs migration from other Hanford tank leaks that have been studied. The data in this report was used to help guide the vadose zone transport analysis of the SX Tank Farm presented in a companion report, Ward et al. (1997). The goal of the vadose zone transport modelling is to attempt to explain the depth and extent of the ${ }^{137} \mathrm{Cs}$ plume under the SX Tank farm, specifically in the vicinity of the greatest leak, near the SX-109 Tank [DOE 1996]. Ward et al. (1997) also analyzes the migration of ${ }^{99} \mathrm{Tc}$ and nitrate, which are generally more mobile than ${ }^{137} \mathrm{Cs}$ and which have been found in elevated concentrations in the groundwater underneath the SX-Tank Farm. Nitrate exists as an anion and is not adsorbed by most sediments because they generally exhibit a net negative surface 
charge. Tc migration is very dependent upon the redox state of the geochemical system. Under oxidizing conditions the most common Tc species is pertechnetate $\left[\mathrm{TcO}_{4}{ }^{-}\right]$.

Pertechnetate anion generally does not adsorb onto sediments as found in most Hanford specific adsorption studies (see Serne et. al 1993 and Kaplan and Serne 1995).

Another report that discusses the enhanced ${ }^{137} \mathrm{Cs}$ migration issue at SX Tank Farm and much background information was recently published by DOE-Richland (Conaway et al. 1997). Readers are encouraged to obtain this document for additional information on the perplexing issue of enhanced ${ }^{137} \mathrm{Cs}$ migration. 


\subsection{CS GEOCHEMISTRY}

\subsection{Cs Aqueous Geochemistry}

In typical groundwaters/solutions $\mathrm{Cs}$ is present as the monovalent cation and shows very little tendency to form aqueous complexes with inorganic or organic ligands. For example the stability constant for various metals complexing with the chelating agent EDTA with stoichiometry 1 metal: 1 ligand, the usual complex formed between trace concentrations of ligand and metal are shown in Table 2.1. As can be seen Cs exhibits the weakest tendency to complex with EDTA of all metals. The same is found for other chelating and complexing agents generally used to process spent fuel at Hanford.

Table 2.1. Stability Complexes for Various Metals with EDTA

\begin{tabular}{|c|c|}
\hline Complex & $\begin{array}{c}\text { Stability } \\
\text { Constant } \\
\text { (log K) }\end{array}$ \\
\hline $\mathrm{CsL}$ & 0.15 \\
\hline $\mathrm{NaL}$ & 1.7 \\
\hline $\mathrm{CaL}$ & 7.7 \\
\hline $\mathrm{AlL}$ & 16.7 \\
\hline $\mathrm{Fe}(\mathrm{II}) \mathrm{L}$ & 14.3 \\
\hline $\mathrm{Fe}(\mathrm{III}) \mathrm{L}$ & 25.1 \\
\hline $\mathrm{U}(\mathrm{IV}) \mathrm{L}$ & 25.8 \\
\hline $\mathrm{Pu}(\mathrm{IV}) \mathrm{L}$ & 17.6 \\
\hline $\mathrm{Co}(\mathrm{II}) \mathrm{L}$ & 16.5 \\
\hline $\mathrm{Co}(\mathrm{III}) \mathrm{L}$ & 41.5 \\
\hline
\end{tabular}

Cesium is a soluble element in soil and groundwater, and forms no sparingly soluble solid phases that could limit its aqueous concentrations. Solubility-limiting synthetic solids do exist, such as $(\mathrm{Na}-\mathrm{Cs})_{2} \mathrm{NiFe}(\mathrm{CN})_{6}$, but these "exotic" solids do not exist in the natural environment. Cs shows no tendency to polymerize or to form true colloids. Cs may adsorb onto fine particulates (i.e., clay colloids or other alumino- and silicate-colloids) and might remain attached to these fine particles as they percolate through sediments. As a consequence, the aqueous concentrations of $\mathrm{Cs}$ in soil and groundwater are controlled primarily by sorption 
reactions to particulate surfaces. In low organic carbon environments (that characterize Hanford subsoils and subsurface sediments) Cs sorption is dominated by surface chemical interactions with the minerals that constitute soils and sediments.

\subsection{Cs Adsorption Mechanisms}

Most radionuclides (e.g., $\mathrm{U}, \mathrm{Th}, \mathrm{Pu}$, and $\mathrm{Am}$ ) and metal ions (e.g., $\mathrm{Co}, \mathrm{Zn}$, and $\mathrm{Pb}$ ) form strong surface coordination complexes on $\mathrm{Fe}, \mathrm{Mn}$, and $\mathrm{Al}$ oxides (Davis and Kent 1990). These oxides, which commonly exist as grain coatings in subsurface sediments, strongly retard radionuclide and metal ion migration by adsorption. $\mathrm{Cs}^{+}$, in contrast, is weakly and nonspecifically sorbed by these same metal oxides (Helferrich 1962; Tien 1965; Churms 1966; Abendroth 1970; Dumont and Watillon 1971; Breeuwsma and Lyklema 1971; and Venkataramani et al. 1978). Cesium is generally adsorbed as a counter-ion, balancing negative surface charge above the $\mathrm{pH}_{2 \mathrm{pc}}$. Weak ion-pair-type surface complexes may also be possible. Excess concentrations of other mono-valent cations (e.g., $\mathrm{Na}^{+}$) virtually eliminate Cs sorption to metal oxides by the common ion effect, although slight preference of the silica surface for Cs over other monovalent cations has been observed (Kinniburgh and Jackson 1981).

In spite of its weak sorptive interactions with metal oxides, Cs is often strongly sorbed by particulate matter in environmental settings. Research initiated by concern over the fate of radiocesium from atmospheric weapons testing showed that cesium was strongly and selectively sorbed by the micaceous fraction of soils, sediments, and suspended particulates (Tamura and Jacobs 1960; Sawhney 1970; Sawhney 1972; and Francis and Brinkley 1976). The initial observations were that Cs sorptive affinity was greatest along the weathered periphery of micas (e.g., biotite and muscovite) and their immediate weathering products (hydrous-mica, illite). It was early recognized (Jackson 1963, Rich and Black 1964) that wedge zones, formed where the $1.0-\mathrm{nm}$ mica core sheets open to $1.4 \mathrm{~nm}$ vermiculite, offer a unique and highly selective steric environment to $\mathrm{K}^{+}$and ions of like ionic radii such as $\mathrm{Cs}^{+}$.

Micaceous minerals include mica, hydrous micas and illite. These are 2:1 layer-silicates that contain permanent negative-charge density as a result of isomorphic structural substitutions. Their interlayer space is $\mathrm{K}^{+}$saturated and generally is not available except around particle peripheries where $\mathrm{K}^{+}$has been depleted. Other $2: 1$ layer-silicate clays (vermiculite, smectite) exhibit similar structure but lower layer-charge density and expansible interlayers. All exhibit a cation exchange capacity (CEC) existing on the external (mica) or external plus interlayer surfaces (illite, vermiculite, smectite). The literature on the mineralogy and cation-exchange properties of these solids is extensive (e.g., Greenland and Hayes 1978; Goulding 1983; Dixon and Weed 1989). An early review (Anderson and Allard 1983) summarized the sorption chemistry of Cs on pure minerals and geologic material.

Recent research has refined our understanding of the sorption process for Cs onto materials containing 2:1 layer-silicates. Cs sorbs by at least four related, but chemically distinct, mechanisms (numbered 1-4 in the following discussion with terms identified in Fig 2.1; 
mechanisms abstracted from the "wet chemical studies" of Evans et al. 1983; Brouwer et al. 1983; Grütter et al. 1986; Cremers et al. 1988; De Preter et al. 1991; Comans et al. 1991; Grütter et al. 1994; and by analogue to $\mathrm{K}^{+}$(Sumner and Bolt 1962; DeHaan et al. 1965).

Mechanism (1). $\mathrm{Cs}^{+}$exchanges with hydrated cations on external or interlayer sites (called planar sites herein) of negative-charge density following selectivity approximated by the lyotropic series (e.g., $\mathrm{Cs}^{+}>\mathrm{Rb}^{+}>\mathrm{K}^{+}=\mathrm{NH}_{4}{ }^{+}>\mathrm{Na}^{+}>\mathrm{Li}^{+}$; [Sposito 1989]). Such behavior may be observed on a large fraction of the CEC sites of a geologic material (e.g., >90\%) and most, if not all of the sites in a clean specimen smectite. The conditional exchange constant (e.g., $\mathrm{K}_{\mathrm{c}}=$ Vanselow selectivity coefficient; Sposito 1984) relative to Na may be approximately $2-5$.

Mechanism (2). Cs adsorbs as in (1) but at higher sorption densities induces partial collapse of the interlayer space (for high charge 2:1 layer-silicates such as vermiculite and illite) and dehydration of sorbed $\mathrm{Cs}^{+}$, increasing $\mathrm{K}_{\mathrm{c}}$ to approximately 10 . The sorption complexes in (1) and (2) are exchangeable to a wide variety of cations $\left(\mathrm{Na}^{+}, \mathrm{NH}_{4}+, \mathrm{H}^{+}, \mathrm{Ca}^{2+}, \mathrm{Mg}^{2+}, \mathrm{Fe}^{2+}\right.$, and $\mathrm{Mn}^{2+}$ ).

Mechanism (3). Cs enters highly selective frayed edge (FES) or wedge sites on hydrous mica or illite, representing only a small fraction $(<5 \%)$ of the CEC. Cs may or may not dehydrate on these sites, but is held with great selectivity relative to $\mathrm{Na}\left(\mathrm{K}_{\mathrm{c}}>>1000\right)$ and is desorbable only by excess concentrations of ions with like ionic radii $\left(\mathrm{NH}_{4}^{+}, \mathrm{K}^{+}, \mathrm{H}_{3} \mathrm{O}^{+}\right)$.

Mechanism (4). Cs diffuses within collapsed illitic or hydromica interlayers and is poorly or non-exchangeable (i.e., fixed).

The specific contribution of reactions $1-4$ in a particular $2: 1$ specimen clay or geologic material is dependent on the relative concentrations of the smectite/vermiculitic and illitic components, as the former are dominated by planar sites and the latter are the primary contributors of wedge or FES sites. In spite of this mineralogic dependence, however, Cs sorption correlates strongly with the $\mathrm{CEC}$ (using $\mathrm{NH}_{4}{ }^{+}$as an index ion; Cs may adsorb in excess of the CEC measured using $\mathrm{Mg}^{2+}$ or $\mathrm{Ca}^{2+}$ as the large size of the hydrated divalent cations prevents their access to wedge sites) as the primary master variable for sorption (Grütter et al. 1990). Methods have been recently described to quantify the numbers of and exchange thermodynamics of the FES (Cremers et al. 1988; DePreter et al. 1991) relative to the total CEC. The FES are highly selective to $\mathrm{Cs}^{+}$and $\mathrm{K}^{+}$and exhibit significant heterogeneity in exchange thermodynamics/selectivity (DePreter et al. 1991) indicating contributions of various micro-structural environments in the solid, such as faults, cleavages, cracks, and stepped edges. Brouwer et al. (1983) suggested that mechanisms 1-3 exhibited reversible thermodynamic behavior over $24 \mathrm{~h}$ equilibration times, and devised a three-site thermodynamic model that described well Cs adsorptive exchange on illite over a large Cs concentration range with different saturating monovalent cations. In contrast, Comans et al. (1991) showed that accessibility to and exchange reversibility of the FES in illite was 


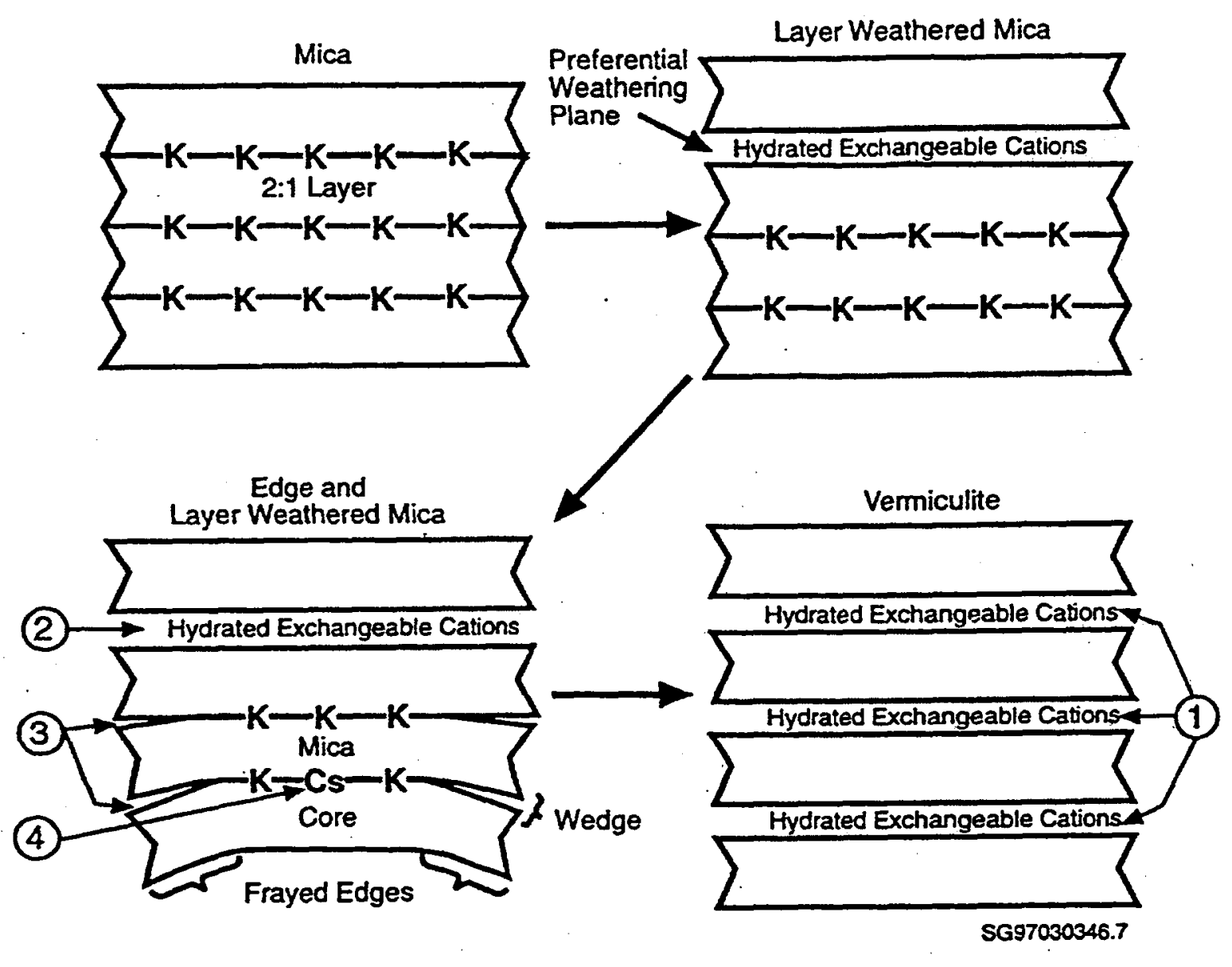

Figure 2.1 Sorption Environments for $\mathrm{Cs}^{+}$Onto 2:1 Layer Silicates: 1) exchange of hydrated Cs with other hydrated cations, 2) high-charge-density collapsible interlayer, 3) wedge or frayed edge sites, and 4) fixed Cs. [adapted from Fanning et al. 1989] 
dependent on the saturating cation (e.g., $\mathrm{K}^{+}$vs $\mathrm{Ca}^{2+)}$. Saturation with $\mathrm{Ca}^{2+}$ enabled greater access of Cs to the FES, and less thermodynamic reversibility. This sorption behavior was described with a two-box kinetic model (Comans and Hockley 1992) containing an instantaneous/reversible reaction and a longer term irreversible reaction, operative over days to months.

The sorption behavior of radiocesium is dependent on its absolute concentration and that of the indigenous, "cold" Cs pool (Brouwer et al. 1983: Grütter et al. 1990). As Cs is added to a sorbing geologic material or clay, it will adsorb/exchange first to sites of high energy. As high affinity, low concentration FES sites become saturated, sites of progressively lower energy will become occupied with eventual saturation of the planar sites occurring at high Cs concentration. If radiocesium is added at trace concentration (e.g., $<10^{-7} \mathrm{~mol} / \mathrm{L}$ ) and there is no indigenous $\mathrm{Cs}$, then it will sorb strongly to high-affinity FES sites. There is very little indigenous (stable) Cs in the Hanford sediments and groundwater, although actual values could not be found in past Hanford literature. Based on the activity levels for ${ }^{137} \mathrm{Cs}$ in REDOX tank liquors (discussed in Section 3) the mass concentration of Cs from just the radioactive isotopes could reach $3 \times 10^{-5}$ to $2 \times 10^{-4} \mathrm{M}$ for full strength liquor. Farther out in the sediments after some mixing with native porewater and reaction products, the $\mathrm{Cs}$ mass concentration in solution may still be greater than trace (e.g., $<10^{-7} \mathrm{~mol} / \mathrm{L}$ ) so that the number of high energy sorption sites would be limiting in the tank environs. Farther away from the tanks, the solution concentration of radioactive $\mathrm{Cs}$ isotopes will drop into the trace range where the number of FES sites will not be the limiting factor controlling Cs sorption. However, if indigenous (stable) Cs concentrations are significant, then the FES may already be saturated with "cold" Cs and the sorption process of the radiocesium will be one of isotopic exchange where it statistically partitions, without selectivity, among all the different Cs forms at a concentration ratio equal to the isotopic ratio. Under such circumstances, only a small fraction of the radiocesium may end up on the high affinity FES sites. Cold Cs functions as a diluent, acting to distribute the radiocesium over a broader site distribution than would occur in its absence. Thus, the labile concentration of "cold" $\mathrm{Cs}$ in a given solid-water system is an important determinant of both the extent and average strength of radiocesium sorption (Grütter et al. 1990).

In spite of the hypothesized importance of phyllosilicate microstructure on Cs sorption as discussed above (e.g., FES sites), there exist few studies that have directly defined the structural environment and location of sorbed Cs. Cesium is not a particularly accessible element for surface vibrational or absorption spectroscopies. Nuclear magnetic resonance (NMR) however, is useful for characterizing Cs-clay/zeolite interactions because the small electric quadrupole moment of ${ }^{133} \mathrm{Cs}$ yields narrow $\mathrm{NMR}$ line widths and its NMR chemical shift is very sensitive to local environment. ${ }^{133} \mathrm{Cs}$ variable-temperature magic-angle spinning (VT-MAS) NMR studies have provided some direct confirmation of the Cs sorption mechanisms inferred from the "wet chemical" studies summarized above (Weiss et al. 1990a; Weiss et al. 1990b; and Kim et al. 1996). ${ }^{133} \mathrm{Cs}$ exchanged 2:1 phyllosilicates typically show motional averaging between multiple sites with distinct chemical/structural environments above 
a temperature of $-70^{\circ} \mathrm{C}$. These sites can be differentiated below $-90^{\circ} \mathrm{C}$, but the presence of structurally heterogeneous $\mathrm{Cs}$ environments is indicated by the significant temperature range over which motional averaging ceases (i.e., -20 to $-50^{\circ} \mathrm{C}$ ). Chemical shifts vary with total $\mathrm{Cs}$ concentration (which influences the occupied site distribution) and 2:1 layer-silicate type and expansibility/charge density (e.g., smectite, vermiculite, illite). By varying relative humidity, temperature, and other experimental variables, structural environments of $\mathrm{Cs}$, including planar, expansible interlayer, collapsed interlayer, and edge sites, have been tentatively identified by ${ }^{133} \mathrm{Cs}$ VT-MAS NMR. Wedge or FES sites have not been definitively identified by ${ }^{133} \mathrm{Cs}$ NMR because their concentrations are low, and a well designed study with appropriate materials (i.e., with known FES concentrations) and methodology (to block high concentration planar or expansible interlayer sites) has not been formulated or performed. Such a study is tractable with FT-high field spectrometers that are now becoming available.

To recapitulate, Cs in the SX tank leak scenario is not expected to adsorb solely by reversible ion exchange reactions such as mechanisms 1 and 2 above. The degree of Cs adsorption is highly dependent on the types and concentrations of special surface sites (see mechanisms 3 and 4 above) on selected minerals such as micas and illites. In only mechanisms 1 and 2 do all other cations in solution compete for sorption sites. For mechanisms 1, 2, and 3 adsorption competition is dependent upon the charge on the solution cation and the size of the hydrated cation species. The larger the charge on the cation the better it adsorbs and the smaller the hydrated ion size the better it adsorbs. Effective ion diameters in aqueous solution are shown in Table 2.2 as calculated by Shannon (1976). Ions of similar size effectively compete with each other for mechanism 1 and 2 and especially for mechanism 3 adsorption sites on soils. Thus among the monovalent cations present in the Hanford vadose zone/tank waste liquors, ammonium and potassium and to a much lesser extent sodium would be expected to compete for FES adsorption sites in the Hanford sediment.

Table 2.2. Hydrated Ion Size, in $\AA$

\begin{tabular}{|c|c|}
\hline Ion & Hydrated Diameter, Angstroms $(\AA)$ \\
\hline $\mathrm{Na}^{+}$ & 4 \\
\hline $\mathrm{K}^{+}$ & 3 \\
\hline $\mathrm{Cs}^{+}$ & 2.5 \\
\hline $\mathrm{NH}_{4}^{+}$ & 2.5 \\
\hline $\mathrm{Ca}^{2+}$ & 6 \\
\hline $\mathrm{Sr}^{2+}$ & 5 \\
\hline
\end{tabular}




\subsection{Hanford Mineralogy}

The tank farms are distributed between the 200 West ( 7 ) and East (11) Areas at Hanford. The 200 Areas reside on the "200-Area plateau" where depth to groundwater ranges from 200-300 feet. Tanks (67) that have leaked or are suspected to have leaked are present in both areas. The 200 Areas are underlain by a sequence of suprabasalt sediments of Pleistocene and Pliocene age (Fig 2.2) (Tallman et al. 1979; Freeman-Pollard et al. 1994). These sediments include four primary units, from youngest to oldest, 1) coarse-grained glacio-fluvial gravels and sands in the Hanford Formation; 2) the eolian, loess-containing early "Palouse" soil; 3) the pedogenic Plio-Pleistocene unit; and 4) fluvial-lacustrine gravel/sand/silt lithofacies of the Ringold Formation. Information on the geology of these formations that is discussed below was abstracted from: Bjornstad (1984); Baker and Bunker (1985); Baker et al. (1991); and Smith (1993). Groundwater is encountered within the Middle Ringold in the 200-West Area and within the Hanford Formation at 200 East. The Cs geochemistry that is the focus of the enhanced Cs migration issue occurs in sediments above the saturated zone. The Hanford Formation represents approximately $85 \%$ of the vadose zone materials, with the remainder being contributed by the Middle and Upper Ringold Formations. A more detailed depiction of the lithology and stratigraphy underlying the T-tank farm (200 West); where one of the largest single-shell tank leak events occurred from 241-T-106, is shown in Fig. 2.3. Shown also for example is the distribution of ${ }^{137} \mathrm{Cs}$ below $241-\mathrm{T}-106$ and lithologic and stratigraphic units in which it resides (Fig. 5; Freeman-Pollard et al. 1994).

Petrographic analyses indicate that the suprabasalt sediments are predominantly a mixture of quartz, plagioclase, and rock fragments. The gravels and sands of the Ringold Formation are quartzo-feldspathic. Quartz is predominant (average 36.2\%), however, as much as $29 \%$ of the mineral grains are feldspar. Plagioclase is 4-8 times more abundant than K-feldspar. Rock fragments (principally indigenous basalt) typically constitute $21-69 \%$ of the sand and coarse sand particles. The Plio-Pleistocene unit contains bulk mineralogy similar to the Ringold Formation.

The Hanford Formation contains glaciofluvial materials deposited in the cataclysmic floods of the Pleistocene. The Hanford Formation is characterized by a succession of alternating and discontinuous layers of gravels, sands, and silts that vary dramatically both laterally and vertically. The formation resulted from repeated episodes of flooding, local erosion, and slack water deposition. The mineralogy reflects diverse provenance from granitic, metamorphic, and sedimentary terrains of the interior Northwest, but the sediments are enriched in mafic rock fragments and mineral phases derived from the ubiquitous Columbia River basalts of the proximate region. The Hanford Formation contains more feldspar and mafic rock fragments than does the Ringold. Layers and lenses of caliche are common within two meters of the existing land surface and in discontinuous zones at depth. Micas (biotite and muscovite) and chlorite are common in the silt and fine sand fractions. 


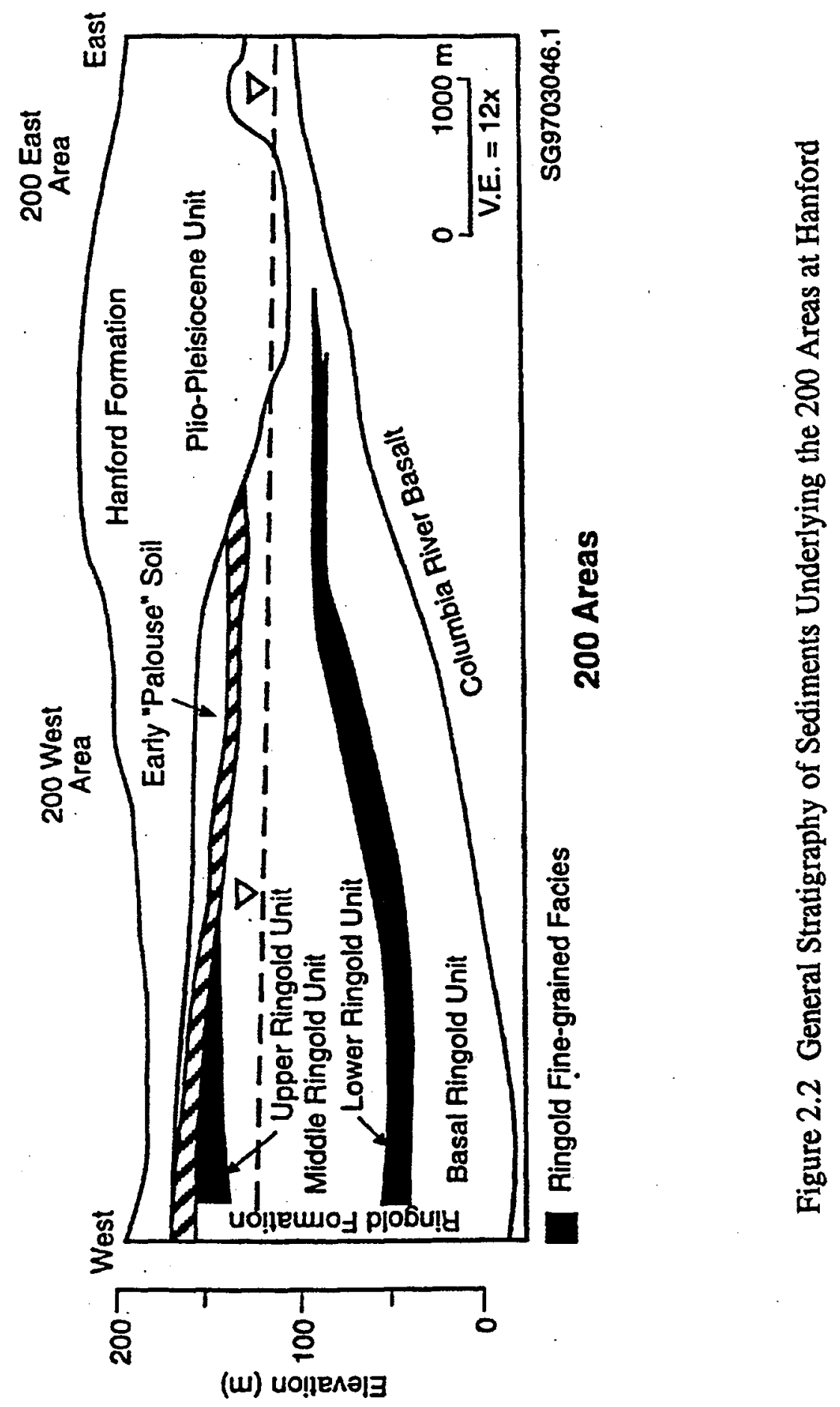


Hanford and Ringold Formation sediments generally range from sands to gravels in texture and display low, but measurable cation exchange capacity (CEC) as shown in Table 2.3. A clay-sized fraction ( $<2 \mathrm{um}$ ) is recoverable from all but the coarsest of samples. This clay fraction, as well as silt-sized particles and fine-grained discontinuous secondary mineral coatings on sand particles, are responsible for minor element and radionuclide sorption in these sediments. Dr. Jim Amonette (PNNL) has studied the clay mineralogy of the Hanford and Ringold Formations beneath the 200 Areas at Hanford; selected unpublished results of that work follow. Smectite is the dominant 2:1 layer-silicate present in clay fractions removed from the Hanford and Ringold Formations (see Fig. 2.4). Illite and its weathering products (vermiculite and chlorite) are common in the Hanford and Upper Ringold Formations (see Fig. 2.5). Mass concentrations of illite, vermiculite, and chlorite correlate with one another, suggesting derivation from similar parent material. Hanford Formation clay mineralogy was found to vary predictably with depth in the 200 Areas. The smectite concentrations are highest at the shallowest depths and lowest at the deepest depths; illite, vermiculite, and chlorite show the opposite trend. Recall that illite and vermiculite contain more of the specialized FES type of sorption sites that selectively adsorb $\mathrm{Cs}^{+}$.

Consistent with our review of Cs adsorption mechanisms above, the 2:1 layer-silicate suite in the Hanford and Ringold Formations imparts significant sorptivity for Cs. This high Cs sorptivity of the Hanford sediments was noted early in the Hanford project, and "in-situ soil column filtration" was relied upon for years as a primary waste-treatment tool for Cscontaining waste streams. Cs adsorption onto Hanford sediments is discussed in Section 4.0.

Table 2.3. Representative Hanford/Ringold Formation Properties

\begin{tabular}{|c|c|c|c|c|c|c|}
\hline \multicolumn{3}{|c|}{} & $\begin{array}{c}\text { Particle } \\
\text { (mass \%) }\end{array}$ & & CEC & CaCO $_{\text {(f) }}$ \\
\hline & Depth (ft) & Gravel & Sand & Silt/Clay & (meq/100 g) & $(\mathrm{g} / 100 \mathrm{~g})$ \\
\hline W-10-109 & 15 & 59 & 41 & 0 & 6.73 & 0.95 \\
\hline W-10-113 & $70-80$ & 5 & 88 & 7 & 5.95 & 2.6 \\
\hline W-11-23 & $100-105$ & 10 & 70 & 20 & 5.28 & 7.65 \\
\hline
\end{tabular}




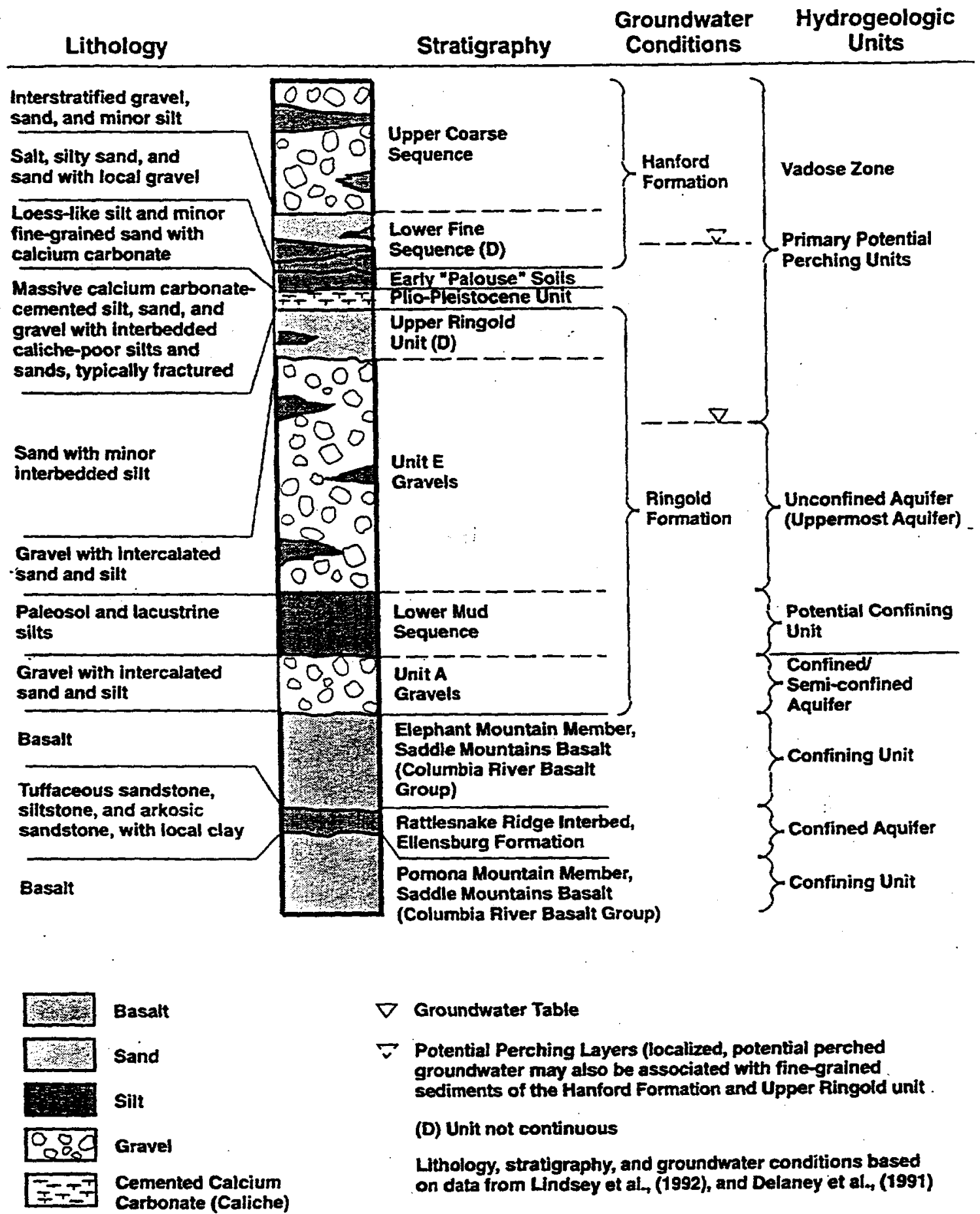

SG97030346.11

Figure 2.3 Hanford and Ringold Formation Lithology and Stratigraphy at T Tank Farm in 200 West Area 


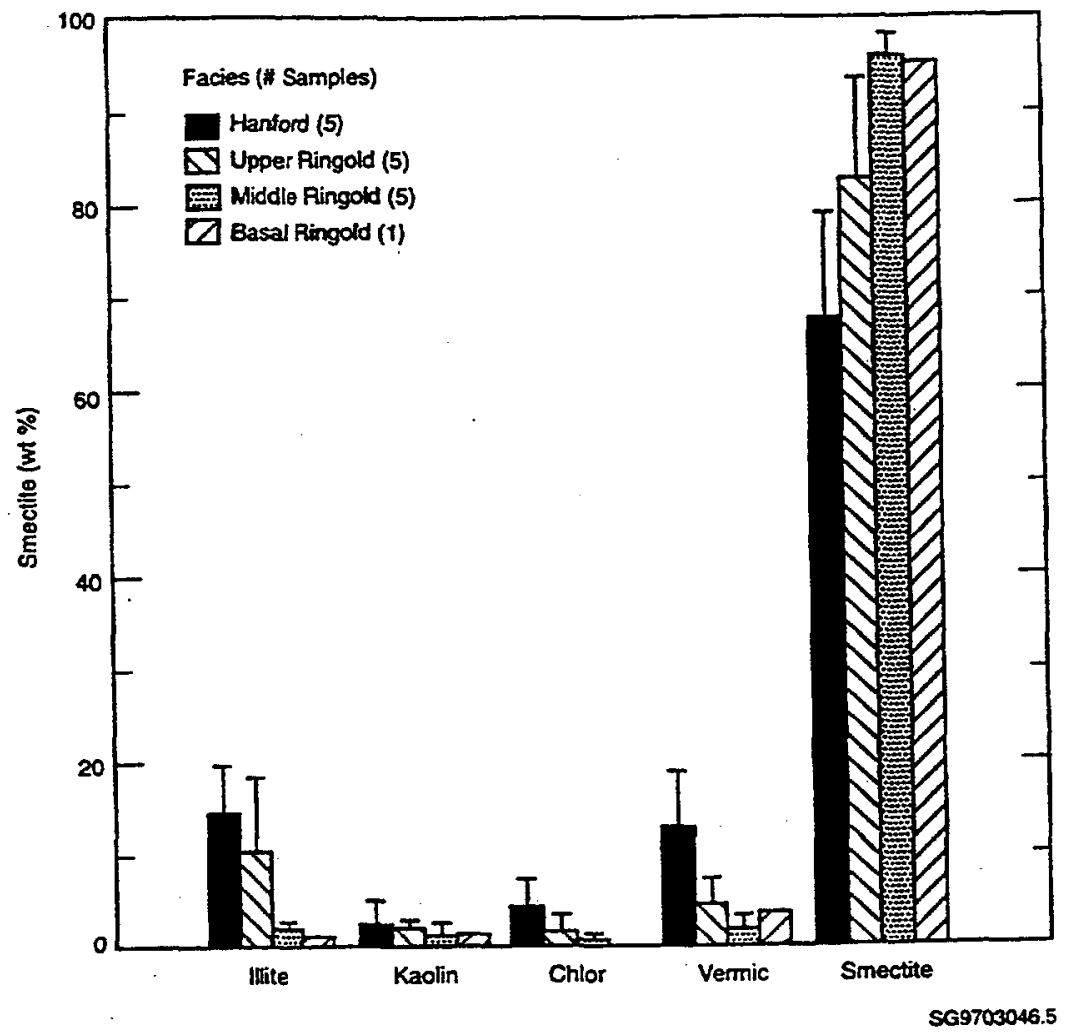

.Figures 2.4 Mineralogy of Clay-Sized Particles in Hanford and Ringold Formations

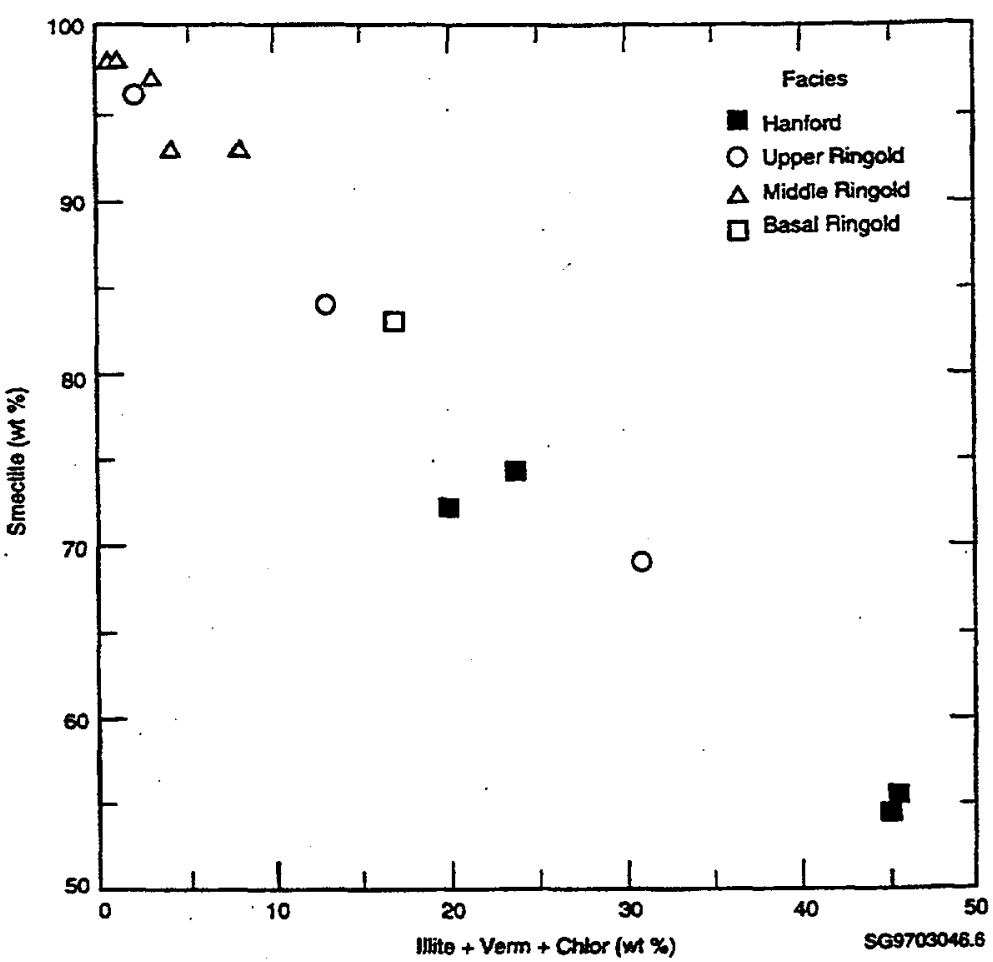

Figure 2.5 Types of Clays in Various Facies of Hanford and Ringold Formations 


\subsection{GENERAL REDOX CHEMISTRY AND SX TANK FARM HISTORY}

\subsection{REDOX Chemistry}

The REDOX process was the first continuous solvent extraction process used at the Hanford Site. It was developed at the Argonne National Laboratory. The REDOX process operated between 1952 and 1966 in the 202-S Building. Types of wastes from the REDOX process that were added to tanks were designated coating waste, high-level waste and sump waste.

The REDOX process was a continuous counter-current column extraction process. The REDOX process involved contacting a methyl isobutyl ketone (hexone) phase with an aqueous aluminum nitrate solution that contained $\mathrm{Pu}$ and $\mathrm{U}$ from the dissolution of spent fuel. The uranium and plutonium were separated from fission products by manipulation of the plutonium valence so that the two actinides could be preferentially extracted with hexone (methyl isobutyl ketone) and then separated from one another and separated from the fission products.

The design feed rate of the REDOX Plant was 3.1 tons of irradiated uranium reactor fuel per day. The product of the REDOX Plant was a liquid plutonium nitrate solution. Two types of high activity waste were sent to underground tank storage: coating waste containing the $\mathrm{Al}$ and $\mathrm{Zr}$ cladding dissolution products and REDOX high-level waste containing most of the fission products. The major components of these two waste streams exiting the REDOX process were chromium, zirconium, iron, silicon, aluminum, sodium, and nitrate compounds. Aqueous waste streams were directly transferred to underground tanks if analytical measurements were within the established limits for discharge. Initially, all of the liquid wastes from the REDOX Plant were transferred to the S Tank Farm.

In the early years REDOX produced 4,378 gallons of waste per ton of fuel processed, but the rate of waste production was decreased to 594 gallons per ton of fuel processed later. More REDOX waste was generated between 1952 and 1958 than after 1958 (Agnew 1995). This lead Agnew (1995) to break the REDOX wastes into two eras. The first era was chosen as 1952 through 1958 in which the average waste generation was 2,106 gallons per ton of fuel processed and the high-level metal waste is designated as R1. The second era lasted from 1959 through 1966 and high-level waste generated averaged 1,119 gallons per ton of fuel processed. This later waste is designated as R2 in Agnew's scheme (see Agnew 1995). These two wastes from REDOX were sent to the S- and SX-tank farms. The R1 and R2 waste streams were assumed to contain $4.4 \mathrm{vol} \%$ and $2.3 \mathrm{vol} \%$ solids, respectively, based on a few actual measurements and Agnew's (1995) thorough review of all Hanford waste streams. Many tanks in SX and S tank farms were self-boiling and the solids content thus increased on their own. SX-109 is estimated to have concentrated its waste up to 14 vol\% solids through formation of salt cake, designated as RSltCk, another REDOX waste in the Agnew scheme. Agnew's REDOX waste compositions have also been modified from the flow sheet data with the inclusion of 50 moles of Si per ton of fuel processed and an unspecified amount of iron to reflect process vessel corrosion and to better reflect actual compositions measured on tank 
samples.

\subsection{SX Tank Farm History}

A succinct summary of the chemical nature of the wastes in Hanford tanks follows based on Beard et al. (1965). Most of the high radioactivity waste streams from the processing plants had high inert salt concentrations and contain some solids. In the storage tanks, the solids settle to the bottom forming a sludge layer. The majority of the fission products are contained in the sludge layer. The few fission products that partitioned to the supernatant liquid are ${ }^{137} \mathrm{Cs}$, ${ }^{99} \mathrm{Tc}$ and some of the ${ }^{103,106} \mathrm{Ru}$. As the separations processes improved over the years the quantity of inert salts added to tanks decreased and a significant reduction in the volume of high radioactivity waste per unit of $\mathrm{Pu}$ production resulted. This economically attractive decrease in unit volume of waste per unit of Pu production increased the fission product concentrations per volume of waste and thus increased the heat generation from radioactive decay. The PUREX and REDOX waste storage tanks, A, AX, and SX Tank Farms; were equipped with vapor handling facilities to condense steam. Over-heating was prevented by returning a portion of the condensed vapors to the tank or by water addition. The rest of the condensate was an intermediate activity waste that was routed to cribs. The transfer of aged REDOX and PUREX supernates from self-boiling to non-boiling storage tanks was made to open up more space in the self-boiling tanks. In 1955, air lift circulators were installed in 9 of the fifteen REDOX SX Tank Farm tanks. The tanks themselves were built in 1954. The circulators augmented natural convection and were effective in minimizing fluctuations in the rate of solution boiling. The liquid level in self-boiling tanks was continually changing so that level measurements were not useful to assure no leaks occurred. In 1961 leak detection systems were installed at SX Tank Farm. The system consisted of vertical and horizontal boreholes around and under many tanks. These boreholes (hollow pipes) were monitored for moisture and radioactivity. "Although some waste would be transferred to the ground before the monitoring systems would notify the operator, the soil can 'hold' up to 50,000 gallons of liquid by specific retention without liquid approaching the regional water table. About 50,000 gallons leaked from a failed SX Farm tank and radioactivity penetrated no more than 15 feet below the tank, still about 200 feet above the water table." Quote is from Beard et al. (1965) but the reader is cautioned that the volume of leakage that can be 'specifically retained' varies with the depth to the water table. Routson et al. (1979) calculates a larger value for the T-106 leak but still claims that no leaking liquid reached the water table. Further Beard et al. (1965) appear to over estimate the depth from the SX tank bottoms to the water table. Currently the bottoms of the SX tanks are at 55 feet below the surface and the water table is at about 210 feet below the surface for a difference of 155 feet. We do not believe that the water table was ever that much lower to allow for Beard et al.'s estimate of 200 feet of vadose zone under the tanks.

In 1965 the non-boiling tanks in S Tank Farm were 14-22 years old and only four were confirmed leakers while the self-boiling tanks in Tank Farm SX were 10-12 years old and only 2 tanks were known to have failed (see Beard et al. 1965). Today it is known that more tanks 
actually leaked and as presented in the Rust Geotechnical report [DOE 1996] and Brevick (1995) on SX Tank Farm, 10 out of the 15 SX tanks have been labeled as leakers. The tanks, years when leaks were suspected/detected, and estimated volume of each leak are shown in Table 3.1. Again the reader is cautioned that the Table notes when large leaks were suspected. Based on personal comments from Steve Agnew (LANL) and Don Wodrich (DOE-RL and formerly WHC and past operating contractors), it seems clear that nominal leaks of 500 1,000 gallons would have been possible on any number of occasions at any one of the tanks and such "small" leaks would not have been able to be detected. Thus waste may have been

Table 3.1 Current Status of SX Tanks

\begin{tabular}{|c|c|c|c|c|c|}
\hline Tank & $\begin{array}{l}\text { Brevick } \\
\text { (1995) } \\
\text { Designation } \\
\text { and Date of } \\
\text { Leak }\end{array}$ & $\begin{array}{l}\text { DOE (1996) } \\
\text { Designation }\end{array}$ & $\begin{array}{c}\text { Drainable } \\
\text { Liquid in } \\
\text { Tank } \\
\text { Today } \\
\text { (Gallons) }\end{array}$ & $\begin{array}{c}\text { Brevick } \\
\text { (1995) } \\
\text { Estimated } \\
\text { Leak } \\
\text { (Gallons) }\end{array}$ & $\begin{array}{c}\text { DOE (1996) } \\
\text { Estimated } \\
\text { Leak } \\
\text { (Gallons) }\end{array}$ \\
\hline $\mathrm{SX}-101$ & sound & sound & 146000 & & \\
\hline$S X-102$ & sound & leaker & 183000 & & \\
\hline SX-103 & sound & unsure & 223000 & & \\
\hline SX-104 & leak, 1988 & unsure & 201000 & 6000. & \\
\hline SX-105 & sound & sound & 261000 & & \\
\hline SX-106 & sound & sound & 233000 & & \\
\hline SX-107 & leak, 1964 & leaker & 0 & $<5000$ & \\
\hline$S X-108$ & leak, 1962 & leaker & 0 & $\begin{array}{c}2400 \text { to } \\
35000 \\
\end{array}$ & \\
\hline SX-109 & leak, 1965 & leaker & 0 & $<10000$ & 250000 \\
\hline SX-110 & leak, 1976 & sound & 0 & 5500 & \\
\hline SX-111 & leak, 1974 & leaker & 0 & 500 to 2000 & \\
\hline SX-112 & leak, 1969 & leaker & 0 & 30000 & \\
\hline SX-113 & leak, 1958 & leaker & 0 & 15000 & \\
\hline SX-114 & leak, 1972 & leaker & 0 & 8000 & \\
\hline SX-115 & leak, 1965 & leaker & 0 & 50000 & \\
\hline
\end{tabular}


slowly "dribbling" out of the tanks on a much more continuous basis than the individual cited events of larger leaks designated in Table 3.1. Only these large leaks were the triggering mechanism to change a tanks status to assumed leaker.

There has been an increased effort in obtaining samples out of tanks in the last ten years, but of most interest to the SX tank farm leak issue is what was the range in chemical composition of the waste at the time of the suspected leaks. Liquid removal operations such as continued self heating, salt-well pumping and others were used on tanks that were suspected as being leakers since the tank farm was put into operation and most recent tank characterization chemistry may not represent the chemical environment at the time of the leak. Based on chemicals used, process flow sheets and analyses of wastes produced, Agnew (1995) has developed estimates of various Hanford process wastes. Combined with other data and assumptions Agnew et al. (1996) have estimated three quantities for each of the 177 Hanford tanks. The three quantities are: (1)the total tank inventory, (2) the sludge/salt cake and interstitial liquid composition for each tank, and (3) the supernatant liquid composition. In agreement with Table 3.1, Agnew et al. (1996) show no free standing supernate liquid currently in SX-107, through -115. Table 3.2 shows Agnew's chemical composition estimates for the two REDOX wastes that make up the bulk of the material in the SX tank farm. These values would represent the dilute starting condition of the waste prior to self-boiling and other operations used to minimize drainable liquid. Table 3.3 shows estimates of supernate liquids in SX-101 through SX-106 as they exist today. The latter six supernate liquids would give an upper estimate based on self boiling and evaporator campaigns that have occurred since the tanks were originally filled. The Rust report [DOE 1996] suggests that the tanks may have leaked early, soon after the tanks were put into operation. This would suggest that the data in Table 3.2 might better represent the chemical composition of leaking fluid. On the other hand sūime of the estimated dates that leaking was confinmed (shown in Table 3.1) suggest that much self-boiling may have occurred prior to the initiation of the leak. Thus we will consider a range in chemical compositions for REDOX liquid when assessing the potential for Cs adsorption onto sediment.

A data base exists on the World Wide Web within the PNNL home page that contains archived analyses of the contents of many of the Hanford SST tanks. A complete description on how to access the data base is given in Appendix $A$ of this report. Within the data base there is some data on SX-108 supernate solution recovered in April 1961 and data on SX-111 supernate solution and solids taken in September 1974. Further, Raymond and Shdo (1966) report gamma activities for tank waste for SX-108 taken on Dec. 15, 1965 and SX-115 taken Sept. 16, 1964. These data are shown in Table 3.4. For the data from the electronic database no other explanation as to where the original data can be found in hard copy is available. Under a different option in the electronic data base, Sample Analysis [Tank Results (no QA)], is a large amount of data for SX-108 solids removed from the tank in August 1995 using an auger tool. The data come from two tank risers and includes analyses in duplicate from both the top and bottom of the auger samples from each riser. Both hot acid extraction and water soluble 
Table 3.2. Agnew's (1995) Estimated Chemical Composition of REDOX Wastes

\begin{tabular}{|c|c|c|c|c|c|c|}
\hline & \multicolumn{3}{|c|}{$\mathbf{R} 1$} & \multicolumn{3}{|c|}{ R2 } \\
\hline & Total Waste & Sludge & $\begin{array}{l}\text { Supernate } \\
\text { Solution }\end{array}$ & Total Waste & Shudge & $\begin{array}{c}\text { Supernate } \\
\text { Solution }\end{array}$ \\
\hline Constituent & (M) & (M) & (M) & (M) & (M) & (M) \\
\hline $\mathrm{Na}$ & 2.94 & 2.37 & 2.97 & 5.34 & 3.19 & 3.96 \\
\hline $\mathrm{Al}$ & 0.65 & 4.14 & 0.14 & 1.13 & 4.77 & 0.30 \\
\hline $\mathrm{Fe}$ & 0.05 & 1.01 & 0.002 & 0.05 & 2.69 & 0.002 \\
\hline $\mathrm{Cr}$ & 0.07 & 0.87 & 0.03 & 0.11 & 4.39 & 0.03 \\
\hline $\mathrm{Bi}$ & 0 & 0 & 0 & 0 & 0 & 0 \\
\hline $\mathrm{La}$ & 0 & 0 & 0 & 0 & 0 & 0 \\
\hline $\mathrm{Zr}$ & 0 & 0 & 0 & 0 & 0 & 0 \\
\hline $\mathrm{Pb}$ & 0 & 0 & 0 & 0 & 0 & 0 \\
\hline $\mathbf{N i}$ & 0.004 & 0.05 & 0.002 & 0.004 & 0.12 & 0.002 \\
\hline Mn & 0 & 0 & 0 & 0 & 0 & 0 \\
\hline $\mathrm{Ca}$ & 0.02 & 0.21 & 0.009 & 0.02 & 0.51 & 0.009 \\
\hline $\mathbf{K}$ & 0.01 & 0.008 & 0.011 & 0.019 & 0.011 & 0.020 \\
\hline OH & 2.70 & 18.62 & 0.012 & 4.90 & 37.96 & 0.023 \\
\hline fres OrI & - & 0.003 & - & - & 0.013 & - \\
\hline $\mathrm{NO}_{3}$ & 2.47 & 0.04 & 1.62 & 4.18 & $<0.01$ & 1.55 \\
\hline $\mathrm{NO}_{2}$ & 0 & 1.95 & 0.87 & 0 & 1.61 & 1.25 \\
\hline $\mathrm{CO}_{3}$ & 0.018 & 0.214 & 0.009 & 0.018 & 0.51 & 0.009 \\
\hline $\mathrm{PO}_{4}$ & 0 & 0 & 0 & 0 & 0 & 0 \\
\hline $\mathrm{SO}_{4}$ & 0.019 & 0.015 & 0.019 & 0.030 & 0.017 & 0.30 \\
\hline $\mathrm{Cl}$ & 0.048 & 0.039 & 0.049 & 0.089 & 0.052 & 0.090 \\
\hline $\mathrm{NH}_{3}$ & 0 & 0.13 & 0.015 & 0 & 0.329 & 0.027 \\
\hline Radiomuclides & $\begin{array}{c}\mathrm{Ci} / \mathrm{l} \\
(\mathrm{Ci} / \mathrm{gal})\end{array}$ & $\underset{(\mathrm{Ci} / \mathrm{gal})}{\mathrm{Cil}}$ & $\underset{(\mathrm{Ci} / \mathrm{gal})}{\mathrm{Ci} / 1}$ & $\begin{array}{c}\mathrm{Ci} / 1 \\
(\mathrm{Ci} / \mathrm{gal})\end{array}$ & $\underset{(\mathrm{Ci} / \mathrm{gal})}{\mathrm{Ci} /}$ & $\begin{array}{c}\mathrm{Ci} / \mathrm{l} \\
(\mathrm{Ci} / \mathrm{gal})\end{array}$ \\
\hline${ }^{157} \mathrm{Cs}$ & - & $\begin{array}{c}0.08 \\
(0.30)\end{array}$ & $\begin{array}{c}0.10 \\
(0.37)\end{array}$ & - & $\begin{array}{c}0.19 \\
(0.70)\end{array}$ & $\begin{array}{c}0.22 \\
(0.84)\end{array}$ \\
\hline${ }^{90} \mathrm{Sr}$ & - & $\begin{array}{c}1.04 \\
(3.95)\end{array}$ & $\begin{array}{c}0.03 \\
(0.13)\end{array}$ & - & $\begin{array}{c}7.83 \\
(29.6)\end{array}$ & $\begin{array}{c}0.03 \\
(0.13)\end{array}$ \\
\hline
\end{tabular}


Table 3.3. Agnew's et al. (1996) Estimate of Supernate Compositions in SX-Tanks

\begin{tabular}{|c|c|c|c|c|c|c|}
\hline & \multicolumn{6}{|c|}{ Tank } \\
\hline & $S X-101$ & SX-102 & SX-103 & SX-104 & SX-105 & SX-106 \\
\hline Constituent & (M) & (M) & (M) & (M) & (M) & (M) \\
\hline $\mathrm{Na}$ & 5.09 & 14.5 & 13.1 & 12.7 & 13.3 & 11.4 \\
\hline $\mathrm{Al}$ & 0.70 & 1.93 & 1.71 & 1.73 & 1.80 & 1.52 \\
\hline $\mathrm{Fe}$ & 0.003 & 0.009 & 0.0086 & 0.0082 & 0.0086 & 0.0074 \\
\hline $\mathrm{Cr}$ & 0.026 & 0.071 & 0.063 & 0.064 & 0.067 & 0.057 \\
\hline $\mathrm{Bi}$ & 0.0006 & 0.002 & 0.002 & 0.001 & 0.0014 & 0.0014 \\
\hline $\mathrm{La}$ & 0.00002 & 0.00006 & 0.00008 & 0.00004 & 0.00005 & 0.00004 \\
\hline $\mathrm{Zr}$ & 0.00038 & 0.0011 & 0.0011 & 0.0009 & 0.0009 & 0.0009 \\
\hline $\mathrm{Pb}$ & 0.00042 & 0.0013 & 0.0011 & 0.0011 & 0.0011 & 0.0010 \\
\hline $\mathrm{Ni}$ & 0.0028 & 0.008 & 0.0074 & 0.0070 & 0.0073 & 0.0064 \\
\hline $\mathrm{Mn}$ & 0.0017 & 0.0050 & 0.0043 & 0.0043 & 0.0046 & 0.0038 \\
\hline $\mathrm{Ca}$ & 0.015 & 0.042 & 0.039 & 0.037 & 0.039 & 0.034 \\
\hline K & 0.024 & 0.070 & 0.065 & 0.060 & 0.063 & 0.055 \\
\hline $\mathrm{OH}$ & 3.03 & 8.50 & 7.52 & 7.56 & 7.89 & 6.59 \\
\hline $\mathrm{NO}_{3}$ & 2.26 & 6.31 & 5.81 & 5.57 & 5.77 & 5.13 \\
\hline $\mathrm{NO}_{2}$ & 1.05 & 2.88 & 2.52 & 2.58 & 2.70 & 2.27 \\
\hline $\mathrm{CO}_{3}$ & 0.188 & 0.577 & 0.528 & 0.491 & 0.515 & 0.433 \\
\hline $\mathrm{PO}_{4}$ & 0.0386 & 0.116 & 0.110 & 0.099 & 0.102 & 0.091 \\
\hline $\mathrm{SO}_{4}$ & 0.104 & 0.314 & 0.284 & 0.276 & 0.280 & 0.239 \\
\hline $\mathrm{Cl}$ & 0.090 & 0.257 & 0.235 & 0.224 & 0.234 & 0.201 \\
\hline $\mathrm{NH}_{3}$ & 0.025 & 0.070 & 0.064 & 0.062 & 0.064 & 0.057 \\
\hline $\begin{array}{c}\text { Radio- } \\
\text { nuclides }\end{array}$ & $\mathrm{Ci} / 1$ & $\mathrm{Ci} / 1$ & $\mathrm{Ci} / 1$ & $\mathrm{Ci} / \mathrm{l}$ & $\mathrm{Ci} / 1$ & $\mathrm{Ci} / 1$ \\
\hline${ }^{137} \mathrm{Cs}$ & 0.112 & 0.302 & 0.276 & 0.270 & 0.278 & 0.245 \\
\hline${ }^{90} \mathrm{Sr}$ & 0.053 & 0.153 & 0.137 & 0.135 & 0.143 & 0.117 \\
\hline
\end{tabular}


Table 3.4. Historical Analysis of Supernate Solutions in SX Tanks and Comparison to Agnew's Predicted Current Supernates in SX Tanks with Drainable Liquor

\begin{tabular}{|c|c|c|c|c|c|}
\hline & \multicolumn{2}{|c|}{ Tank SX-108 } & \multirow{2}{*}{$\frac{\text { Tank SX-111 }}{\text { Sep. } 1974}$} & \multirow{2}{*}{$\begin{array}{c}\text { Tank } \\
\text { SX-115 } \\
\begin{array}{c}\text { Sep. } 16, \\
1964\end{array} \\
\end{array}$} & \multirow{2}{*}{$\begin{array}{c}\begin{array}{c}\text { Representative } \\
\text { Agnew Supernate } \\
\text { (see Table 3.3) }\end{array} \\
1995\end{array}$} \\
\hline Date Sampled & Apr. 1961 & $\begin{array}{c}\text { Dec. 15, } \\
1965\end{array}$ & & & \\
\hline Constituents & (M) & (M) & (M) & (M) & (M) \\
\hline $\mathrm{Al}$ & 1.7 & - & 0.805 & - & 0.7 to 1.9 \\
\hline $\mathrm{Cl}$ & 0.25 & - & - & -- & 0.09 to 0.26 \\
\hline $\mathrm{CO}_{3}$ & - & - & 0.168 & - & 0.2 to 0.3 \\
\hline $\mathrm{F}$ & - & - & 0.014 & - & \\
\hline $\mathrm{OH}$ & 1.52 & - & 1.47 & 0.51 & 3 to 8.5 \\
\hline $\mathrm{NO}_{3}$ & 8.14 & - & 4.72 & - & 2.3 to 6.3 \\
\hline $\mathrm{NO}_{2}$ & 0.45 & - & 0.84 & - & 1 to 2.9 \\
\hline $\mathrm{PO}_{4}$ & - & - & 0.0055 & - & 0.04 to 0.12 \\
\hline $\mathrm{SO}_{4}$ & 0.01 & - & 0.06 & - & 0.1 to 0.3 \\
\hline $\mathrm{Na}$ & 10.52 & - & 8.05 & - & 5 to 14 \\
\hline $\mathrm{Si}$ & - & - & 0.0015 & - & - \\
\hline Radionuclides & $\begin{array}{c}\mathrm{Ci} / 1 \\
\text { (Ci/gal) }\end{array}$ & $\begin{array}{c}\mathrm{Ci} / 1 \\
(\mathrm{Ci} / \mathrm{gal}) \\
\end{array}$ & $\begin{array}{c}\mathrm{Ci} / 1 \\
(\mathrm{Ci} / \mathrm{gal})\end{array}$ & $\begin{array}{c}\mathrm{Ci} / 1 \\
\text { (Ci/gal) }\end{array}$ & \\
\hline${ }^{137} \mathrm{Cs}$ & $\begin{array}{l}0.925 \\
(3.5)\end{array}$ & $\begin{array}{r}1.91 \\
(7.22) \\
\end{array}$ & $\begin{array}{r}1.2 \\
(4.5) \\
\end{array}$ & $\begin{array}{c}0.20 \\
(0.763) \\
\end{array}$ & 0.11 to 0.30 \\
\hline${ }^{90} \mathrm{Sr}$ & $\begin{array}{c}0.018 \\
(0.068) \\
\end{array}$ & - & $\begin{array}{c}0.00013 \\
(0.00049) \\
\end{array}$ & - & 0.05 to 0.15 \\
\hline${ }^{95} \mathrm{Zr} / \mathrm{Nb}$ & - & 0.12 & & - & \\
\hline${ }^{134} \mathrm{Cs}$ & - & 0.13 & 0.0033 & 0.0024 & \\
\hline${ }^{106} \mathrm{Ru}$ & - & 3.30 & - & - & \\
\hline${ }^{144} \mathrm{Ce} / \mathrm{Pr}$ & - & 2.39 & - & - & \\
\hline
\end{tabular}


compositions are reported but we will not dwell on these data. They can be found in hard copy in a WHC report number WHC-SD-WM-DP-151, Rev 1. We have also found a much larger amount of historical data on both supernates, solids and evaporator concentrates that were returned to the tanks for each of the twelve tanks in the S Tank Farm. These data show a much wider range in chemical compositions than those shown in Tables 3.2-3.4. We have determined that the $S$ Tank Farm data certainly corroborates that REDOX liquid wastes can vary at least as much as shown in Tables 3.2-3.4. Therefore our further analysis on Cs adsorption potential using the range presented herein should be adequate for the conceptual transport model development and preliminary calculations provided in Ward et al. (1997).

The data in Tables 3.2 through 3.4 suggest the following. The liquid disposed in SX tanks apparently can self-concentrate to a significant extent based on the comparison of the initial waste composition (Table 3.2) versus the measured values for supernate and predicted values for tanks SX-101 through SX -106 shown in Tables 3.3 and 3.4, respectively. The two more comprehensive historical analyses of tank supernate shown in Table 3.4 exhibit a very good cation-anion balance suggesting that the analyses are accurate. If so, the solution composition exhibits ionic strengths and bascity well beyond that studied in past $\mathrm{Kd}$ experiments and described below for the T-106 tank leak characterization. SX tank supernate ionic strength, hydroxide and $\mathrm{Al}$ concentrations exceed values used in past laboratory studies that will be described later in this report. Other available information germane to Hanford tank chemical and radiological compositions, but not REDOX waste or S-SX Tank Farms, that have been found will be described next to provide additional perspective.

\subsection{Observed Cs Concentrations/Activities in Other Tanks}

Maximum ${ }^{137} \mathrm{Cs}$ activities observed in tank liquors/supernates have been reported from measurements in 5 tanks in the late 1970's by Schulz (1978). The maximum value was 0.54 $\mathrm{Ci} / 1$ in Tank U-111. This value is lower than the values for SX tanks' supernatant liquid after self-concentration as shown in Table 3.4. Thus it appears that SX tank farm may have contained drainable liquid in the 1950's through 1970 's that were higher in ${ }^{137} \mathrm{Cs}$ and perhaps other soluble nuclides such as ${ }^{99} \mathrm{Tc}$ than other tank waste types, specifically bismuth phosphate-type wastes. It is interesting to note that Agnew et al. (1996) predict that the ${ }^{137} \mathrm{Cs}$ content in SX tanks that still contain drainable liquid should be more in line with values found by Schulz (1978) and data on tank solids leaching by Weiss and Schull to be discussed next. Aside from significant concentration by self-boiling we have no other explanation for the high ${ }^{137} \mathrm{Cs}$ values measured in the supernate liquids from two SX tanks in the 1960's and 1970's (see Table 3.4).

Weiss and Schull (1988a-i) report on the proclivity of SST core material to leach into water using laboratory leach tests on nine SST tank cores [A-102, A-103, A-106, BX-104, BX-105, C-103, C-104, C-105, and C-106]. Based on Agnew et al. (1996) these tanks currently contain the types of wastes presented in Table 3.5. There have been some changes in tank 
contents between the time that these samples were analyzed and the present such that the estimated compositions for today, shown in Table 3.5, do not necessarily reflect the tank composition at the time when Weiss and Schull performed their tests. Most of the changes represent removal of waste contents from tanks to extract Sr and addition to tanks of material from evaporators (see Agnew et al. 1996 Appendix B. for details on the time history of individual tanks.) In no case does the tank composition for Weiss and Schull's tanks look to be dominated by REDOX waste, thus use of the Weiss and Schull data to draw specific conclusions about the SX Tank Farm leak issue is not warranted. Weiss and Schull's laboratory leach tests took $-5 \mathrm{~g}$ (dry weight basis) of tank core solids and mixed them with $\sim 15$ $\mathrm{ml}$ of distilled water for 30 minutes in an ultra-sonicator. The leachate was then decanted and saved. Distilled water was added again and the leach process repeated two more times. All three leachates were combined and brought to a fixed $50 \mathrm{ml}$ volume and dissolved constituents measured. The amount of $\mathrm{Cs}$ that leaches is generally near $50 \%$ of the total in the core sample. Leachate concentrations of ${ }^{137} \mathrm{Cs}$ varied from 0.26 to $39,300 \mu \mathrm{Ci} / 1$. These values are lower than the measured ${ }^{137} \mathrm{Cs}$ in SX tanks supernate values shown in Table 3.4. Again one might conclude that REDOX liquids contained higher values of ${ }^{137} \mathrm{Cs}$ than other waste streams.

Of more interest is measurement of the ${ }^{137} \mathrm{Cs}$ content of drainable liquor when the cores were opened up and sampled. Weiss and Schull's data range from 9 to $442,000 \mu \mathrm{Ci} / 1$ with a median value of about $22,000 \mu \mathrm{Ci} /$ l. Again these values are not as high as those observed for SX Tank Farm liquids shown in Table 3.4.

Table 3.5. Estimate of the Types of Waste Currently in Tanks Studied by Weiss and Schull

\begin{tabular}{|c|c|c|c|c|}
\hline & \multicolumn{4}{|c|}{ Waste Category (\% by volume) } \\
\hline Tank & Bismuth Phosphate & REDOX & PUREX & Other \\
\hline A-102 & 24 & 17 & 59 & 0 \\
\hline A-103 & 24 & 17 & 59 & 0 \\
\hline A-106 & 17 & 24 & 59 & 0 \\
\hline BX-104 & 11 & 24 & 65 & 0 \\
\hline BX-105 & 15 & 22 & 63 & 0 \\
\hline C-103 & 21 & 1 & 78 & 0 \\
\hline C-104 & 13 & 18 & 61 & 8 \\
\hline C-105 & 11 & 0 & 89 & 0 \\
\hline C-106 & 0 & 0 & 100 & 0 \\
\hline
\end{tabular}


Recently, WHC obtained samples of solids from tank SX-108 using an auger. Some of the solids were leached in water and chemical analyses were performed but no data for water leachable ${ }^{137} \mathrm{Cs}$ was reported. An acid extract of the solids showed between 140 and $170 \mu \mathrm{Ci} / \mathrm{g}$ ${ }^{137} \mathrm{Cs}$ in the top (near the surface of the tank solids) and 220 to $260 \mu \mathrm{Ci} / \mathrm{g}$ in the bottom of the auger samples, suggesting that there is slightly more $\mathrm{Cs}$ in the solids as depth increases in the material. On a liter of solids basis these values would be about 0.2 to $0.4 \mathrm{Ci} / 1$ which is more in line with Agnew et al. (1996) predictions of the amount of ${ }^{137} \mathrm{Cs}$ in the tanks, if one assumes that most of the ${ }^{137} \mathrm{Cs}$ is water and acid soluble.

The chemical composition of the supernatant liquid in Tank T-106 at the time of its 1973 leak is shown in Table 3.6 as reported by Routson et al. (1979). At the time of the leak the tank contained first cycle bismuth phosphate waste from the later campaigns (1950-56) and both early and later REDOX cladding wastes from mainly $\mathrm{Al}$ clad fuel but with some $\mathrm{Zr}$ clad fuel in the later campaign (see Agnew et al. 1996 for details). The mix was about $38 \%$ bismuth phosphate and $62 \%$ REDOX cladding waste (27\% early cladding and $35 \%$ later cladding waste: Agnew designations CWR1 and CWR2, respectively). The chemical composition of these waste types as predicted by Agnew et al. (1996) is shown in Table 3.7.

Based on these percentages being present in $\mathrm{T}-106$ at the time of the leak and the chemical composition of the three wastes predicted by Agnew et al. (1996), the bulk composition of supernate would have been $2.4 \mathrm{M} \mathrm{Na}$ and the hydroxide concentration(excluding hydroxides bound to $\mathrm{Al}$ in solution would have been $0.036 \mathrm{M}$. Data in Table 3.6 which are actual tank measurements show that the $\mathrm{Na}$ was $4 \mathrm{M}$ and the $\mathrm{OH}$ content not associated with Al could have been quite small. If the reported $\mathrm{pH}$ is accurate, the free hydroxide would have been $-0.01 \mathrm{M}$ and the hydroxide content combined with other metals excepting Al could raise the value towards the $0.036 \mathrm{M}$ predicted by Agnew et al. It is difficult to determine whether the agreement between Agnew et al.'s predictions and the actual reported chemical composition of the T-106 supernate solution is adequate to conclusively state that we can use predictive tools to estimate tank contents as a function of fill history.

Some other miscellaneous information on tank waste compositions found in the literature search include the following. Schulz (1977) measured the total dissolved organic carbon concentration in several tank supernate/salt cake leachates and waste streams before transfer to tanks. Solution formed from dissolution of salt cake in Tanks SX-102 and SX-103 yielded organic carbon values of $0.211 \mathrm{M}$ organic carbon, which if present as the strong chelating agent EDTA would yield a value of $-0.02 \mathrm{M}$ ETDA.

Rhodes et al. (1954) describe work performed by Honstead in 1952 where supernate solution from Tank T-112 was analyzed for radionuclide content over a 3 month period. The ${ }^{137} \mathrm{Cs}$ content varied from 9.4 to $62 \mu \mathrm{Ci} / 1$ in this second cycle bismuth phosphate waste stream. The inorganic salt content was measured by evaporation and found to be $80 \mathrm{~g} / \mathrm{l}$ and was assumed to be mostly sodium nitrate with some sulfate, phosphate and other salts. 
Table 3.6. Chemical/Radionuclide Composition of Supernate Liquid Tank T-106

\begin{tabular}{|c|c|}
\hline Component & Concentration (M) \\
\hline Sodium & 4 \\
\hline Ammonium & 0.065 \\
\hline Potassium & 0.016 \\
\hline Calcium & 0.002 \\
\hline Nitrite & 1.18 \\
\hline Carbonate & 0.79 \\
\hline Nitrate & 0.77 \\
\hline Sulfate & 0.25 \\
\hline Hydroxide & 0.24 \\
\hline Aluminum & 0.06 \\
\hline $\mathrm{pH}$ & 11.9 \\
\hline Radionuclides & Concentration $(\mu \mathrm{Ci} / 1)$ \\
\hline Cs-137 & $8.85 \times 10^{4}$ \\
\hline $\mathrm{Sr}-90$ & $2.98 \times 10^{4}$ \\
\hline $\mathrm{Ru} / \mathrm{Rh}-106$ & $6.12 \times 10^{5}$ \\
\hline $\mathrm{Ce} / \mathrm{Pr}-144$ & $1.18 \times 10^{4}$ \\
\hline Cs-134 & $1.32 \times 10^{3}$ \\
\hline $\mathrm{Sb}-125$ & $1.12 \times 10^{3}$ \\
\hline Pu-239 & 9 \\
\hline
\end{tabular}

Nelson et al. (1960) report on the chemical makeup of Redox Decladding Waste obtained from Tank U-201. The waste contained $6 \mathrm{M} \mathrm{Na}, 0.2 \mathrm{M} \mathrm{AlO}_{2}, 0.03 \mathrm{M} \mathrm{CrO}_{4}, 0.02 \mathrm{M} \mathrm{PO}_{4}$, and 3.4 $\mathrm{M} \mathrm{NO}_{3}+\mathrm{NO}_{2}$. The phosphate and chromate indicate that a heel of older bismuth phosphate process waste was present.

Mercer et al. (1968) give the chemical composition of SX condensate and 242-T evaporator. SX condensate that is formed when vapor from boiling SX tanks is routed to Tank SX-106 where it recondenses. 242-T evaporator condensate is produced by evaporation of supernate liquor from non-boiling tanks in $200-\mathrm{W}$ Area. The vapor from a pot evaporator that is being 
Table 3.7 Agnew Predictions of Chemical Composition of Waste in Tank T-106 in 1973

\begin{tabular}{|c|c|c|c|c|c|c|c|c|c|}
\hline & \multicolumn{3}{|c|}{$1 \mathrm{C} 2$} & \multicolumn{3}{|c|}{ CWR1 } & \multicolumn{3}{|c|}{ CWR2 } \\
\hline & $\begin{array}{l}\text { Total } \\
\text { Waste }\end{array}$ & Sludge & Sol'n & $\begin{array}{c}\text { Total } \\
\text { Waste }\end{array}$ & Sludge & Sol'n & $\begin{array}{l}\text { Total } \\
\text { Waste }\end{array}$ & Sludge & Sol'n \\
\hline Species & (M) & (M) & (M) & (M) & (M) & (M) & (M) & (M) & (M) \\
\hline $\mathrm{Na}$ & 2.17 & 3.54 & 1.708 & 3.95 & 3.54 & 3.98 & 1.79 & 1.40 & 1.81 \\
\hline $\mathrm{Al}$ & 0.23 & 0.86 & 0.007 & 2.0 & 6.54 & 0.45 & 0.78 & 5.87 & 0.179 \\
\hline $\mathrm{Fe}$ & 0.05 & 0.18 & 0.002 & 0.015 & 0.165 & 0.002 & 0.015 & 0.457 & 0.002 \\
\hline $\mathrm{Cr}$ & 0.005 & 0.004 & 0.006 & 0.003 & 0.003 & 0.003 & 0.003 & 0.002 & 0.003 \\
\hline $\mathrm{Bi}$ & 0.014 & 0.044 & 0.004 & 0 & 0 & 0 & 0 & 0 & 0 \\
\hline $\mathrm{La}$ & - & 0 & 0 & -- & 0 & 0 & - & 0 & 0 \\
\hline $\mathrm{Zr}$ & 0.002 & 0.005 & 0.002 & 0 & 0 & 0 & 0 & 0 & 0 \\
\hline $\mathrm{Pb}$ & 0 & 0 & 0 & 0 & 0 & 0 & 0 & 0 & 0 \\
\hline $\mathrm{Ni}$ & 0.002 & 0.001 & 0.002 & 0.002 & 0.001 & 0.002 & 0.002 & 0.001 & 0.002 \\
\hline $\mathrm{Mn}$ & 0 & 0 & 0 & 0 & 0 & 0 & 0 & 0 & 0 \\
\hline $\mathrm{Ca}$ & 0.018 & 0.046 & 0.009 & 0.018 & 0.121 & 0.009 & 0.018 & 0.322 & 0.009 \\
\hline $\mathrm{K}$ & 0.003 & 0.003 & 0.004 & 0.002 & 0.002 & 0.002 & 0.003 & 0.003 & 0.003 \\
\hline $\mathrm{OH}$ & 0.89 & 3.18 & 0.029 & 7.76 & 22.82 & 0.035 & 3.12 & 21.91 & 0.045 \\
\hline free $\mathrm{OH}$ & - & 0.023 & - & - & 0.028 & - & & 0.035 & - \\
\hline $\mathrm{NO}_{3}$ & 0.59 & 0.39 & 0.54 & 0.885 & 0.702 & 0.879 & 0.886 & 0.670 & 0.876 \\
\hline $\mathrm{NO}_{2}$ & 0.17 & 0.25 & 0.26 & 1.4 & 1.185 & 1.44 & 0.28 & 0.241 & 0.298 \\
\hline $\mathrm{CO}_{3}$ & 0.018 & 0.046 & 0.009 & 0.018 & 0.121 & 0.009 & 0.018 & 0.322 & 0.009 \\
\hline $\mathrm{PO}_{4}$ & 0.33 & 0.88 & 0.152 & 0 & 0 & 0 & 0 & 0 & 0 \\
\hline $\mathrm{SO}_{4}$ & 0.06 & 0.05 & 0.065 & 0.002 & 0.0013 & 0.002 & 0.002 & 0.001 & 0.002 \\
\hline $\mathrm{Cl}$ & 0.015 & 0.013 & 0.016 & 0.010 & 0.008 & 0.010 & 0.016 & 0.012 & 0.016 \\
\hline $\mathrm{NH}_{3}$ & 0 & 0 & 0.001 & 0 & 0 & $\begin{array}{l}8 \mathrm{x} \\
10^{-4} \\
\end{array}$ & $\begin{array}{l}4 \times x \\
10^{4} \\
\end{array}$ & $7 \times 10^{-5}$ & $\begin{array}{c}1.4 \mathrm{x} \\
10^{-4} \\
\end{array}$ \\
\hline
\end{tabular}




\begin{tabular}{|c|c|c|c|c|c|c|c|c|c|}
\hline & \multicolumn{3}{|c|}{$1 \mathrm{C} 2$} & \multicolumn{3}{|c|}{ CWR1 } & \multicolumn{3}{|c|}{ CWR2 } \\
\hline & $\begin{array}{l}\text { Total } \\
\text { Waste }\end{array}$ & Sludge & Sol'n & $\begin{array}{l}\text { Total } \\
\text { Waste }\end{array}$ & Sludge & Sol'n & $\begin{array}{l}\text { Total } \\
\text { Waste }\end{array}$ & Sludge & Sol'n \\
\hline $\begin{array}{l}\text { Radio- } \\
\text { nuclides }\end{array}$ & $\begin{array}{l}\mathrm{Ci} / 1 \\
(\mathrm{Ci} / \\
\text { gal })\end{array}$ & $\begin{array}{l}\mathrm{Ci} / 1 \\
(\mathrm{Ci} / \\
\mathrm{gal})\end{array}$ & $\begin{array}{l}\mathrm{Ci} / 1 \\
(\mathrm{Ci} / \\
\mathrm{gal})\end{array}$ & $\begin{array}{l}\mathrm{Ci} / 1 \\
(\mathrm{Ci} / \\
\mathrm{gal})\end{array}$ & $\begin{array}{l}\mathrm{Ci} / 1 \\
(\mathrm{Ci} / \\
\mathrm{gal})\end{array}$ & $\begin{array}{l}\mathrm{Ci} / 1 \\
(\mathrm{Ci} / \\
\mathrm{gal})\end{array}$ & $\begin{array}{l}\mathrm{Ci} / 1 \\
(\mathrm{Ci} / \\
\mathrm{gal})\end{array}$ & $\begin{array}{l}\mathrm{Ci} / 1 \\
(\mathrm{Ci} / \\
\mathrm{gal})\end{array}$ & $\begin{array}{l}\mathrm{Ci} / 1 \\
(\mathrm{Ci} / \\
\mathrm{gal})\end{array}$ \\
\hline${ }^{137} \mathrm{Cs}$ & - & $\begin{array}{l}0.029 \\
(0.11)\end{array}$ & $\begin{array}{l}0.037 \\
(0.14)\end{array}$ & - & $\begin{array}{c}0.003 \\
(0.011)\end{array}$ & $\begin{array}{c}0.004 \\
(0.015)\end{array}$ & - & $\begin{array}{c}0.004 \\
(0.015) \\
\end{array}$ & $\begin{array}{c}0.005 \\
(0.019) \\
\end{array}$ \\
\hline${ }^{90} \mathrm{Sr}$ & - & $\begin{array}{l}0.0003 \\
(0.001)\end{array}$ & $\begin{array}{l}0.0003 \\
(0.001) \\
\end{array}$ & - & $\begin{array}{l}0.003 \\
(0.01)\end{array}$ & $\begin{array}{l}0.003 \\
(0.01) \\
\end{array}$ & - & $\begin{array}{l}0.003 \\
(0.01) \\
\end{array}$ & $\begin{array}{r}0.004 \\
(0.02) \\
\end{array}$ \\
\hline
\end{tabular}

fed supernate liquor is collected and condensed. Both streams are rather dilute, near neutral solutions ( $\mathrm{pH}=7$ and $=9$ for the SX and $242-\mathrm{T}$ condensates, respectively). The SX condensate contains $1-3 \mathrm{mg} / 1$ ammonia, $1-2 \mathrm{mg} / 1$ sodium and $1-3 \mu \mathrm{Ci} / 1$ of ${ }^{137} \mathrm{Cs}$. The $242-\mathrm{T}$ condensate contains much more ammonia $(-158 \mathrm{mg} / 1)$, less $\mathrm{Na}(0.1 \mathrm{mg} / \mathrm{l})$ and less ${ }^{137} \mathrm{Cs}(0.15$ $\mu \mathrm{Ci} / 1)$.

\subsection{Section Summary}

In summary, we find that the REDOX liquid chemical composition can vary significantly from its original state as time passes largely because of its high radioactivity content that creates self-boiling conditions. Fresh REDOX waste had a chemical composition shown in Table 3.2 and was predominately a $4 \mathrm{M}$ sodium-nitrate-nitrite-aluminate-hydroxide solution. This composition was similar to other Hanford process wastes such as bismuth phosphate and PUREX waste liquids. But after self-boiling or other concentrating processes, the residual REDOX liquid exhibits a much higher ionic strength and perhaps higher basicity (free hydroxide content) in the range of 8-10 M Na and perhaps 0.5 to $1 \mathrm{M}$ free hydroxide. This chemical composition is beyond any for which sediment-contaminant adsorption studies have been performed as discussed in the next section.

The REDOX supernatant has unusually high concentrations of certain chemical components that will react with Hanford and Ringold Formation sediments, potentially changing their sorptivity for Cs. We briefly note several important issues that are germane to resolving the $\mathrm{SX}$ tank farm Cs migration issue.

Hydroxide. The normal $\mathrm{pH}$ of Hanford vadose-zone sediments ranges from 7.5 to 8.5, with higher values recorded in zones of caliche. Single-shell tank supernatant $\mathrm{pH}$ ranges from 9 to $>14$ with REDOX wastes containing free [OH-] in excess of $1.0 \mathrm{~mol} / \mathrm{L}$ being on the extreme end. Base equivalents $\left(\mathrm{OH}^{-}\right)$are also associated with aluminate $\left(\mathrm{Al}(\mathrm{OH})_{4}{ }^{-}\right)$. It is expected, although not documented, that leaking SST tanks will be surrounded by a pH neutralization 
aureole resulting from waste-mineral interactions. Within the aureole a gradient in $\mathrm{pH}$ will exist, decreasing from its very caustic tank value near the exit point to the natural $\mathrm{pH}$ at depth.

The primary neutralization process is mineral dissolution. The dissolution of oxides and alumino-silicates (e.g., feldspars, mica, clays, etc.) has been studied widely at low pH, as rates are proton-promoted. Such dissolution reactions are fundamental to the process of weathering and the chemical composition of natural waters. Little information exists, for mineral dissolution or weathering under high $\mathrm{pH}$ conditions.

The Hanford and Ringold sediments contain a complex association of mineral phases, including unstable primary phases (e.g., feldspars) that are weathering slowly in place and stable secondary phases (e.g., Al oxides, poorly crystalline $\mathrm{SiO}_{2}$, smectite) that have formed in-situ. Elevated [OH] will greatly enhance the solubility of most $\mathrm{Al}$ - and $\mathrm{Si} /$ containing oxides and mixed oxides (see for example Lindsay 1979), and increase their dissolution rates by many orders of magnitude (Brady and Walther 1989) over those at pH 8. The solubility of silica compounds, in particular, reaches high values $(>0.1 \mathrm{~mol} / \mathrm{L})$ above $\mathrm{pH} 12.8$ because of silicic acid ionization to $\mathrm{H}_{2} \mathrm{SiO}_{4}{ }^{2-}$. Dissolution rates of many aluminosilicates above $\mathrm{pH} 12$ are comparable to those at and below pH 3 (Brady and Walther 1989). The dissolution of oligoclase will release $\mathrm{K}^{+}$, a potential competitive ion for Cs, and sorbent phases with $\mathrm{Cs}$ selectivity may be altered. Micas are unstable in $\mathrm{NaOH}$; their particle and edge morphology changes with time signifying dissolution, and interlayer $\mathbf{K}$ is slowly released (Choquette et al. 1991). Smectites are also unstable at high $\mathrm{pH}$, and their small size and high surface area promote rapid reactivity (Ferrel and Grim 1967). Highly Cs selective wedge or frayed edge sites on illite or hydro-mica may be especially sensitive to high $\mathrm{pH}$ conditions that promote dissolution because their high surface area relative to the bulk sediment enables greater access to the silica tetrahedral layers for base hydrolysis.

Limited studies of aluminosilicate dissolution at high $\mathrm{pH}$ indicate that the reaction is typically congruent (i.e., $\mathrm{Si}$ and $\mathrm{Al}$ are released in mole ratios equal to their mole fraction in the solid [Casey et al. 1988; 1989]). The presence of high aluminate in the REDOX supernate, however, may force incongruence; i.e., the selective solubilization of silica. Such incongruence has implications to the fate of Cs-sorbing FES sites that may be transformed to dangling $\mathrm{Al}(\mathrm{OH})_{\mathrm{x}}$ octahedra as a result of selective silica dissolution. The reverse process, i.e., the selective dissolution of the octahedral layer, has been noted at low pH (Fanning et al. 1989).

Choquette et al. (1991) observed that increases in temperature from $23^{\circ}$ to $80^{\circ} \mathrm{C}$ greatly accelerated mineral dissolution/transformation rates in $1 \mathrm{~mol} / \mathrm{L} \mathrm{NaOH}$. The acceleration results from both solubility and kinetic effects. We surmise therefore, that mineral dissolution, and hence alteration of fine grained Cs-mineral sorbents, may be or have been greatest around leaking tanks of higher temperature, such as those containing highly radioactive, self-boiling REDOX wastes. We also surmise that aluminosilicate precipitation will occur near the margin of the thermal aureole as the temperature and carrying capacity of 
the aqueous phase decrease.

Aluminate. High concentrations of aluminate $\left[\mathrm{Al}(\mathrm{OH})_{4}{ }^{-}\right]$are present in the REDOX tank supernatants. Aluminum oxides, notably boehmite, are ubiquitous tank sludge solids; the tank supernatants likely are in equilibrium with these phases at the elevated temperatures and hydroxide concentrations present in the tanks. Aluminate will precipitate as 1) temperature decreases through the thermal aureole; and 2) leaked solution $\mathrm{pH}$ decreases as a result of aluminosilicate- and oxide-dissolution reactions. A wide variety of precipitating phases is possible, including bayerite, gibbsite, and boehmite, depending on temperature, precipitation rate, and the nature of other solutes (Hayden and Rubin 1974). Laboratory studies with tank supernatants and simulants document active Al-oxide precipitation when the temperature is decreased or when the solutions contact Hanford geologic materials (see Section 5.4). Thus Hanford subsurface sediments receiving tank supernatant, especially REDOX liquors, will become enriched in Al oxides and their depth distribution below the tanks will reflect the thermal regime, the kinetics of dissolution/neutralization, and moisture flux rate.

Under acidic soil pH conditions (e.g., pH 4-6) soluble $\mathrm{Al}^{3+}$ or cationic $\mathrm{Al}(\mathrm{III})$ hydrolysis polymers sorb to negatively charged surface sites on vermiculites and smectites, creating both continuous and discontinuous layers of hydroxy-interlayer $\mathrm{Al}$ polymers (see Fig. 3.1A for continuous or uniform and Figure 3.1B for discontinuous layers). Such hydroxy interlayered clays are ubiquitous in acid soils containing 2:1 layer-silicates. The continuous or uniform hydroxy interlayer prevents both expansion and collapse but the discontinuous interlayer version allows collapse. These two different types of interlayers allow different cation exchange capacity (e.g., Tullock and Roth 1975), cation exchange selectivity (Murdock and Rich 1972), and $\mathrm{K}^{+}$selectivity and fixation (Rich and Black 1964). Cs sorption either may be increased or decreased on hydroxy interlayered materials (Elprince et al. 1977), depending on temperature and mineralogy of the 2:1 layer-silicate fraction. The formation, synthesis, chemical properties, and chemical behavior of hydroxy-interlayered clays have seen much research attention by the soils community as summarized in a recent review (Barnhisel and Bertsch 1989).

It is unclear whether Al-oxide precipitation in Hanford sediments will impact the structure or chemistry of Cs reactive sites on the 2:1 layer-silicate fraction. Can hydroxy interlayers form in vermiculites and smectites when $\mathrm{Al}$ oxide is precipitating from basic solution dominated by aluminate? Do conditions of $\mathrm{pH}\left(\mathrm{e} . \mathrm{g} .\right.$, below the $\left[\mathrm{H}^{+}\right]_{\text {zpc }}$ where alumina colloids may carry positive charge) and aluminate concentration exist in specific locations of the neutralization aureole that may allow hydroxy-interlayer formation? If so, how does such interlayering influence the sorption chemistry of Cs? Can Al-oxide precipitation at high pH or colloidal Aloxide precipitates with predominantly negative charge block or otherwise alter the chemical reactivity of highly selective FES sites? The literature does not help us address such questions. We have been unable to locate any examples of Al-hydroxy interlayers formed at $\mathrm{pH}$ values where aluminate is the dominate solution species or where the surface charge on the Al oxide is likely to be negative (e.g., $\mathrm{pH}>9.5$ ). Significant literature exists on the hydrolysis and 
polymerization of Al(II) under circumneutral conditions (Bertsch 1989), but comparable data is virtually nonexistent at the high $\mathrm{pH}$ values relevant to $\mathrm{SX}$ tank leak issues. Thus, it is unclear whether precipitate precursors (e.g., Bertsch et al. 1987; hydrolysis polymers with the requisite charge and size properties) exist in basic solutions that could even represent plausible candidates for participation in hydroxy-interlayer formation.

A final conclusion from the review through Section 3 is that a comparison of the T-106 tank leak with SX Tank Farm leak(s) is not warranted given the dissimilar chemical composition of leaking liquids. Further, we suspect that the adsorption reactions between contaminants, especially Cs would be quantitatively different for the two tank farms. As shown in Table 3.7 the expected chemical composition of the supernatant solution in T-106 at the time of the leak and the actual composition shown in Table 3.6 show a much lower $\mathrm{Na}$ and hydroxide content than the REDOX supernate measurements shown in Table 3.3 and 3.4. It is quite possible that the migration of Cs from the SX tank liquors is faster than that observed for the T-106 tank leak to be described in more detail in the next section. 

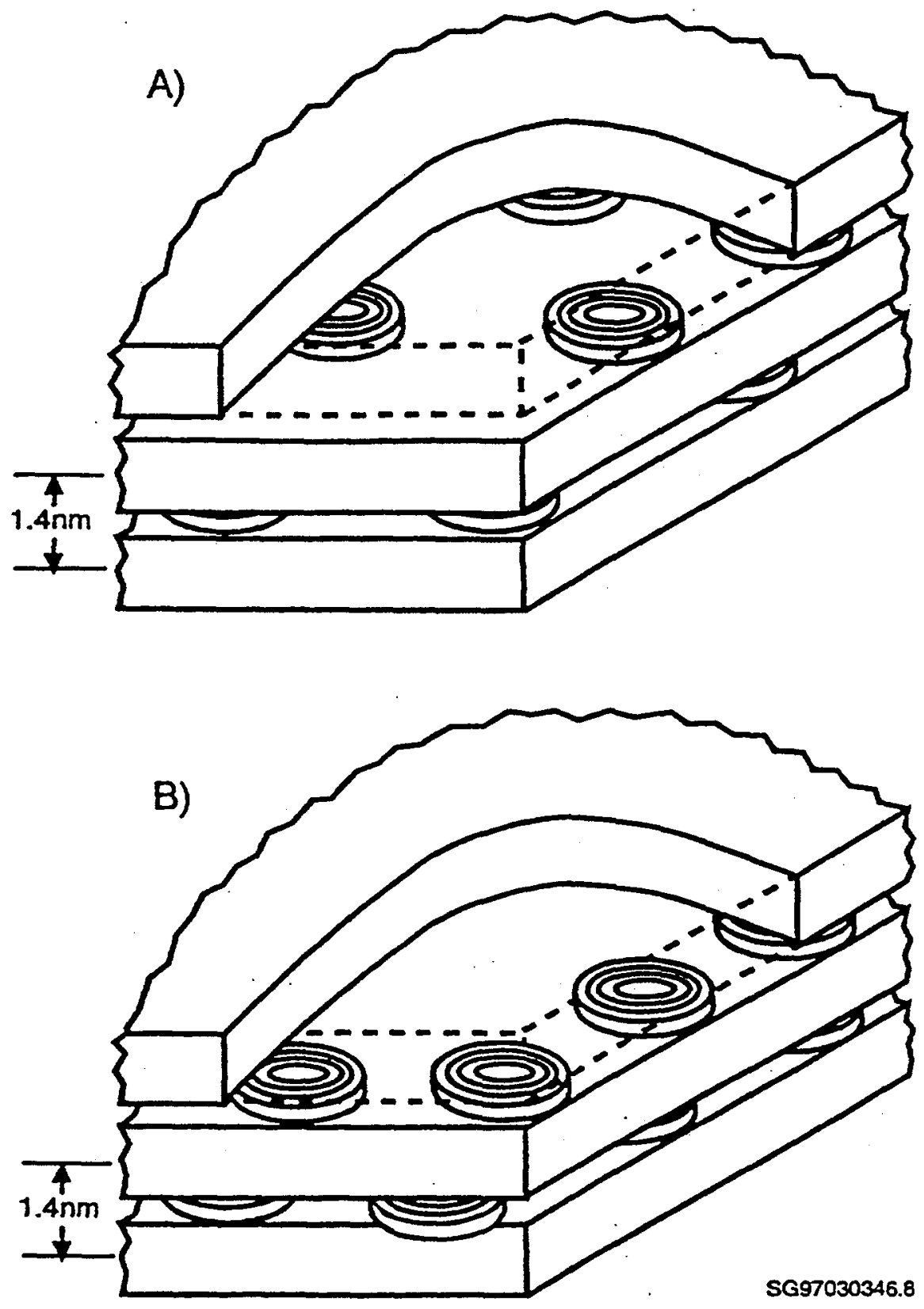

Figure 3.1 Conceptual Structures of Al-Hydroxy Interlayered 2:1 Layer-Silicates: A) uniform or continuous interlayering and B) discontinuous layering [From Barnhisel and Bertsch (1989)]. 


\subsection{HISTORY OF CS KD VALUES FOR HANFORD SEDIMENTS [BASED ON LABORATORY STUDIES]}

\subsection{Bismuth Phosphate Waste Streams}

Rhodes et al. (1954) describe work performed by Honstead in 1952 where supernate solution from Tank T-112 was analyzed for radionuclide content over a 3 month period. The ${ }^{137} \mathrm{Cs}$ content varied from 9.4 to $62 \mu \mathrm{Ci} / 1$ in this second cycle bismuth phosphate waste stream. The inorganic salt content was measured by evaporation and found to be $80 \mathrm{~g} / \mathrm{l}$ and was assumed to be mostly sodium nitrate with some sulfate, phosphate and other salts. Some of the actual supernate solution was percolated through a $30-\mathrm{cm}$ long soil column until 7 pore volumes had drained. The column was then rinsed with 11 pore volume of water and the sediment sectioned into thin wafers. The ${ }^{137} \mathrm{Cs}$ was found to be adsorbed in the upper $5 \mathrm{~cm}$ of the column whereas $\mathrm{Ru}$ was found throughout the column and rare-earths, plutonium, zirconium and $\mathrm{Sr}$ were found in the upper two $\mathrm{cm}$ of the soil column. This suggests that $\mathrm{Cs}$ is moderately mobile but much less mobile than Ru.

In a simple successive batch contact where 4 grams of soil were contacted with $40 \mathrm{ml}$ batches of T-112 supernate solution Rhodes et al. (1954) found that no more Cs could be removed by the soil on the fifth contact with fresh solution. This led to the ${ }^{137} \mathrm{Cs}$ saturation capacity to be calculated as $0.09 \mu \mathrm{Ci} / \mathrm{g}$ of soil. This value was used to estimate how far $\mathrm{Cs}$ should have moved under the 241-T crib that received the cascading supernate from the T110-111-112 Tanks cascade. Records showed that 37.5 million liters had been discharged to the crib with a total ${ }^{137} \mathrm{Cs}$ inventory of 1,130 curies. A nearby well (100 feet downgradient from the direction that the discharged water is thought to migrate) perforated above a fine aquitard lens (depth 110 feet below ground) showed ${ }^{137} \mathrm{Cs}$ concentrations about $3 \%$ of the initial waste solution. Based on the volume of soil in the cone between the crib and well and the calculated saturation capacity, about $70 \%$ of the Cs would be calculated to be adsorbed whereas the water extracted from the well suggests as much as $97 \%$ of the Cs was adsorbed. Thus the tank supernate solution either adsorbs better than the laboratory tests predict or some dilution of the solution occurs with native pore water causing the Kd to increase.

McHenry (1957) measured the Cs Kd for first cycle bismuth phosphate waste that was scavenged with nickel ferrocyanide to remove as many fission products as possible. The residual solution was run through Hanford soil columns and the number of column volumes before any measurable radionuclide breakthrough was measured. This particular waste stream contacting Hanford sediment showed better removal of ${ }^{90} \mathrm{Sr}$ than ${ }^{137} \mathrm{Cs}$. Typically the effluent ${ }^{137} \mathrm{Cs}$ concentration reached 0.1 of the original liquid waste concentration within one to four column volumes ( 2.5 to 10 pore volumes). This would equate to a $\mathrm{Kd}$ value of greater than 10 $\mathrm{mL} / \mathrm{g}$. Synthetic and actual first cycle scavenged bismuth phosphate waste (from Tanks TY101,103 and 104) was used in soil flow-through columns run with a soil from 200-W Area that had a particle size distribution of $87 \%$ sand, $12 \%$ silt and $~ 2 \%$ clay. The soil was 
calcareous and had a cation exchange capacity of $6 \mathrm{meq} / 100 \mathrm{~g}$. The breakthrough of ${ }^{137} \mathrm{Cs}$ was strongly dependent upon the amount of stable Cs added to solution. As more stable Cs was added to the solution the breakthrough of ${ }^{137} \mathrm{Cs}$ occurred earlier as would be expected from ion exchange theory where the higher the mass present for an element the faster the sediment adsorption sites become loaded, especially highly preferred but scarce sites such as FES discussed in Section 2. Twenty percent breakthrough was observed to vary between 2.5 and 7 pore volumes dependent upon the solution Cs concentration. Extrapolating these breakthrough curves to $50 \%$ in order to estimate a Cs $\mathrm{Kd}$ yields values $>6$ to $15 \mathrm{ml} / \mathrm{g}$.

Rhodes and Nelson (1957) measured Cs adsorption onto Hanford sediment using high ionic strength solutions (between 0.3 and $6 \mathrm{M}$ ) and found the Cs $\mathrm{Kd}$ dropped from a value of 240 to $18 \mathrm{ml} / \mathrm{g}$ as the ionic strength was increased over this range. For one actual Hanford Site liquid waste known as U Recovery Plant scavenged waste, which was created by taking the bismuth phosphate metal waste and processing it to recover $U$, with subsequent scavenging of some fission products with nickel ferrocyanide precipitate, the $\mathrm{Cs} \mathrm{Kd}$ on Hanford soils was found to be $6 \mathrm{ml} / \mathrm{g}$. The U Recovery Plant scavenged waste has a pH of about 9.5 and about $4 \mathrm{M}$ $\mathrm{NaNO}_{3}$ and $\mathrm{O} .1 \mathrm{M} \mathrm{Na}_{3} \mathrm{PO}_{4}$. The Hanford soil was $89 \%$ sand, $8 \%$ silt and 3\% clay sized with a cation-exchange capacity of about $2 \mathrm{meq} / 100 \mathrm{~g}$ and a saturated paste $\mathrm{pH}$ value of 8.6 . Two grams of soil and $10 \mathrm{ml}$ of U Recovery Plant scavenged waste were used in the batch Kd tests. Soil flow through column tests with variable length were also run and gave calculated $\mathrm{Kd}$ values (based on observed retardation factors) of 6 to $10 \mathrm{ml} / \mathrm{g}$.

In other tests using simulated solutions, the authors studied the effect of varying the initial concentration of ${ }^{137} \mathrm{Cs}$ (from $0.1 \mu \mathrm{Ci} / 1$ to $100 \mu \mathrm{Ci} / 1\left[-10^{-11}\right.$ to $\left.-10^{-8} \mathrm{M}\right]$ ), Na solution concentration $(0.3$ to $6 \mathrm{M})$, and $\mathrm{pH}(0.4$ to 10.1$)$. The variation in starting Cs concentration had no effect on the $\mathrm{Kd}$ as required for trace constituents. The $\mathrm{Cs} \mathrm{Kd}$ as a function of $\mathrm{Na}$ in solution drops steeply ( $\mathrm{Kd}=240$ to $50 \mathrm{ml} / \mathrm{g}$ ) as the $\mathrm{Na}$ is increased from 0.3 to $2 \mathrm{M}$ and then continues to drop less sharply ( $\mathrm{Kd}=50$ to $18 \mathrm{ml} / \mathrm{g}$ ) as the $\mathrm{Na}$ solution concentration is increased to $6 \mathrm{M}$. The change in $\mathrm{pH}$ for a $4 \mathrm{M} \mathrm{NaCl}$ background electrolyte from 0.4 to 10.1 showed little effect on the $\mathrm{Kd}$ value for $\mathrm{Cs}$ which ranged from 12 to $19 \mathrm{ml} / \mathrm{g}$. This would suggest that a REDOX tank supernate with high $\mathrm{Na}$ concentration (above $4 \mathrm{M}$ ) and high $\mathrm{pH}$ $>10$ might give a $\mathrm{Kd}$ between 6 and $20 \mathrm{ml} / \mathrm{g}$ if the sorption mechanisms remain the same.

\subsection{T-106 Tank Simulants}

Serne (1973 unpublished) measured Cs sorption for a range of synthetic T-106 liquors. Measured $\mathrm{Kd}$ values were between 1 and $12 \mathrm{ml} / \mathrm{g}$ and are found in Table 4.1. The most representative liquor among the five solutions used, in comparison to the measured T-106 $\operatorname{tank}$ liquor (shown in Table 3.6), gave a Cs Kd value of 2 to $6 \mathrm{ml} / \mathrm{g}$ for seven different 200-W sediments. The most representative simulated liquor was $4 \mathrm{M} \mathrm{Na}, 0.025 \mathrm{M} \mathrm{K}$, and $0.065 \mathrm{M}$ $\mathrm{NH}_{4}$. A description of the sediments and the synthetic liquors used are given in Ames and Rai (1978). The synthetic solutions differ from the data shown in Table 3.6 only in that the value of ammonium cation was $0.65 \mathrm{M} \mathrm{NH}_{4}^{+}$in all the simulated solutions. This is 10 times higher 
than the measured T-106 composition reported in Routson et al. (1979) as shown in Table 3.6. If Serne really did use $0.65 \mathrm{M}$ ammonia in the simulants as opposed to $0.065 \mathrm{M}$ measured then all the $\mathrm{Kd}$ values reported in Table 4.1 may be biased low. If the Routson report is in error in reporting the measured ammonium concentration and it really was $0.65 \mathrm{M}$ then the $\mathrm{Kd}$ values reported in Table 4.1 would be realistic for the Tank T-106 leak conditions. Unfortunately we can't determine which ammonium value is correct from available lab notebooks.

All the details available on the seven sediments and the five simulated tank liquors are shown in Tables 4.2 and 4.3 for completeness. The information in Ames and Rai (1978) on the sediments was inadvertently placed in the report out of order. To conform with all the Kd data presented in Table 4.1, Table 4.2 includes the sediment description in the right order. The sample from borehole W-10-109 represents backfill placed around tanks after emplacement and is a rather coarse sediment despite having the larger-sized material removed prior to backfilling. The material from borehole $\mathrm{W}-11-24$ is from the top of the caliche layer in the Plio-Pleistocene unit. The particle size analysis given may not mean much seeing as this material is usually cemented and we have no knowledge of how the sample was obtained. The sediment from the 85 foot-depth in borehole W-10-112 is rather fine grained compared to all the others but its cation-exchange-capacity (CEC) is not significantly greater than other sediments.

\subsection{Miscellaneous Simulated Solutions}

Rhodes and Nelson (1957) measured Cs adsorption on Hanford sediments using dilute solutions and varying $\mathrm{pH}$. For $\mathrm{pH}$ values between 3 and 10 , there was not much dependence

Table 4.1. Kd Values (units $=\mathrm{ml} / \mathrm{g}$ ) for Cs Using 7 Hanford Sediments and Five Simulated Tank T-106 Liquors

\begin{tabular}{|c|c|c|c|c|c|}
\hline & \multicolumn{5}{|c|}{ Solutions } \\
\hline Sediment & I & II & III & IV & V \\
\hline 1 & 13.5 & 6 & 1.8 & 0.8 & 12 \\
\hline 2 & 9.4 & 3.5 & 1.4 & 0.6 & 7.1 \\
\hline 3 & 9.1 & 3.4 & 1.3 & 0.6 & 7.2 \\
\hline 4 & 8.1 & 3.1 & 1.4 & 0.7 & 7.7 \\
\hline 5 & 10.9 & 3.7 & 1.8 & 2.9 & 11.3 \\
\hline 6 & 7.9 & 2 & 0.9 & 1.2 & 7.9 \\
\hline 7 & 8.7 & 2.8 & 1.1 & 1.5 & 9.5 \\
\hline
\end{tabular}


Table 4.2. Description of Sediments Used in Kd Tests for T-106 Leak

\begin{tabular}{|c|c|c|c|c|c|c|c|}
\hline \multirow{2}{*}{$\begin{array}{c}\text { Sed. } \\
\#\end{array}$} & \multirow[t]{2}{*}{ Borehole } & \multirow[t]{2}{*}{ Depth (ft.) } & \multicolumn{3}{|c|}{$\begin{array}{c}\text { Particle Size } \\
\text { (wt. \%) }\end{array}$} & \multirow{2}{*}{$\begin{array}{c}\text { Cation } \\
\text { Exchange } \\
\text { Capacity } \\
\text { (meq } 100 \mathrm{~g})\end{array}$} & \multirow{2}{*}{$\begin{array}{l}\mathrm{CaCO}_{3} \\
\text { Content } \\
\text { (g/100 g) }\end{array}$} \\
\hline & & & gravel & sand & silt/clay & & \\
\hline 1 & W-10-113 & $20-40$ & 39 & $?$ & $?$ & 6.73 & 1.24 \\
\hline 2 & W-10-113 & $45-65$ & 20 & $?$ & $?$ & 6.16 & 1.30 \\
\hline 3 & W-10-113 & $70-80$ & 5 & 88 & 7 & 5.95 & 2.60 \\
\hline 4 & W-11-24 & 102 & 41 & $?$ & $?$ & 7.88 & 37.00 \\
\hline 5 & W-10-109 & 15 & 59 & 41 & 0 & 6.73 & 0.95 \\
\hline 6 & W-11-23 & $100-105$ & 10 & 70 & 20 & 5.28 & 7.65 \\
\hline 7 & W-10-112 & 85 & 0 & 62 & 38 & 6.96 & 13.2 \\
\hline
\end{tabular}

Table 4.3. Chemical Composition of the Five Simulated T-106 Tank Liquors

\begin{tabular}{|c|c|c|c|c|c|}
\hline & \multicolumn{5}{|c|}{ Solution Number } \\
\hline Constituent & I & II & III & IV & V \\
\hline & \multicolumn{5}{|c|}{ Chemical Composition (M) } \\
\hline $\mathrm{NaNO}_{3}$ & 1.0 & 4.0 & 1.0 & 4.0 & 0.6 \\
\hline $\mathrm{Ca}\left(\mathrm{NO}_{3}\right)_{2}$ & 0.002 & 0.002 & 3.5 & 3.5 & 0.002 \\
\hline $\mathrm{NH}_{4} \mathrm{NO}_{3}$ & 0.65 & 0.65 & 0.65 & 0.65 & 0.15 \\
\hline $\mathrm{KNO}_{3}$ & 0.025 & 0.025 & 0.025 & 0.025 & 0.01 \\
\hline $\mathrm{NaNO}_{2}$ & 0 & 0 & 0 & 0 & 1.18 \\
\hline$\left(\mathrm{NH}_{4}\right)_{2} \mathrm{SO}_{4}$ & 0 & 0 & 0 & 0 & 0.25 \\
\hline $\mathrm{Na}_{2} \mathrm{CO}_{3}$ & 0 & 0 & 0 & 0 & 0.79 \\
\hline $\mathrm{pH}$ & 12 & 12 & 12 & 12 & 12 \\
\hline
\end{tabular}


on $\mathrm{pH}$ and the $\mathrm{Cs} \mathrm{Kd}$ was always greater than $200 \mathrm{ml} / \mathrm{g}$. At $\mathrm{pH}$ values of 1.8 and 0.4 the $\mathrm{Cs}$ $\mathrm{Kd}$ value dropped to 138 and $36 \mathrm{ml} / \mathrm{g}$, respectively.

Hajek and Ames (1966) measured the adsorption of Cs from various solutions onto a Hanford soil. For groundwater the $\mathrm{Cs}$ adsorption $\mathrm{Kd}$ was between 325 and 9,000 $\mathrm{ml} / \mathrm{g}$ dependent upon the amount of groundwater and soil mixed together. For a $3 \mathrm{M} \mathrm{NaNO}_{3}$ solution the $\mathrm{Cs} \mathrm{Kd}$ ranged from 1,100 to $1,450 \mathrm{ml} / \mathrm{g}$ compared to only 0.4 to $2 \mathrm{ml} / \mathrm{g}$ for Sr's $\mathrm{Kd}$. Solutions containing $\mathrm{Ca}$ up to $0.25 \mathrm{M} \mathrm{CaCl}_{2}$ did not reduce the Cs adsorption appreciably with the $\mathrm{Kd}$ ranging from 1,300 to $5,400 \mathrm{ml} / \mathrm{g}$ dependent upon the mix ratio of solution and soil.

Routson et al. (1981a,b) investigated the effects of varying the concentrations of potassium, sodium, and calcium dissolved individually in water on Cs adsorption using a typical Hanford soil from 200-E Area. Potassium was the strongest competitor for sorption sites. The Cs Kd value dropped from 280 to $5.8 \mathrm{ml} / \mathrm{g}$ as $\mathrm{K}$ solution concentrations increased from 0.001 to 0.2 $\mathrm{M}$ [39 to $7800 \mathrm{ppm}$ ]. In the presence of $\mathrm{Na}, \mathrm{Cs}$ adsorption dropped from 1,600 to 570 and then to $26 \mathrm{ml} / \mathrm{g}$ as the sodium solution concentration increased from 0.001 to 0.01 and then to $3 \mathrm{M}$ [23 to 230 to $69,000 \mathrm{ppm}$ ]. Ca was the least influential competing cation with the Cs adsorption decreasing only slightly, from a $\mathrm{Kd}$ of 2,200 to $790 \mathrm{ml} / \mathrm{g}$, when the solution $\mathrm{Ca}$ concentration increased from 0.002 to $0.02 \mathrm{M}[80$ to $800 \mathrm{ml} / \mathrm{g}]$. The authors also measured the $\mathrm{Kd}$ for $\mathrm{Cs}$ on the 200-E Area soil using mixed solutions of these three cations. Na was varied between 0.001 and $3.0 \mathrm{M}$, Ca was varied from 0.002 to $0.2 \mathrm{M}$ and $\mathrm{K}$ was varied from 0.002 to $0.1 \mathrm{M}$. When all three cations were present at their highest concentrations, the $\mathrm{Kd}$ for Cs was between 3 to $5 \mathrm{ml} / \mathrm{g}$ and when all three cations were present at their lowest concentration the $\mathrm{Cs} \mathrm{Kd}$ value was $370 \mathrm{ml} / \mathrm{g}$. In a second batch adsorption test again using a factorial design protocol the authors repeated Cs adsorption tests on the same 200-E sediment and the same types of mixed $\mathrm{Na}-\mathrm{Ca}-\mathrm{K}$-nitrate solutions. In this second test $\mathrm{K}$ was allowed to vary from 0.002 to $0.2 \mathrm{M}$, slightly higher than in the first test. When all the cations were at or near their highest concentrations the $\mathrm{Kd}$ for $\mathrm{Cs}$ was 1.8 to $3.2 \mathrm{ml} / \mathrm{g}$ and when they were present at their lower concentrations the Cs Kd value was 24 to $88 \mathrm{ml} / \mathrm{g}$. In this second test the $\mathrm{Ca}$ concentration appeared to have more influence on the $\mathrm{Cs} \mathrm{Kd}$ value than in the first test, but again the $\mathrm{K}$ concentration influenced the $\mathrm{Cs} \mathrm{Kd}$ more than other variables.

In a more ambitious study the authors took 21 Hanford sediments from 6 boreholes that were chosen to represent all the strata from the ground surface to the water table at both $200-\mathrm{E}$ and $200-\mathrm{W}$ areas. Twelve sediments were used to represent $200-\mathrm{E}$ and 9 sediments were used to represent $200-W$. A similar factorial design scheme using these 21 sediments and mixed cation solutions of $\mathrm{Na}-\mathrm{K}-\mathrm{Ca}-\mathrm{NO}_{3}$ was used to develop predictor equations for the adsorption of $\mathrm{Cs}, \mathrm{Sr}$, and $\mathrm{Co}$. The range of solution concentrations used were 0.001 to $3.0 \mathrm{M} \mathrm{Na}$, and 0.002 to $0.2 \mathrm{M}$ for both $\mathrm{Ca}$ and $\mathrm{K}$. These ranges cover natural groundwater compositions up through Hanford tank liquor concentrations (although the latter solution's pH would be much different than the neutral values used in this factorial test). The authors found that the regression coefficients for the individual sediment predictor equations ( 21 soils) did not vary significantly for any given nuclide. They thus averaged the regression coefficients and the 
resulting predictor equation for a generic Hanford sediment for Cs adsorption from a mixed cation bearing $(\mathrm{Na}-\mathrm{Ca}-\mathrm{K})$ water was

$$
\begin{aligned}
\operatorname{lnKd}(\mathrm{Cs})= & 2.26-0.672\left[2 / 3\left(\mathrm{Na}^{+}\right)-1\right]-1.42\left[10\left(\mathrm{~K}^{+}\right)-1\right]-0.177\left[2 / 3\left(\mathrm{Na}^{+}\right)-1\right]^{2} \\
& -0.853\left[10\left(\mathrm{~K}^{+}\right)-1\right]^{2}+0.429\left[2 / 3\left(\mathrm{Na}^{+}\right)-1\right]\left[10\left(\mathrm{~K}^{+}\right)-1\right]
\end{aligned}
$$

where $\left(\mathrm{Na}^{+}\right)$and $\left(\mathrm{K}^{+}\right)$are the solution concentrations of sodium and potassium in units of molarity.

This equation could be used to calculate the $\mathrm{Kd}$ for $\mathrm{Cs}$ for any mixed solution (at neutral $\mathrm{pH}$ ) that contained mostly $\mathrm{Na}, \mathrm{K}$, and $\mathrm{Ca}$ and only minor amounts of other competing cations for Hanford site conditions. The equation might also be used to extrapolate to higher $\mathrm{pH}$ conditions based on previous observations that the Cs Kd does not change significantly with $\mathrm{pH}$ over the $\mathrm{pH}$ range 4 to 10 . We question whether the equation could be used for extremely alkaline solutions such as REDOX tank liquors.

Barney (1978) measured the adsorption of Cs onto Hanford sediments using mixed cation solutions composed of $\mathrm{Na}$ and $\mathrm{K}$ with humic acid present (17 to $33 \mathrm{mg} / \mathrm{l})$. The maximum $\mathrm{K}$ and $\mathrm{Na}$ solution concentrations studied were $0.01 \mathrm{M}[390 \mathrm{ppm}]$ and $0.1 \mathrm{M}[2300 \mathrm{ppm}]$, respectively. The lowest $\mathrm{Cs} \mathrm{Kd}$ value for this highest solution concentration mixture was 200 $\mathrm{ml} / \mathrm{g}$. A parametric equation was developed to predict the Cs Kd value for Hanford sediments and mixed Na-K-Ca-nitrate-nitrite-humic acid solutions (within the concentrations just noted) as follows:

$$
\begin{aligned}
\ln \mathrm{Kd}(\mathrm{Cs})= & 16.9-1928\left[\mathrm{~K}^{+}\right]-173\left[\mathrm{Na}^{+}\right]+0.19[\text { humic acid }]+71,000\left[\mathrm{~K}^{+}\right]^{2}+1000\left[\mathrm{Na}^{+}\right]^{2} \\
& -0.005[\text { humic acid }]^{2}+1300\left[\mathrm{~K}^{+}\right]\left[\mathrm{Na}^{+}\right]
\end{aligned}
$$

where $\left[\mathrm{K}^{+}\right]$and $\left[\mathrm{Na}^{+}\right]=$molarity of potassium and sodium present in water [humic acid] $=\mathrm{ppm}$ of humic acid present in water.

Ames and Hajek (1966a,b) determined sorption of Cs as a function of $\mathrm{Na}, \mathrm{K}, \mathrm{Ca}$, and $\mathrm{H}$ in nitrate solutions for an unidentified Hanford soil using Yates' factorial design and analysis scheme. A complete 2-level design was used which required $2^{4}$ or 16 tests. The sorption method was a recirculating column with $1 \mathrm{~g}$ of sediment contacting the recirculating solution until the solution maintained a constant $C s$ activity. The range of mixed solution cation concentrations were 1.0 to $3.0 \mathrm{M} \mathrm{Na}, 0.00$ to $0.001 \mathrm{M} \mathrm{K}, 0.00$ to $0.05 \mathrm{M} \mathrm{Ca}$, and 0.00 to $0.05 \mathrm{M} \mathrm{H}$. Unfortunately the authors do not state how much solution was used in each test and they only report the ratio of the final concentration of Cs to the starting concentration such that $\mathrm{Kd}$ values can not be calculated. The most dilute solution showed only $12 \%$ of the Cs remained in solution while the most concentrated solution showed $62 \%$ of the Cs remained in solution. Thus the range in Kd values would vary by a factor of 5 . Hydrogen and potassium concentrations showed the largest impacts on adsorption and seeing as $\mathrm{K}$ was present at lower concentrations than $\mathrm{H}$ in the test matrix it would be the most influential parameter controlling 
Cs adsorption on a mole per mole basis (assuming that $\mathrm{H}^{+}$was not consumed in reactions with the sediment.

Knoll (1969) could remove less than $12 \%$ of Hanford sediment adsorbed Cs after leaching contaminated sediment with 70 pore volumes using a $0.4 \mathrm{M}$ organic chelator $-0.2 \mathrm{M}$ TBP solution.

Barney (1982a,b) measured the $\mathrm{Kd}$ for Cs on several basalt interbed materials generically called sandstone using a deep groundwater from the Grande Ronde flow that has a rather high $\mathrm{pH}$ value of 10 and higher $\mathrm{Na}, \mathrm{Cl}$, and $\mathrm{SO}_{4}$ concentrations in comparison to shallow upper unconfined aquifer groundwaters. The $\mathrm{Kd}$ for $\mathrm{Cs}$ onto the sandstone was quite high at room temperature [500 to $1,600 \mathrm{ml} / \mathrm{g}$ ] and dropped to values between $\left[200\right.$ to $1,400 \mathrm{ml} / \mathrm{g}$ ] at $60^{\circ} \mathrm{C}$ and $[100$ to $700 \mathrm{ml} / \mathrm{g}]$ at $85^{\circ} \mathrm{C}$. Potassium concentration was the most important variable in determining the $\mathrm{Kd}$ for $\mathrm{Cs}$ as a function of groundwater composition. These data suggest that increasing the $\mathrm{pH}$ of groundwater from about 8 to 10 and increasing the dissolved salt content somewhat does not lower the Kd for Cs significantly.

\subsection{Miscellaneous Actual Waste Streams}

Rhodes (1956) performed laboratory adsorption tests using REDOX cell drainage liquid and process condensates and showed that Hanford soil could adsorb $>90 \%$ of the ${ }^{137} \mathrm{Cs}$ but $<10 \%$ of the ${ }^{90} \mathrm{Sr}$. The tests were performed with $1 \mathrm{~g}$ of soil and $10 \mathrm{ml}$ of waste, thus for $>90 \%$ removal of $\mathrm{Cs}$, the $\mathrm{Kd}$ must be $>90 \mathrm{ml} / \mathrm{g}$. The poor adsorption of ${ }^{90} \mathrm{Sr}$ was attributed to the acidic nature $(\mathrm{pH} \sim 2.1)$ of the wastes. After neutralization of the $\mathrm{pH}$ to 8 to 10 the $\mathrm{Sr}$ adsorption increased to $>90 \%$ also. Neutralization did not affect the Cs adsorption which remained high. Such neutralization would occur before the wastes were disposed to tanks. The SX Tank Farm received such neutralized REDOX waste.

\subsection{Section Summary}

In summary, none of the available $\mathrm{Kd}$ tests were run with liquids that contained more than $4 \mathrm{M}$. sodium and $\mathrm{pH}$ values were likely never above 12 (free hydroxide $-0.01 \mathrm{M}$ ). The data that are available may be adequate to estimate $\mathrm{Kd}$ values for $\mathrm{Cs}$ in very fresh REDOX liquid that has not self-concentrated, but the data are not adequate to estimate $\mathrm{Kd}$ values for the higher ionic strength and higher $\mathrm{pH}$ solution that forms through self-boiling and other processes. Dependent upon when the SX tank leaks actually occurred, the chemical composition of the draining liquid would vary over a rather significant range. The resultant $\mathrm{Cs} \mathrm{Kd}$ would also be expected to vary as the $\mathrm{Na}$ solution concentration changes. The extremely high $\mathrm{pH}$ condition might also impact the Cs adsorption and perhaps dissolve bulk sediment or severely etch the fine particulates that likely perform most of the adsorption. See the end of Section 3 for more discussion on the impacts of hydroxide and aluminate on the adsorbing minerals and Cs adsorption processes. About the only conclusion that can be offered, without empirical testing using such high ionic strength/high $\mathrm{pH}$ solutions, is that the $\mathrm{Cs} \mathrm{Kd}$ values could be lower than 
those reported in the available literature. As shown for the less concentrated T-106 liquid simulants, the Cs Kd value ranges from 0.5 to $12 \mathrm{ml} / \mathrm{g}$ across a range of solution compositions, with a more realistic range of 2 to $6 \mathrm{ml} / \mathrm{g}$ for the simulant most representative of the tank liquor (see Table 4.3 Solution II). 


\section{0 SCOPING LAB TESTS ON SX TANK LIQUOR INTERACTIONS WITH HANFORD SEDIMENTS}

After the literature review on the chemical nature of REDOX liquid wastes and their subsequent interactions with Hanford sediments showed that no work has been performed on this type of solution, we solicited a small amount of money ( $\$ 20 \mathrm{~K}$ ) from WHC (Don Engelman) to perform a few scoping studies at the end of FY96. The REDOX waste appears unique from other Hanford tank wastes; it has a very high ionic strength, very high $\mathrm{pH}$ or hydroxide content, and high soluble $\mathrm{Al}$ content. All three of these variables can affect the adsorption properties of the two radionuclides that constitute the bulk of the activity in the tanks, namely ${ }^{90} \mathrm{Sr}$ and ${ }^{137} \mathrm{Cs}$. We discuss some of the available knowledge on the effects of hydroxide and aluminate on adsorption and mineral stability at the end of Section 3.

We attempted to perform many of the scoping experiments at elevated temperature to better simulate the environment surrounding the tanks at the time of the leaks. Our goals in the scoping tests were to get an indication on the adsorption tendencies of Sr and Cs from a solution with very high ionic strength, high $\mathrm{Na}$, high $\mathrm{Al}$ and high $\mathrm{OH}$ content and to see whether the high $\mathrm{OH}$ might significantly dissolve the existing sediment. The latter issue is further discussed in section 7.0. Work was conducted over one month starting in the second week of September 1996. One similar study was found in the Hanford literature wherein a simulated caustic tank liquor that did not contain any dissolved Al was contacted with a Hanford sediment and a pure mineral, anorthite, using a recirculating-flow through column technique.

\subsection{Summary of Past Sediment-Caustic Tank Liquor Interactions}

Shade (1974) presents data on experiments where a Hanford sandy sediment, taken from the SY-Tank Farm excavation (base of the $\mathrm{N}$ face), and a pure mineral, anorthite $\left[\mathrm{CaAl} \mathrm{Si}_{2} \mathrm{O}_{8}\right.$ or $\mathrm{CaO} \cdot \mathrm{Al}_{2} \mathrm{O}_{3} \cdot 2 \mathrm{SiO}_{2}$ ], were contacted with liquid that was continually recirculated in a flowthrough column configuration. The anorthite was crushed and sized to obtain 0.5 to $1 \mathrm{~mm}$ sized material similar to the predominate particle size for Hanford sediments. Anorthite is one of the predominate minerals in Hanford sediment. Each solid was packed into a separate column with dimensions of $2.85 \mathrm{~cm} \mathrm{ID}$ and $7.8 \mathrm{~cm}$ length. 80 grams of solid were used in each case. A synthetic tank liquor patterned after an analysis of BX-100 solution was reacted with the two solids. The chemical composition of the synthetic liquor is shown in Table 5.1. Dissolved $\mathrm{Al}$ was not included in the synthetic waste which is an unfortunate omission for the SX tank liquor/sediment interactions issue. Shade gives the weight of reagents mixed with a set weight of water which allows one to calculate the molality of the solution. If one had the density of the resultant solution one could also calculate the molarity of the solution which is the units used in all the other tables in this report. Using data available in the Handbook of Chemistry and Physics [Weast 1981] for pure solutions we have estimated the molarities of the components in the synthetic solution but we stress that the values are purely estimates. The 
solution contains much higher hydroxide concentrations than the tank liquor analyses reported from actual measurements and estimates found in Section 3 (see Tables 3.3-3.4). The sodium, nitrate, and nitrite concentrations are comparable to values expected in SX tank liquors. Thus based on the hydroxide content, the synthetic solution listed in Table 5.1 may be more corrosive upon reacting with sediment than actual SX tank liquors. It is possible that the free hydroxide content of the BX waste was greatly over-predicted if it is based on an acid titration of actual waste. The acid titration would have also been influenced by aluminate, carbonate, phosphate and part of the sulfate and other components in the actual tank liquor such that the free hydroxide content would be over-predicted..

At any rate Shade reacted the highly caustic solution with Hanford sediment and anorthite at a ratio of $650 \mathrm{~g}$ of solution to $80 \mathrm{~g}$ of solids. The ratio was chosen to be similar to a study of caustic dissolution of $\mathrm{K}$-feldspar found in the literature where the solubility of $\mathrm{K}$ feldspar was determined over a pH range of 4 to 10 . Shade recirculated the solution through the columns for 26 days and periodically removed a small aliquot of the reacted solution to measure $\mathrm{Al}$ and Si content. The reacting solution quickly dissolved ( $<2$ days) enough $\mathrm{Si}$ out of the Hanford sediment to yield a concentration of $600 \mathrm{ppm}$. The Si concentration continued to increase at a slowing rate over the 26-d test. At the end of the test the Si concentration had reached 1,200 $\mathrm{ppm}$ but steady-state was not reached. Al in solution was $\sim 100 \mathrm{ppm}$ at two days reaction and appeared to reach a steady-state value of about $200 \mathrm{ppm}$ between about 17 and 26 days. The anorthite reaction was tracked for only 9 days and the $\mathrm{Si}$ and $\mathrm{Al}$ concentrations were still increasing significantly at the end of the test. The amount released suggested that the anorthite was leaching congruently such that two moles of $\mathrm{Si}$ released for each mole of $\mathrm{Al}$. As mentioned in Section 3 others have reported congruent mineral dissolution in pure caustic environments but no data are available for highly caustic and high aluminate solutions such as the REDOX waste. The rate of anorthite dissolution was much higher than a literature value for a $\mathrm{pH}=10$ solution. This should be expected because the simulated tank liquor would have a starting $\mathrm{pH}$ greater than 14 . The chemical and mineralogic composition of the

Table 5.1 Composition of the Synthetic Tank Liquor Used by Shade (1974)

\begin{tabular}{|c|c|c|}
\hline Component & Molal & - Molarity \\
\hline $\mathrm{NaNO}_{2}$ & 2.19 & 2.6 \\
\hline $\mathrm{NaNO}_{3}$ & 3.74 & 4.6 \\
\hline $\mathrm{NaOH}$ & 4.49 & 5.3 \\
\hline $\mathrm{Na}_{2} \mathrm{CO}_{3}$ & 0.11 & 0.11 \\
\hline $\mathrm{NASA}$ & 0.08 & 0.08 \\
\hline $\mathrm{Na}_{3} \mathrm{PO}_{4}$ & 0.012 & 0.01 \\
\hline
\end{tabular}


Hanford sediment was not determined so quantitative results are not possible. A rough calculation based on Si release and a nominal Hanford sediment chemical analysis suggests that about $2 \%$ by weight of the sediment may have dissolved in 26 days. The rate was also slowing down appreciably by this time. Shade presents more calculations that such tank liquor might dissolve about $0.13 \mathrm{~cm}^{3}$ of soil matrix for each liter of waste liquor that escapes. Shade's work does not address the fact that some tank liquors, including REDOX wastes, already contain large amounts of soluble Al that might precipitate upon contact with sediments such that the net mass change may not be negative (dissolution controlled).

\subsection{Preparation of Simulated Tank Liquor}

Within the data base that exists on the World Wide Web within the PNNL home page there is some data on SX-108 supernate solution taken in April 1961 and data on SX-111 supernate solution and solids taken in September 1974. No other explanation as to where the original data can be found in hard copy is available in the data base. These data are shown in Table 3.4 along with predictions from Agnew (1995) and Agnew et al. (1996) for representative SX Tank Farm solution compositions.

Given these compositions, REDOX solutions exhibit high ionic strength, soluble aluminum and hydroxide concentrations well beyond that studied in past sorption experiments. In the literature review, we found that the REDOX liquid chemical composition can change significantly with time because of its high radioactivity content that creates self-boiling conditions. Fresh REDOX waste chemical composition was predominately a $4 \mathrm{M}$ sodiumnitrate-nitrite-aluminate-hydroxide solution. This composition was similar to other Hanford process wastes such as bismuth phosphate and PUREX waste liquids. But after self-boiling or other concentrating processes, the residual REDOX liquid can exhibit a much higher ionic strength and perhaps higher basicity (free hydroxide content) in the range of 8-10 M Na and perhaps 0.5 to $1 \mathrm{M}$ free hydroxide. This chemical composition is beyond any for which sediment-contaminant adsorption studies have been performed.

We attempted to make a liter of the REDOX solution shown in Table 3.4 for Tank SX-108 because it had the highest ionic strength, $\mathrm{Al}$ and hydroxide content. These are the three variables that need to be studied regarding sediment interactions and contaminant adsorption.

We used reagent grade chemicals: sodium aluminate, sodium chloride, sodium nitrite, sodium nitrate, and sodium sulfate. The chemicals were added to deionized water in the following order: $\quad$ sodium aluminate

sodium chloride

sodium nitrite

sodium sulfate

sodium nitrate.

The sodium aluminate all dissolved and formed a viscous solution with a $\mathrm{pH}$ greater than 14 . 
All the sodium chloride, sodium nitrite, and sodium sulfate also dissolved. The sodium nitrate did not all dissolve following overnight agitation and some chemical reaction was obvious. The solution changed color and precipitates other than sodium nitrate were observed. The slurry was heated to $60^{\circ} \mathrm{C}$ overnight but there was still considerable undissolved material in the container, comprising approximately one-tenth the total volume. Upon settling the $\mathrm{pH}$ of the supernate was still greater than 14. We elected to filter the solution and to continue tests with the resultant solution. An aliquot of the undissolved solids was analyzed by XRD and several crystalline phases were identified including nitratine $\left[\mathrm{NaNO}_{3}\right]$, bayerite $\left[\mathrm{Al}(\mathrm{OH})_{3}\right]$ and a mixed sodium-aluminum-nitrate compound. There was also evidence of amorphous material in the precipitate. The resultant solution phase was also analyzed by AA and IC for major cations and anions. The results are shown in Table 5.2. Table 5.2 clearly shows that some of the $\mathrm{Al}$ that originally dissolved was re-precipitated upon adding the sodium nitrate. Some of the sodium nitrate did not dissolve. The chloride and nitrite appear to remain completely dissolved. The measured nitrite value is likely biased high because of interferences of the large quantity of nitrate in the solution. The solids that were identified in the undissolved material corroborate the solution analyses in that $\mathrm{Na}$ and $\mathrm{Al}$ are present in the solids thus lowering the solution composition from that desired.

We have no explanation on why the chemicals did not all dissolve as one might have expected from the actual tank supernate analysis from 1961. Recall we heated the slurry overnight at an elevated temperature (albeit not as high as boiling) and much undissolved material still remained.

\subsection{Adsorption Test Descriptions}

\subsubsection{Batch Kd Tests}

The resultant solution (see Table 5.2) was spiked with trace amounts of ${ }^{85} \mathrm{Sr}$ and ${ }^{137} \mathrm{Cs}$ and used

Table 5.2. Measured Composition of the Solution Vs. Desired Composition

\begin{tabular}{|c|c|c|}
\hline Constituent & Measured $(\mathrm{M})$ & Desired $(\mathrm{M})$ \\
\hline $\mathrm{Al}$ & 0.58 & 1.7 \\
\hline $\mathrm{Na}$ & 4.75 & 10.52 \\
\hline $\mathrm{Cl}$ & 0.27 & 0.25 \\
\hline $\mathrm{NO}_{3}$ & 5.99 & 8.14 \\
\hline $\mathrm{NO}_{2}$ & 0.67 & 0.45 \\
\hline $\mathrm{OH}$ & not measured & 1.5 \\
\hline
\end{tabular}


in batch adsorption tests with a representative coarse Hanford sand sediment from the 200-E Area grout vault excavation. A complete characterization of the sediment (MSG-1) is given in Serne et al. (1993). The sediment used in the batch adsorption tests had a particle size of $89 \%$ sand, $7 \%$ silt, and $4 \%$ clay. The sediment contains a small amount of calcium carbonate [0.83\% by wt.] and very little organic carbon [0.023\% by wt.]. The cation-exchange-capacity of the sediment is on the high end for Hanford coarse grained sands with a value of 7.8 meq $/ 100 \mathrm{~g}$. Ninety-nine $\%$ of the exchange sites are naturally filled by calcium and magnesium and only $1 \%$ contain alkali metals $[\mathrm{Na}$ and $\mathrm{K}]$. The mineralogy of the bulk sediment is predominately plagioclase and quartz with small amounts of hornblende and mica. The small amount of clay sized particles are predominately smectite (85\%), kaolinite (8\%), mica (5\%) and vermiculite (3\%). Although this sediment is from 200-E Area its mineralogy is similar to sediments from the SX tank farm in 200-W Area such that a the Kd values obtained should be representative of SX tank farm sediments.

Duplicate sediment samples and a blank tube were used in each batch adsorption test. The blank tube was used to determine the stability of the tracers in the simulated tank liquor. Additionally, a sample where soil was contacted with non-radioactive solution was included. A solution-to-solid ratio of $10 \mathrm{ml}: 1 \mathrm{~g}$ was used. The tubes were gently rocked on a linear shaker for 11 days at room temperature. After 4 and 11 days small aliquots of solution were removed from the tubes after the sediment was allowed to settle for several hours. The aliquots were then counted for gamma emissions on a high efficiency Ge detector. The blank tube with only spiked solution was used to compare whether the sediment or the container removed the tracers. During the sediment-solution contact there was evidence of continued precipitation of a whitish solid. The calculated $\mathrm{Kd}$ values for the tracers are shown in Table 5.3 for unfiltered solutions that were gravity settled. As shown in Table 5.3 the Kd value for $\mathrm{Sr}$ is quite variable but the $\mathrm{Kd}$ for $\mathrm{Cs}$ is fairly stable at a value of about $22 \mathrm{ml} / \mathrm{g}$. The $\mathrm{Cs}$ tracer in the solution remains stable (remains in solution) over the time period studied. When the blank solution and sediment contacted solutions are all filtered through $0.22 \mu \mathrm{m}$ membranes, the $\mathrm{Kd}$ for $\mathrm{Cs}$ onto Hanford sediment increases further to values as high as 64 $\mathrm{ml} / \mathrm{g}$. The increase is apparently caused by further removal of fine suspended whitish precipitate from the solution in contact with sediment. The fine precipitate has some ${ }^{137} \mathrm{Cs}$ adsorbed to it.

Table 5.3. Unfiltered Kd Values [ml/g] for Sr and Cs From REDOX Liquor Contacting a Coarse Hanford Sand

\begin{tabular}{|c|c|c|}
\hline Contact Time (d) & ${ }^{85} \mathrm{Sr}$ & ${ }^{137} \mathrm{Cs}$ \\
\hline 4 & 4 & 28 \\
\hline & 28 & 20 \\
\hline 11 & $0.2 \pm 0.2$ & $20 \pm 4$ \\
\hline
\end{tabular}


On the other hand the ${ }^{85} \mathrm{Sr}$ is not stable. Most of the $\mathrm{Sr}$ is found to be attached to fine white precipitate that forms in the tubes with time, including the blank tubes with no soil present.

We suspect that the precipitate is bayerite or an $\mathrm{Al}$ oxyhydroxide. With long settling times, on the order of a week or longer, the simulated tank liquor separates into a white, dense phase and a yellow, clear, aqueous phase. There is no measurable ${ }^{85} \mathrm{Sr}$ in the yellow liquid but most of the ${ }^{137} \mathrm{Cs}$ still is present in the yellow-clear solution. The effluent liquid from the soil contact tests also separates into two phases but the radionuclide content of the clear yellow supernate contains no ${ }^{85} \mathrm{Sr}$ and reduced activities of ${ }^{137} \mathrm{Cs}$. Because we did not filter the solutions after contact with the sediment and because the ${ }^{85} \mathrm{Sr}$ in the blank tube (solution only and no soil) became attached to fine grained partially suspended precipitate, the batch Kd tests yielded very inconsistent $\mathrm{Sr} \mathrm{Kd}$ 's. From a practicable standpoint one should not attempt to measure a Sr Kd value for this system onto Hanford sediment because the $\mathrm{Sr}$ is not stable in the evolving solution and tends to attach and precipitate onto $\mathrm{Al}$ bearing precipitates prior to or in conjunction with contacting the sediment.

The solution after contact with the sediment at a $10 \mathrm{ml}: 1 \mathrm{~g}$ ratio and 11 days had a $\mathrm{pH}$ value of 12.6 and the composition shown in Table 5.4. In general the $\mathrm{pH}$ dropped from $>14$ to 12.6 and a small amount of nitrite, large amounts of nitrate and aluminum hydroxide/oxide were lost from solution. Conversely a large amount of sodium appears to have been released from the sediment. We can not at the moment explain the apparent large release of sodium, but we do note that the value reported appears to be in error because the cation-anion charge balance is way out of balance. The loss of the other species is caused by the continued formation of precipitates as the sediment reacts with the REDOX solution.

Table 5.4. REDOX Solution Chemical Composition After Contacting Sediment

\begin{tabular}{|c|c|c|}
\hline Constituent & After Contact (M) & Before Contact (M) \\
\hline $\mathrm{Al}$ & 0.41 & 0.58 \\
\hline $\mathrm{Na}$ & $9.57^{*}$ & 4.75 \\
\hline $\mathrm{Cl}$ & 0.27 & 0.27 \\
\hline $\mathrm{NO}_{3}$ & 4.52 & 5.99 \\
\hline $\mathrm{NO}_{2}$ & 0.57 & 0.67 \\
\hline $\mathrm{OH}$ & not measured & not measured \\
\hline $\mathrm{pH}$ & 12.6 & $>14$ \\
\hline
\end{tabular}

* sodium value seems wrong; cation-anion balance is way off 
The measured $\mathrm{Kd}$ value for $\mathrm{Cs}$ is higher than values found for other Hanford tank waste solutions with comparable Na concentrations. We are not sure at this time whether the high $\mathrm{Al}$ content and continued precipitation of Al-bearing (inferred from the white precipitate) solids plays a significant role. Note that no other adsorption studies for Cs onto Hanford sediments (see Section 4.0) used $\mathrm{Al}$ as one of the solution variables. The $\mathrm{Al}$ appears to continue to react in the presence of sediment to form additional solid phases such as $\mathrm{Al}$ oxides, $\mathrm{Al}$ hydroxides and $\mathrm{Al}$ oxyhydroxides. These solids are known to have a large exchange capacity for many metals and they are used along with ferric oxyhydroxides to remove trace metals from water in numerous water treatment processes. See Clark (1990), Kepak (1971), Kinniburgh and Jackson (1981), Righetto et al. (1988), and Schindler (1981) for discussions on Al oxide adsorption properties.

At the moment the preliminary finding that the $\mathrm{Kd}$ for Cs is slightly above $20 \mathrm{ml} / \mathrm{g}$ does not correspond with the modeling done recently by Ward et al. (1997). Their predictions suggest that a $\mathrm{Kd}$ for Cs in the range of $3 \mathrm{ml} / \mathrm{g}$ compares best with the observed plume of Cs below the SX tanks. Without performing additional calculations we can't show quantitatively how much less the Cs would be predicted to travel with a Kd value of 20 to 25 but the reduction in travel should be substantial. If the gross-gamma and gamma energy logging studies performed to date [DOE 1996] are accurately measuring the Cs plume below the tanks it would appear that the in-situ $\mathrm{Kd}$ is considerably less than the values reported in Table 5.3.

\subsubsection{Flow Through Column Tests}

The first column test consisted of a Teflon column filled with the MSG-1 sediment to a bulk density of $1.34 \mathrm{~g} / \mathrm{cm}^{3}[31.5 \mathrm{~g}$ of sediment in a column with $2.5 \mathrm{~cm}$ diameter and $4.8 \mathrm{~cm}$ length]. Using the measured particle density of $2.72 \mathrm{~g} / \mathrm{cm}^{3}$, the calculated porosity is 0.51 and one pore volume would be $12 \mathrm{ml}$. The flow rate of solution through the column was $0.3 \mathrm{ml} / \mathrm{hr}$ which would yield a residence time for the water of 40.0 hours. The sediment column was first run with distilled water to check for leaks. After one day the SX Tank simulated liquor was pumped into the column to displace the water. This flow-through column adsorption test failed after three days when the influent REDOX solution spiked with ${ }^{85} \mathrm{Sr}$ and ${ }^{137} \mathrm{Cs}$ formed enough additional white precipitate to plug the column influent line. The test was being performed with the column and influent reservoir held at $65^{\circ} \mathrm{C}$. At the time of failure we had collected three aliquots of effluent and the $\mathrm{pH}$ had just risen to a value of 12.5 from a value of 7.5 as the distilled water was flushed out. The last effluent contained about $0.1 \%$ of the influent's ${ }^{137} \mathrm{Cs}$ activity. The exact volume infused cannot be determined as some sample was lost at the influent-end of the column as salt creep, but it was not more than $9.3 \mathrm{ml}$, representing 0.77 pore volumes. Thus we had not completely flushed the one pore volume of deionized water that was present initially.

The second column test consisted of the same physical set-up as the first test with one exception; this column was run at room temperature, approximately $20^{\circ} \mathrm{C}$, rather than $65^{\circ} \mathrm{C}$. There was no column plugging at this lower temperature, however, precipitates did form in 
smaller quantities in both the influent and effluent tubing. This column was initially wetted with SX-108 simulant rather than deionized water. Therefore, no dilution of the initial effluent sample occurred. We exhausted the available simulated REDOX tank liquor after collecting 6.68 pore volumes. Some breakthrough of ${ }^{137} \mathrm{Cs}$ was seen (up to $6.08 \%$ ) but the breakthrough was inconsistent among the samples analyzed (see Figure 5.1). The slight leakage of ${ }^{137} \mathrm{Cs}$ through the column may represent colloidal migration as opposed to solution transport. No ${ }^{85} \mathrm{Sr}$ was measurable in the effluents but ${ }^{85} \mathrm{Sr}$ was also not stable in the yellow liquid influent being pumped into the column. The ${ }^{85} \mathrm{Sr}$ tends to associate with the white precipitate that formed originally in the simulated liquor and it was filtered out of the solution prior to starting the column tests.

Analysis of thin segments of the sediment from the second column test (once finished) revealed decreasing ${ }^{137} \mathrm{Cs}$ activity with increasing distance from the influent end. This is illustrated in Figure 5.2. The recovery of ${ }^{137} \mathrm{Cs}$ in the liquid (effluent) and solid phases totalled $98.4 \%$. Table 5.5 presents the total ${ }^{137} \mathrm{Cs}$ activity present in the sediment as a function of distance from the influent end of the column. Based on a simple analysis that the distance travelled by the center of mass of adsorbed Cs to the total distance that water travelled is the reciprocal of the retardation factor, one can calculate a $\mathrm{Kd}$ value from the sediment profile. Data shown in Table 5.5 and Figure 5.2 suggest that the center of mass of the adsorbed ${ }^{137} \mathrm{Cs}$ is just passed the end of the first slice. If we assume that the adsorbed ${ }^{137} \mathrm{Cs}$ varies linearly within each slice the position of the $50 \%$ adsorbed mass is about $0.33 \mathrm{~cm}$ from the influent end. A total of 80 $\mathrm{ml}$ of effluent was collected during the test. This value represents 6.67 pore volumes and the length traversed by each pore volume is the column length $(4.8 \mathrm{~cm})$. Thus the water traversed [4.8 cm x 6.67] $32 \mathrm{~cm}$. The ratio of the center of mass of adsorbed $C s$ to water travel distance is the reciprocal of the retardation factor. Thus $1 /(0.33 / 32)$ is equal to 97 . The retardation factor is related to the $\mathrm{Kd}$ for an initially dry column by the relationship

$$
\mathbf{R}=\{\rho / \theta\} \mathbf{K d}
$$

where $\rho$ is the bulk density of the sediment in the column and $\theta$ is the moisture content or porosity under saturated conditions. The value of $\rho$ is $1.34 \mathrm{~g} / \mathrm{cm}^{3}$ and the value of $\theta$ is 0.51 . Substituting these values into the equation and solving for $\mathrm{Kd}$ yields a value of [97*0.51/1.34] $37 \mathrm{ml} / \mathrm{g}$ for the $\mathrm{Kd}$ of ${ }^{137} \mathrm{Cs}$. This column derived $\mathrm{Kd}$ is slightly larger than the batch $\mathrm{Kd}$ value just discussed. Both values are larger than expected based on the literature review and both values would not allow Cs migration through the sediment to the bottom of dry wells used to monitor tank leaks.

The $\mathrm{pH}$ of the effluent solution that passed through the second soil column rose rapidly to a value greater than 14 (see Figure 5.3). The first sampling at 0.11 pore volumes had a $\mathrm{pH}$ of 7.8 and the following 0.37 pore volume showed a $\mathrm{pH}$ value of 12.1 . The next sampling occurred after 1.12 pore volumes; the corresponding $\mathrm{pH}$ was above 14 as indicated by an error message given by the $\mathrm{pH}$ meter. Each sample after this point also indicated a pH above 14 . 
Table 5.5 Data From the Dissected Column

\begin{tabular}{|l|l|l|l|l|l|l|}
\hline Sample \# & $\begin{array}{l}\text { Dry } \\
\text { Wt. (g) })\end{array}$ & $\begin{array}{l}\text { Cs-137 } \\
\text { Activity } \\
(\mu \mathrm{Ci} / \mathrm{g})\end{array}$ & $\begin{array}{l}\text { Total } \\
\text { Activity } \\
(\mu \mathrm{Ci})\end{array}$ & $\begin{array}{l}\text { Cum. } \\
\text { Activity(\%) }\end{array}$ & $\begin{array}{l}\text { Cum. } \\
\text { Distance } \\
(\mathrm{cm})\end{array}$ & $\begin{array}{l}\text { Cum. } \\
\text { Center of } \\
\text { Slice }(\mathrm{cm})\end{array}$ \\
\hline 1 & 2.15 & 0.13700 & 0.29440 & 46.80 & 0.29 & 0.15 \\
\hline 2 & 3.54 & 0.06820 & 0.24163 & 85.20 & 0.77 & 0.53 \\
\hline 3 & 4.91 & 0.00192 & 0.00942 & 86.70 & 1.43 & 1.10 \\
\hline 4 & 4.76 & 0.01070 & 0.05097 & 94.80 & 2.08 & 1.75 \\
\hline 5 & 3.69 & 0.00237 & 0.00875 & 96.19 & 2.58 & 2.33 \\
\hline 6 & 5.01 & 0.00161 & 0.00807 & 97.48 & 3.25 & 2.91 \\
\hline 7 & 5.32 & 0.00104 & 0.00554 & 98.36 & 3.97 & 3.61 \\
\hline 8 & 2.58 & 0.00251 & 0.00647 & 99.39 & 4.32 & 4.15 \\
\hline 9 & 3.55 & 0.00109 & 0.00387 & 100.00 & 4.80 & 4.56 \\
\hline Total & 35.52 & & 0.62911 & & 4.80 & \\
\hline
\end{tabular}

The rapid jump in $\mathrm{pH}$ to values above 14 seems to occur sooner in the column than one might expect based on the drop in pH to values between 12 and 12.6 reported for the batch adsorption tests discussed in Section 5.3.1 and the dissolution tests to be described in Section 5.4. We can only speculate that the reactions that lower $\mathrm{pH}$ (between the caustic solution and sediment) are promoted by the shaking and stirring that occurred in the batch tests. The amount of time allowed for reaction in the dissolution tests is quite similar to the residence time of fluid in the flow through column test, but both of these tests had less time for reaction than the batch adsorption tests. The evolving $\mathrm{pH}$ appears to have slow kinetics that require more than days and perhaps a few weeks or longer to reach a steady-state. The reactions that lower the pH likely cause the observed precipitation of bayerite, the Al hydroxide and other constituents such as $\mathrm{Si}$ and $\mathrm{Na}$ also appear to be changing. Detailed tests where the complete chemical composition of the solution and solids as well as solid mineralogy would be necessary to interpret the observed changes.

\subsection{Sediment Dissolution Tests}

Tank wastes that contain high concentrations of free hydroxide can react and partially dissolve silica and alumino-silicate minerals and coatings naturally present in the sediments. The 


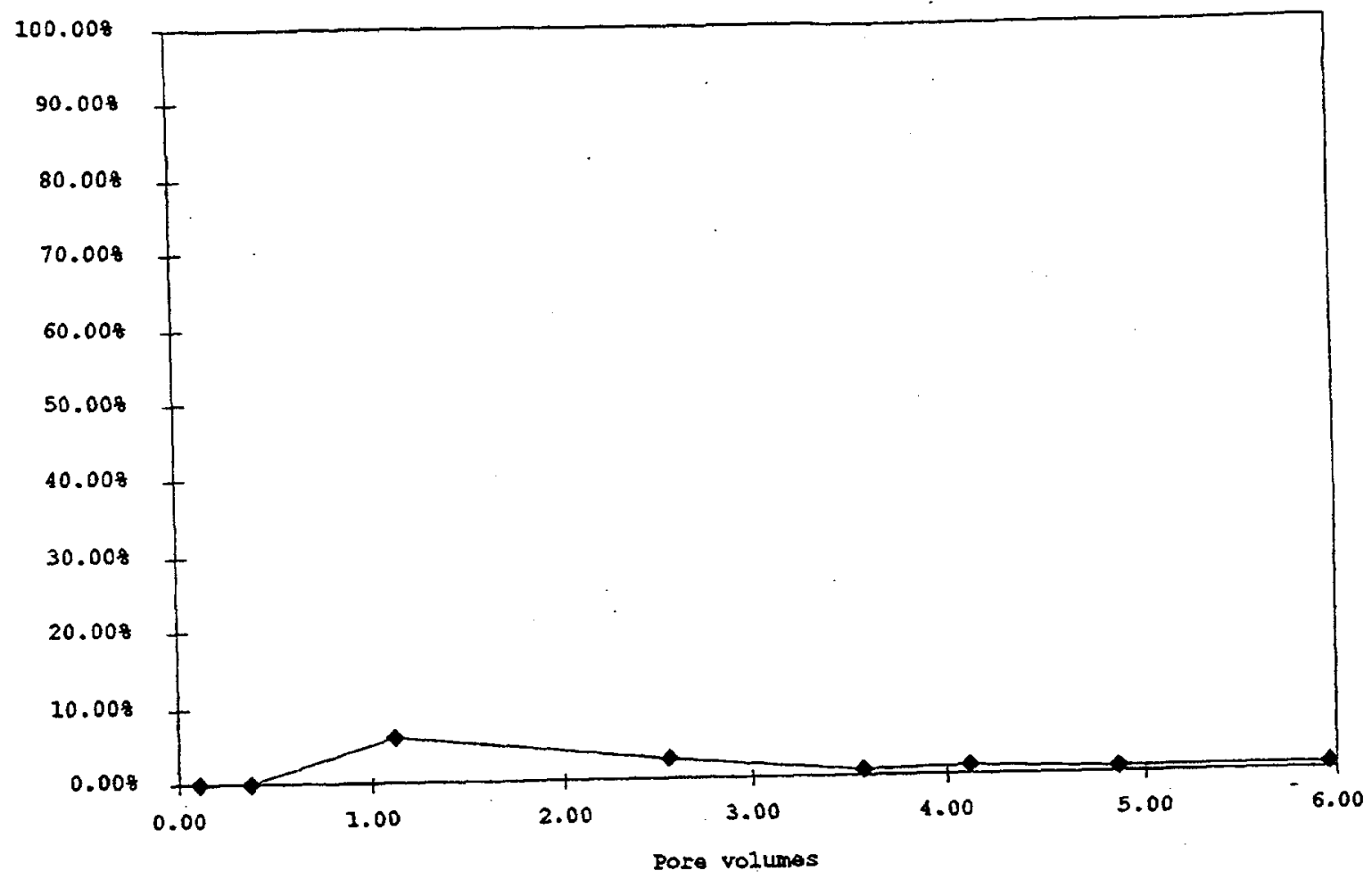

Fig. 5.1 ${ }^{137}$ Cs Breakthrough for SX Tank Simulant in Hanford Sediment

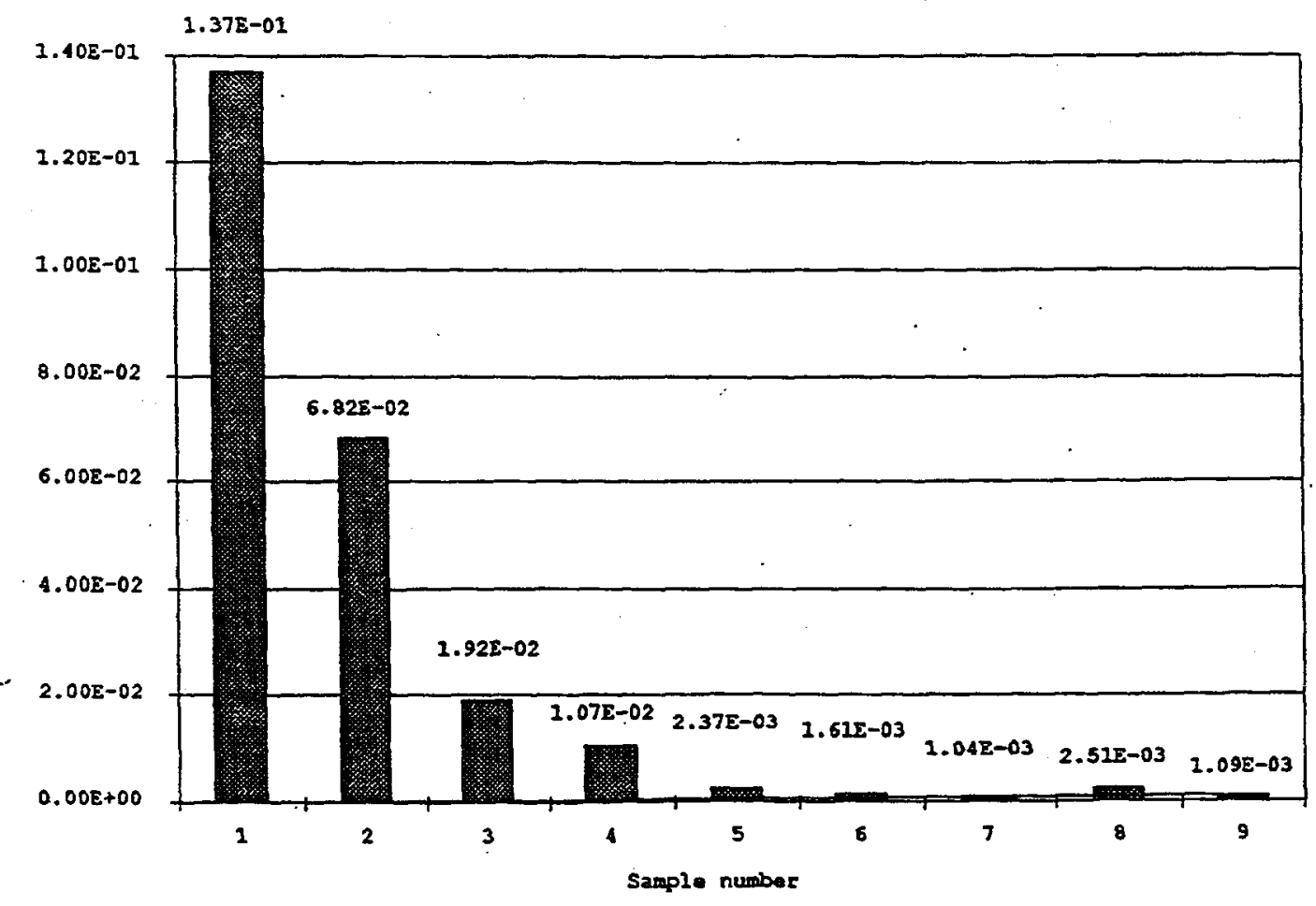

Fig. 5.2 ${ }^{137} \mathrm{Cs}$ Adsorbed in Sediment Column as a Function of Depth 


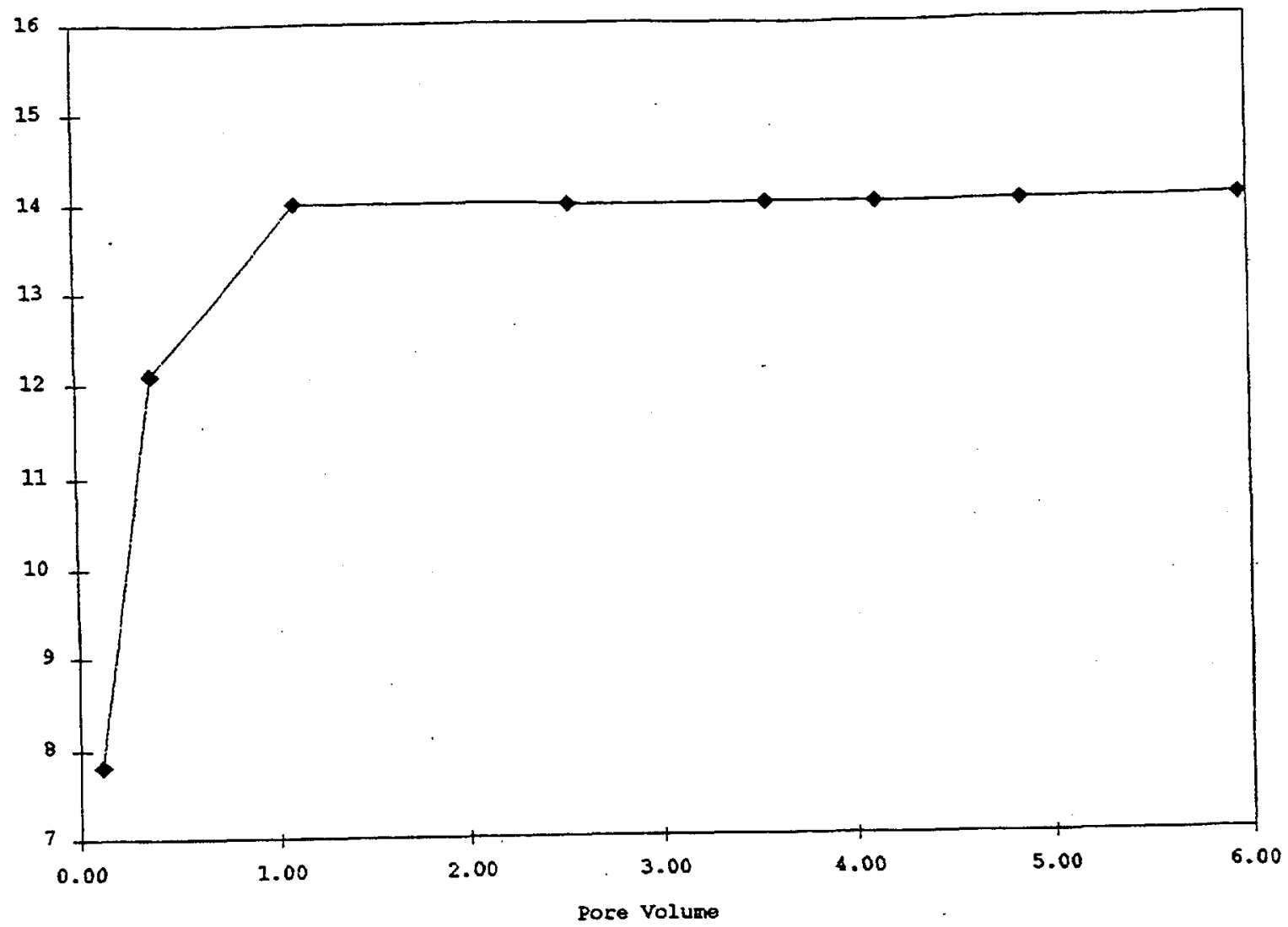

Fig. 5.3 pH in Effluent from Sediment Column vs. Pore Volume

solubility of amorphous silica and aluminum compounds are quite high at $\mathrm{pH}$ values above 12 . In contrast alumino-silicate phases such as feldspars, and clays which make up a fair proportion of the sediment are much more resistant to dissolution under caustic (high $\mathrm{pH}$ ) conditions. Should the waste liquors have free hydroxide concentrations above $10^{-2} \mathrm{M}$ then sediment matrix dissolution for silicates and pure aluminum phases may become significant.

Both silica $\left(\mathrm{SiO}_{2}\right)$ and $\mathrm{Al}$ compounds also show increased solubility as temperature is increased. Seeing as the tank liquors, especially from self-boiling REDOX tanks, are elevated the matrix dissolution process may be enhanced directly around the tanks. The dissolution of the sediment matrix consumes the free hydroxide so that the $\mathrm{pH}$ effect will likely be localized. The unique characteristics of the REDOX waste does warrant some attention, seeing as it may contain the highest concentration of free hydroxide and is among the hottest (temperature) of the wastes placed in Hanford SST tanks.

It should be mentioned that none of the flow-through column laboratory work performed on actual or simulated bismuth phosphate waste discussed any unusual loss of sediment mass through dissolution or sediment plugging because of dissolution and re-precipitation of amorphous gel-like material farther down the column as the pH drops. Because no work has 
been performed on REDOX waste streams or at elevated temperatures expected in the sediments in the vicinity of the buried tanks, past observations do not adequately address the matrix dissolution issue. We recommend that some laboratory testing be performed to better evaluate this issue. Should matrix dissolution in the very near field around the tanks be important, especially for REDOX waste bearing tanks such as SX Tanks, the migration of Cs (and other contaminants thought to interact with sediments) might be expected to increase. At some point away from the tanks, the tank leak liquor would be expected to be "neutralized" by the sediment's large buffering capacity to consume free hydroxide during the dissolution process and one should see a re-precipitation of the silica and aluminum to form amorphous coatings/gel that could lower permeability as well as coprecipitate (physically trap) or adsorb other soluble components such as Cs.

There does not appear to be any indication that matrix dissolution products (high $\mathrm{Si}, \mathrm{Al}$ and $\mathrm{pH}$ ) have reached the groundwater below SX tanks and further one might expect that massive dissolution would manifest itself in the near vicinity of the tanks as more porous material with perhaps copious gel-like coatings. It is possible that the high ${ }^{137} \mathrm{Cs}$ found in several SX Tank Farm boreholes at the 75 foot level is an indication of how far the matrix dissolution impact has reached. This would imply a zone of reaction of about 20-25 feet below the tank bottoms. Following is a description of some scouting tests that we recently performed to address the dissolution issue.

Some simple weight-loss experiments were performed at three temperatures to see if the REDOX solution would dissolve measurable quantities of sediment. One gram of the MSG-1 sediment was placed in a centrifuge tube and $10 \mathrm{ml}$ of the supernate solution with the chemical composition shown in Table 5.2 was added. Duplicate tests (labeled A and B in Table 5.6) were performed at 32,50 and $83^{\circ} \mathrm{C}$. The test containers were placed in ovens at the appropriate temperatures for $\sim 40$ hours. After contact the sediment was rinsed onto filter paper, washed generously with deionized water at the temperature of the test and then the filters with captured solids were oven dried overnight. The final weight of dried solids was compared with the starting weight. The results as a percent weight loss $(-)$ or gain $(+)$ are shown in Table 5.6. The initial solution $\mathrm{pH}$ was $>14$ but after contact all solutions had $\mathrm{pH}$ values of $12.0 \pm 0.05$. The captured solids on the filter papers also showed the presence of white precipitate that was apparently a reaction product. As shown in Table 5.6 there was no consistent weight loss that would suggest that the highly alkaline solution was dissolving significant amounts of the sediment. Conversely it appears that the reaction may actually increase the sediment's weight by precipitation of the whitish material that is undoubtedly Al containing phases. The weight gain is especially evident at the higher temperature. It appears that $\mathrm{Al}$ compounds precipitate as the temperature is raised. This is consistent with the first flow-through column test where enough of the white precipitate formed within the influent reservoir to cause plugging of the pump and column before reaction with the sediment occurred. This increased precipitation at higher temperature is the opposite trend expected based on the known solubilities of Si and $\mathrm{Al}$ compounds, which increase as temperature increases. Our observed increased precipitation at the higher temperature may be caused by 
kinetics and the simulated tank liquor interactions with the sediment not being near equilibrium in our short laboratory tests.

Additional weight measurements of reacted sediment from the second flow through column test are available. The total weight of solids following solution contact was greater than the initial sediment weight prior to solution contact. This is consistent with the results of the simple dissolution tests described herein. While there was no visible increase in packed sediment volume in the column and no visually apparent change in nature of the solid material in the column upon being dissected, the weight increase ( $35.5 \mathrm{~g}$ at end and $31.5 \mathrm{~g}$ at the start) was measurable. Some of the weight gain likely is evaporated salt from the solution left in the column at the end of the flow through test.

The lack of significant sediment dissolution is consistent with an unpublished manuscript entitled "Hanford Defense Waste Stabilization: Single Shell (TY) Tank Waste/Basalt DomeFill Chemical Interaction Studies" authored by R. D. Scheele, F. N. Hodges and S. G. McKinley in October 1986. In this study the interaction of basalt with simulated single-shell waste slurry (solids and liquid) was studied in both short-term and long-term tests. The short term tests were carried out over a few days at temperatures up to $250^{\circ} \mathrm{C}$ while the long-term tests were carried out at temperatures up to $100^{\circ} \mathrm{C}$ for times up to 280 days. Using thermoanalytical tools such as TG (thermogravimetric weight loss) and DSC (differential scanning calorimetric analyses of changes in enthalpy), the short term studies showed no signs of significant interaction. The long-term tests did show some dissolution of the glassy portion of the basalt rock. The plagioclase and pyroxenes were affected to lesser degrees. At most the $100^{\circ} \mathrm{C}$ long term test data allowed the authors to conclude that $5 \%$ of the basalt would dissolve in one year but some of the loss represents spalling of fine grains loosened by

Table 5.6 Net Weight Change in Sediment/Rxn Product Solids After Contacting REDOX Solution

\begin{tabular}{|c|c|}
\hline Temperature $\left({ }^{\circ} \mathrm{C}\right)$ & Weight Change (\%) \\
\hline $32\left({ }^{\circ} \mathrm{C}\right)-\mathrm{A}$ & -3.4 \\
\hline $32\left({ }^{\circ} \mathrm{C}\right)-\mathrm{B}$ & 0.6 \\
\hline $50\left({ }^{\circ} \mathrm{C}\right)-\mathrm{A}$ & -9.8 \\
\hline $50\left({ }^{\circ} \mathrm{C}\right)-\mathrm{B}$ & 3.7 \\
\hline $83\left({ }^{\circ} \mathrm{C}\right)-\mathrm{A}$ & 6.5 \\
\hline $83\left({ }^{\circ} \mathrm{C}\right)-\mathrm{B}$ & 6.7 \\
\hline
\end{tabular}


dissolution of the glass matrix that "glues" minerals together. The net loss of material is significantly less at lower temperatures. Bismuth phosphate waste was slightly more aggressive (dissolved more basalt glassy phase) than REDOX waste in their studies. The authors clearly point out using SEM techniques that a simple weight loss or gain is not indicative of all the chemical reactions that are occurring when highly alkaline SST wastes contact rocks (and by inference sediments). The weight loss or gain is the net result of dissolution and reprecipitation reactions that occur.

\subsection{Comments}

These preliminary tests have not been successful at bounding the probable fate of $\mathrm{Sr}$ and $\mathrm{Cs}$ radionuclides in REDOX waste tanks in the SX Tank Farm. It appears that the historical data on supernate compositions may not be accurate, despite the good cation-anion balance reported. The very high $\mathrm{Al}, \mathrm{Na}$, and nitrate contents measured in the past were not sustained in our simulated tank liquor as shown by the analyses in Table 5.2. The Al especially seems to remain reactive with time and elevated temperatures resulting in the precipitation of very fine grained (high surface area) material that has been identified as bayerite, an Al hydroxide. The measurement of the adsorption properties of $\mathrm{Sr}$ and $\mathrm{Cs}$ from the evolving REDOX solution is difficult. Sr is not soluble in the REDOX solution as long as Al precipitation is occurring. The literature review and past analytical measurements of tank waste phases also supports this conclusion. Cs is essentially soluble but upon contact with sediment and further precipitation of $\mathrm{Al}$ bearing material there appears to be a higher than expected sorption (Kd). The flow-through column Cs adsorption data corroborates the batch Kd tests. It is clear that more resources and testing would be needed to better interpret the fate of cesium, strontium and other contaminants present in tank liquors. More detailed and complete solution and solid (both sediment and reaction products) characterization using techniques such as inductively coupled plasma-mass spectrometry [ICP-MS], scanning electron microscopy [SEM-EDS], $x-$ ray diffraction [XRD], high resolution transmission electron microscopy [HRTEM] and atomic force microscopy [AFM] would be needed to help interpret the complicated reactions. The observed $\mathrm{Kd}$ for ${ }^{137} \mathrm{Cs}$ is in the range of 20 to $60 \mathrm{ml} / \mathrm{g}$ dependent on whether the solution is filtered or only gravity settled. This range in $\mathrm{Cs} \mathrm{Kd}$ values is much larger than expected and appears to disagree with the values necessary to get the results of transport predictions to mimic field measurements of Cs in vadose zone sediments underlying the SX Tank Farm (see Ward et al. 1997). The very high caustic REDOX solution does not appear to promote significant dissolution of the sediment in preliminary laboratory tests, but the possibility of significant dissolution with simultaneous reprecipitation of other phases is still possible. That is, there does not appear to be large losses of mass in the sediment matrix but perhaps the mineral composition changes dramatically. It seems certain that the high Al content in the REDOX solution does react with soil to precipitate Al hydroxide phase(s) and perhaps Al oxide phases which perhaps lead to net mass accumulation as opposed to net mass loss in the sediment matrix.

More experimental research is needed to identify how the sorption chemistry of Cs on Hanford 
sediments may change after contact with solutions characteristic of REDOX tank wastes. Our central hypothesis is that the high ionic-strength conditions of the REDOX wastes (i.e., > 5 mol/L $\mathrm{NaNO}_{3}$ ) will suppress all surface-exchange reactions of $\mathrm{Cs}$, except those to the highly selective frayed edge sites (FES) of the micaceous fraction. We further speculate that the concentrations, ion selectivity, and structural aspects of the FES will change after contact with the harsh chemical conditions of tank liquors and these changes will be manifest in the macroscopic sorption behavior of Cs. We believe that migration predictions of Cs can be improved substantially if such changes are understood and quantified. The research should focus on the aqueous chemical system Cs- $\mathrm{Na}-\mathrm{K}-\mathrm{NH}_{4}-\mathrm{Al}-\mathrm{OH}-\mathrm{NO}_{3}$ at concentration ranges relevant to our best estimate of those present in REDOX tank waste discharges (see Section 3). These solutes represent major electrolytes $\left(\mathrm{NaNO}_{3}\right)$, constituents with high potential subsurface reactivity $(\mathrm{Al}, \mathrm{OH})$, and Cs-sorption competitors $\left(\mathrm{K}^{+}, \mathrm{NH}_{4}{ }^{+}\right)$in the waste supernatant.

The research of Francis and Brinkley (1976), Elprince et al. (1977) and others leads us to surmise that the micaceous fraction (e.g., biotite, illite and vermiculite) and their associated FES will be the primary determinant of Cs sorption in the Hanford subsurface sediments. This speculation, and the nature of the Cs sorbing phase in the Hanford sediments needs to be verified.

Studies should focus on the FES, a challenging yet necessary decision as these sites are a subset of the sorbing-site population and are present in relatively low concentration (e.g., $<0.5 \mathrm{mmol} / \mathrm{g}$ ). We have identified in Section 2 techniques to isolate the reactivity of these sites at the macroscopic scale, and to visualize them at the microscopic and molecular scale (0.1 - $2.0 \mathrm{~nm}$ ). Two scientific studies (Le Roux et al. 1970 and De Preter et al. 1991) provide noteworthy precedence and guiding concepts for future research.

Future research should integrate studies of ion-exchange thermodynamics for the FES (other sites blocked with appropriate ions or sorbates), with high resolution surface microscopies and spectroscopy to probe the structure of FES in Hanford sediments and to describe how the chemical environment of sorbed Cs changes when tank liquors promote silica dissolution and aluminum precipitation. Newly available atomic-force microscopies and improved highresolution electron-beam microscopies afford previously unavailable opportunities to visualize and characterize FES. Specifically, such research would:

- Identify how the macroscopic sorption behavior of Cs on the micaceous fraction of the Hanford and Ringold sediments changes after contact with simulants of REDOX tank supernatants over a range of relevant chemical ([OH], [Na], [Al], $\left.\left[\mathrm{K}, \mathrm{NH}_{4}\right]\right)$ and temperature conditions $\left(23^{\circ}-80^{\circ} \mathrm{C}\right)$.

- Reconcile observed changes in sorption chemistry with microscopic and molecular changes in adsorption-site distribution (with emphasis on FES), chemistry, mineralogy, and morphology/structure of the micaceous sorbent fraction. 
- Integrate mass-action-solution-exchange measurements with changes in the structure/site distribution of the micaceous-sorbent fraction to yield a multicomponent/site-exchange model relevant to high ionic strength and hydroxyl concentrations for prediction of environmental Cs sorption. 


\subsection{FIELD OBSERVATIONS OF CS MIGRATION UNDERNEATH HANFORD DISPOSAL FACILITIES}

\subsection{Studies of Past Tank Leaks-Cs Data}

\subsubsection{SX-108 and SX-115}

In 1966 Raymond and Shdo (1966) reported on a field study to determine the extent of leaking that occurred under two SX tanks. For SX-108 gross gamma logs of the laterals placed about ten feet below the tank were used to guide the drilling of five additional wells around the northwest quadrant of the tank to a depth of 65 to 75 feet dependent upon the well. The wells were drilled by drive barrel (either 2-1/4- or 5- inch OD pipe) that allowed sediment to be obtained as a function of depth. The new wells were placed anywhere from 2 to 12 feet from the edge of the tank as estimated by figures in the report. Their report also notes seven existing wells that may be the dry wells recently logged by Rust Geotechnical, although no Hanford well designations appear in the text or figures to verify this possibility. Based on gamma measurements of sediment retrieved from the boreholes at one-foot intervals (at least between 55 and 75 feet), the authors conclude that SX-108 tank had two thin zones of contamination in the northwest quadrant of the tank. The first zone was about 55 feet below ground surface and was about two feet thick and the second zone occurred at the 60-foot level and was one foot thick. The shallower zone was only slightly larger in area than the deeper zone. The waste appeared to leak and migrate in a southerly direction from the tank wall. ${ }^{137} \mathrm{Cs}$ activities in the sediment ranged from $2 \mathrm{pCi} / \mathrm{g}$ up to $10^{+8} \mathrm{pCi} / \mathrm{g}$ dependent upon location and distance from the tank wall and depth. The highest concentrations observed $\left(\sim 10^{+8} \mathrm{pCi} / \mathrm{g}\right)$ would represent filling the available pores in sediment to one-third moisture saturation if there was no Cs adsorption onto sediments prior to the leaked liquid reaching the location of the sediment in the new boreholes. Thus the sediment either wets to one-third saturation ( $10 \%$ by volume) or alternatively the sediment was saturated with tank liquid but up to two-thirds of its activity had been removed by sediments closer to the tank through adsorption reactions. Based on the contour maps developed for the two depths and knowledge of the Cs activity in the leaking solution, the authors estimate that 2400 gallons of liquid leaked from SX-108. This assumes that most of the Cs was not adsorbed directly under the tank or very near the tank wall where samples could not be obtained. Cesium was the only long-lived radioisotope detected but there is brief mention that ${ }^{106} \mathrm{Ru}$ was also present that spread slightly farther than the Cs at the same depths and locations. Based on the relatively low count rates in the uncalibrated laterals data, the authors suggest that the tank leak has not substantially penetrated the full 10 to 12 feet between the tank bottom and the laterals. The authors suggest that the leak was first detected in August 1964 although the tank had been filled previously in 1955 and again in 1963. The document does not state the dates that the new boreholes were emplaced but the date must have been between August 1964 and June 1966. The tank supernate was sampled Dec. 15, 1965 and the results are shown in Table 3.4. If the tank bottom is about 51.5 feet below ground surface (the nominal depth for any SX tank as cited in DOE (1996), then the leaked liquid had 
migrated between 3.5 and 8.5 feet in the vertical direction in a time period of perhaps less than a year to about two years.

For SX-115 ten new wells were drilled in all quadrants around the tank to total depths from 68 to 75 feet at distances from 2 to 12 feet from the tank wall using the same techniques as discussed for SX-108. Gross gamma data from the laterals below SX-115 suggested a larger aerial extent for the leak or several leaks such that the new wells were spaced to cover the whole tank circumference. The figures in the report also show eight pre-existing wells, seven perhaps being dry wells recently logged by Rust Geotechnical [DOE 1996] and one designated W23-70 implying a groundwater monitoring well about seven feet beyond the southwest quadrant tank wall. The leak at SX-115 was found to be more complicated than the one below SX-108 and the authors suggest three separate zones in the tank bottom may have acted as small sources. The leak from SX-115 occurred between February 24 and March 3, 1965 based on liquid level drops and activity measurements in the laterals under the tank. Only four of the new wells produced contaminated sediment that could be used to estimate the extent of the leak(s). Only two of the new wells contained sediment with ${ }^{137} \mathrm{Cs}$ activities above $10^{+7}$ $\mathrm{pCi} / \mathrm{g}$. The highest activity measured was again $\sim 10^{+8} \mathrm{pCi} / \mathrm{g}$ in six sediment samples (representing a 4-foot thick zone) from one well close to the tank wall. From these data and three other wells with much lower activities in the southwest quadrant of the tank, the first zone of contamination was delineated. Zone One was estimated to be a four-foot thick layer between 58 and 62 feet below the surface at about the "8- o'clock position" near the tank wall. A second zone of contamination was estimated to be a 2-foot region (between 60 and 62 feet below ground surface) at the "3-o'clock position" under the tank bottom. The third zone of contamination was at about the "12- o'clock position" under the tank bottom that had no extension outside the tank walls excepting a very low concentration in a new well placed within a few feet of the tank wall at the "12-o'clock position". Based on simple assumptions, the authors estimated that the total leak volume for the three zones was 31,000 gallons. Independent estimates based on changes in tank liquid levels suggested 50,000 gallons leaked. The simple assumptions that Raymond and Shdo used should underestimate the leak volume if significant amounts of ${ }^{137} \mathrm{Cs}$ binds to the sediment in the very near vicinity of the tank walls and sediment directly below the tank bottom.

Because the supernate solution in SX-115 contained about an order of magnitude less ${ }^{137} \mathrm{Cs}$ activity than the supernate in SX-108 one might expect that the highest levels detected in sediment around SX-115 should be lower than sediment around SX-108. The highest activity in sediments very near the tank walls for both tanks were similar and the authors suggest that the most contaminated sediment obtained in the southwest quadrant of SX-115 would need to adsorb all the Cs out of 3.4 pore volumes of supernate liquid to reach the observed $10^{+8} \mathrm{pCi} / \mathrm{g}$ in the sediment. Thus for this tank with lower concentrations of $\mathrm{Cs}$ in the leaking liquid adsorption must be invoked to obtain activities as large as observed. In other words, if the Cs present in the sample was simply material that dried in the pores upon sample drying (to perform the analysis) then the activities observed could not reach the levels measured. The porosity of the sediment could not hold enough liquid to reach such observed levels. The 
authors state several times in their report that the Cs appears to exist in a narrow band directly below the tanks and out in a narrow region projected vertically from the tank walls at depths below the tank bottoms. The authors suggest that the $\mathrm{Cs}$ in the sediment poses little or no risk of contaminating the groundwater.

\subsubsection{BX-102}

Womack and Larkin (1971) describe a field study around Tank BX-102 to determine the extent of leakage after the tank was suspected of being a leaker. Tank BX-102 was constructed in 1946 and filled for the first time in June 1948 with bismuth phosphate metal waste and later U recovery waste. Since 1954 through 1970 the tank was utilized intermittently for storage of non-boiling waste. The level of liquid waste in the tank was held static from 1957 through mid 1962 at the minimum level of 22 inches (pump heel that can't be removed). From mid 1962 through 1968 the tank was filled to maximum capacity. The 1971 investigation suggested that the carbon steel liner failed at the 22 inch level during the 1957-1962 time period. In January 1972 about 95 tons of diatomaceous earth was added to absorb any remaining liquid. Brevick et al. (1994) estimate that the leak was 70,000 gallons.

Because there was spillage (from pipes/flanges or connectors) between Tanks BX-102 and BX103 in 1951 of 30,000 to 90,000 gallons of first cycle [Bi-phosphate] process waste, dry wells around tank BX-102 always showed high readings and since there was no observable drop in the liquid level within the tank, it was not suspected to be a leaker between 1959-1969. Between 1963 and 1968 the dry well reading remained off-scale at $>1$ million cpm. Starting in 1969 the scintillation readings decreased rapidly until October, when they again rose above the probe's saturation value. This corresponded with the time that the tank was returned to active operations. In May 1970 the tank was pumped out to the minimum heel (22 in.). and taken out of service.

In 1970, 19 new dry wells were drilled to determine the extent of the leak. Scintillation probe values dropped to less than $1 / 3$ of the values observed in October 1969. A neutron probe was used in May 1970 in each dry well to determine the relative moisture content in all the wells as a function of depth. The high moisture contents corresponded with the high scintillation readings. One dry well (\#27) was drilled all the way to the water table in July 1970 and soil samples were collected at one-foot intervals and analyzed for ${ }^{137} \mathrm{Cs}$. The field geology logs showed that the sediment 40 to 70 feet deep (from tank bottom to 70 feet) was sand. The sediment from 70 to 120 feet was coarse sand and silt; while sediment from 120 to 150 feet was sand. The sediment from 150 to 175 feet was again coarse sand and silt. The sediment from 175 to the water table (at 210 feet) was sand and gravel. The highest ${ }^{137} \mathrm{Cs}$ activities were right at the tank bottom(at 40 feet) with the sediment having 60 to $100 \mu \mathrm{Ci} / \mathrm{g}$ as measured in borehole E-33-27.

Two very narrow peak activities were also observed at 58 and 65 foot depths each measuring $50 \mu \mathrm{Ci} / \mathrm{g}$. These peaks were attributed to either contamination from above or thin lenses of 
finer material (stringers) with higher exchange capacity within the Hanford Fine formation. There was smaller amounts of activity, 0.04 to $0.3 \mu \mathrm{Ci} / \mathrm{g}$, perhaps at the interface of the PlioPleistocene- Upper Ringold contact where silty-sand overlies clayey sand and sandy silt around 120 feet deep. This assumes that the geology under the BX Tank Farm is very similar to that under the TX tank farm for which detailed geologic data are known (see Freeman-Pollard et al. 1994.) Beyond 120 feet there was no ${ }^{137} \mathrm{Cs}$ detected above a small value of $0.02 \mu \mathrm{Ci} / \mathrm{g}$.

${ }^{137} \mathrm{Cs}$ was also detected in the groundwater (well 299E-33-27) below and near Tank BX-102 in Jan 1971 at concentrations of $9,200 \mathrm{pCi} / 1$ but 8 other wells in the vicinity of BX tank farm showed less than $100 \mathrm{pCi} / 1$ ( detection limit in those days). The Atomic Energy Commission control limit in 1971 was $20,000 \mathrm{pCi} / 1$ so no issue was made about the well 299E-33-27 measurement. Further, the source of the ${ }^{137} \mathrm{Cs}$ in the groundwater was believed to be from Bcribs or other disposal sites in the area. Breakthrough of ${ }^{137} \mathrm{Cs}$ from the B-cribs was observed in 1957-1959 and at that time the cribs were taken out of service. The Jan. 1971 finding of ${ }^{137} \mathrm{Cs}$ in well $299 \mathrm{E}-33-27$ was then attributed to contamination while drilling through the contaminated sediments up above at the depth of the tank bottom rather than from the B-cribs.

The chemical content of the tank heel liquid in the first quarter of 1970 is shown in Table 6.1.

Based on the scintillation and neutron probe results in the 19 new and one old dry well, a

Table 6.1. Chemical Composition of Liquid Waste in Tank BX-102

\begin{tabular}{|c|c|}
\hline Constituent & Value \\
\hline $\mathrm{Na}$ & $3.07 \mathrm{M}$ \\
\hline $\mathrm{OH}$ & $1.16 \mathrm{M}$ \\
\hline $\mathrm{pH}$ & 12.6 \\
\hline specific gravity & $1.03(\mathrm{~g} / \mathrm{ml})$ \\
\hline${ }^{137} \mathrm{Cs}$ (three measurements over time) & 0.12 to $0.73 \mathrm{Ci} / \mathrm{gal}$. \\
\hline Cs-134(two measurements over time) & 6.5 to $23 \mathrm{mCi} / \mathrm{gal}$. \\
\hline Sb-125 & $2.1 \mathrm{mCi} / \mathrm{gal}$. \\
\hline Co-60 & $0.3 \mathrm{mCi} / \mathrm{gal}$ \\
\hline RuRh-106 & $4.4 \mathrm{mCi} / \mathrm{gal}$. \\
\hline ZrNb-95 & $2.8 \mathrm{mCi} / \mathrm{gal}$. \\
\hline Sr-90 & $0.16 \mathrm{mCi} / \mathrm{gal}$. \\
\hline
\end{tabular}


contamination pattern was developed and it was estimated that $31,000 \mathrm{ft}^{3}$ of sediment was wetted by the tank leak. The leak generated plume was estimated to have reached 100 feet east of the tank at a depth of $75 \mathrm{ft}$ from ground surface ( 35 feet from the tank bottom). Based on a soil porosity of $30 \%$ by volume, the tank leaked 70,000 gallons and released 51,000 curies of ${ }^{137} \mathrm{Cs}$; yet liquid level measurements in the tank do not show evidence of a leak.

One interesting field observation showed a higher than expected ${ }^{137} \mathrm{Cs}$ activity (based on scintillation probe data from the 1970 logging) in one old dry well (\#61) constructed in 1947 at the 70-foot level. The authors suggest that a deposit on the well casing had entrapped radionuclides from the liquid and created a casing hot spot that is not supported by the activity in the surrounding soil. To test this hypothesis the well casing was raised ten feet and another scintillation profile taken, followed by lowering the casing to its original depth with yet another profile taken. The results of the three profiles showed that the hot spot moved along with the casing and thus the authors suspicion was confirmed.

\subsubsection{T-106}

On June 8, 1973 Tank T-106 was confirmed as a leaker (Atlantic Richfield 1973). Monitoring via surrounding dry wells showed the deepest penetration of liquid was 87 feet $(27 \mathrm{~m})$ below the surface which is still 116 feet $(35 \mathrm{~m})$ above the water table. The operating contractor estimated that $115,000\left(435 \mathrm{~m}^{3}\right)$ gallons of liquid containing 40,000 curies of ${ }^{137} \mathrm{Cs}$ and over 280,000 curies of other isotopes (mostly short-lived) had leaked out of the tank into the sediment. The estimates were based on drilling 16 new wells around the tank and using the $1 \mu \mathrm{Ci} / 1 \mathrm{Ru}-106$ isopleth to estimate the contaminated zone based on gamma logging the boreholes after completion and actual sediment analyses from material from the new boreholes. Four wells drilled southeast of the tank showed the highest gamma readings. Interestingly the well drilling also encountered a leak from a transfer line that brought waste to the tank. This leak (nearer to Tank T-103) was estimated to be $5 \mathrm{~m}^{3}$, which affected $1700 \mathrm{~m}^{3}$ of sediment compared to the T-106 leak which affected $25,000 \mathrm{~m}^{3}$ of sediment. The furthest vertical depth that this transfer line leak reached was $25 \mathrm{~m}$ below ground surface quite similar to the tank leak itself. Two additional reports updated the status of the leak as of May 1978, Routson et al. $(1979,1980)$. These reports note that an additional $17 \mathrm{dry}$ wells were drilled to further delineate the leaking plume's extent. Between 1973 and 1978 the $1 \mu \mathrm{Ci} / 1 \mathrm{Ru}-106$ isopleth had moved down from 87 feet $(27 \mathrm{~m})$ to 108 feet $(33 \mathrm{~m})$. This is still $29 \mathrm{~m}$ above the water table. In May 1978 the furthest horizontal movement of the $1 \mu \mathrm{Ci} / 1 \mathrm{Ru}-106$ isopleth was 75 feet $(23 \mathrm{~m})$ at a depth of 82 feet $(25 \mathrm{~m})$ from the ground surface. This horizontal spreading is equivalent to one tank diameter.

Prior to discovering the leak there were 5 groundwater monitoring wells and seven dry wells in the vicinity of the T Tank Farm. The dry wells penetrated down to 46 meters. The 16 new wells allowed a detailed cross section of the underlying geologic strata to be developed based on driller logs and samples taken every $1.5 \mathrm{~m}$. From the surface down to 12 meters (the tank 
excavation bottom) well mixed backfill is found. From 12 down to 25 meters the natural sediment is very coarse grained. Below this layer is a 3-m thick wind-blown silt. Below this zone ( 27 to 33 meters below ground) is a caliche cemented sediment. Below the caliche layer is older Ringold sediments with diverse particle size ranges. The ground water table is $62 \mathrm{~m}$ below ground surface. The 1973 gamma logs showed that ${ }^{137} \mathrm{Cs}$ moved only small distances ( $<10 \mathrm{~m}$ in lateral extent and vertical extent) from the SE corner of T-106's bottom.

According to Routson et al. $(1979,1980)$ even though the leak was thought to be the largest single accidental release in AEC/DOE's operational history up to 1973, the volume released $(115,000 \mathrm{gal})$ was still less than the "specific retention" volume often used to determine when to quit disposing liquid to a crib. The specific retention concept relies upon the fact that the Hanford sediments are relatively dry and can absorb liquid without allowing it to drain at significant rates until it reaches field capacity when drainage is quite noticeable. Past Hanford work suggests that one can wet the sediment to $10 \%$ by volume and not see appreciable drainage. Routson et al. $(1979,1980)$ reasoned that the "specific retention" volume under Tank T-106 from the tank bottom to the water table projecting the cross section straight down is 480,000 gallons, thus if the leak was isolated to the tank footprint it would represent only $24 \%$ of the allowable specific retention volume. In reality the leak was observed to spread beyond the footprint of the tank which would imply that the leaked liquid would penetrate even smaller depths below the tank. However, two facts do not appear to have been considered in any of the early specific retention calculations. First the actual tank leak appears to have been localized to one quadrant of the tank bottom and thus the whole footprint below the tank likely was not absorbing the liquid (see Freeman-Pollard et al. 1994 for more discussion). The second fact is specific retention calculations presented by Routson et al. $(1979,1980)$ do not consider the existence of optimal natural recharge and enhanced recharge around the edges of the tanks caused by the tank domes that can continue to add liquid to the sediment impacted by the leak and thus push the tank liquor deeper in the vadose zone profile. Some discussion of recharge and tank influences on the amount and location of recharge percolation into the vadose zone sediments is found in Ward et al. (1997). For the reasons just mentioned, we caution the reader that simple "specific retention" calculations may be misleading regarding the depth of penetration of liquid from tanks that have released significant volumes of tank liquor. Specific retention calculations are more appropriately used to discuss planned liquid discharges such as those to cribs, drains, and trenches as opposed to tank leaks.

Routson et al. $(1979,1980)$ state that gamma logging various dry wells since 1974 show only isolated evidence that lateral movement of the leaking plume has occurred. At least one of the indications of lateral movement was later attributed to rapid snow melt flooding in the winter of 1977-78 that put relatively contaminated surface water down the casing and into the dry bore hole at depth. In fact the lateral extent of the plume as delineated by the Ru-106 isopleth has been shrinking back towards the tank because $\mathrm{Ru}$ is decaying faster than the liquid is migrating. In 1978 the migration of Cs from the tank had increased a bit in the vertical direction but very little in the horizontal direction over the estimated plume in 1973. The Cs migration deeper into the profile occurs at only one borehole (\#111) which might bear further 
analysis to be sure there has not been inadvertent casing contamination. Groundwater analyses for four wells in the environs of the T-106 leak continued and there was no indication that any tank liquor had influenced the groundwater chemistry below the T-Tank farm. Wells that were monitored were 299-W10-1, 299-W10-4, 299-W 11-9, and 299-W11-24. For predictive transport calculations on the migration of radionuclides from the plume liquid Routson et al. (1979) used a Kd range for Cs of 7.1 to $12 \mathrm{mV} / \mathrm{g}$ for the T-106 liquor chemistry contacting Hanford sediments.

In early 1993, a limited vadose zone field investigation was performed within the T-106 tank leak zone. A telescoped cased borehole [Well 299-W10-196] was drilled to a depth of $54.5 \mathrm{~m}$ $(179.6 \mathrm{ft})$. A total of 43 split-spoon sediment samples were taken and analyzed for numerous chemicals and radionuclides. In addition spectral gamma logging was performed eight times within the borehole using 80 second count times and $0.5 \mathrm{ft}$ depth increments. The results are summarized herein but the reader is referred to Freeman-Pollard et al. (1994) for details and numerous excellent figures of contaminant profile versus depth.

Gross alpha, individual nuclides ( $\mathrm{Pu}, \mathrm{Am}, \mathrm{Np}$ ) show similar depth profiles. The bulk of these contaminants is found in the sediment at the bottom of the tank (between 11 and $12 \mathrm{~m}$ depth) to a depth of $20 \mathrm{~m}$. Below $20 \mathrm{~m}$ the activities of these constituents drop off by several orders of magnitude and essentially reach the background or detection limit level. For the gross alpha and $\mathrm{Pu}$ profiles there are small peaks (two orders of magnitude smaller in activity) at 30 $\mathrm{m}$ depth. There is no measurable $\mathrm{Np}$ or Am at these deeper depths.

Gross beta profiles also show the bulk of the activity is present at the tank bottom (11 to $12 \mathrm{~m}$ ) with an activity of $\sim 10^{+6} \mathrm{pCi} / \mathrm{g}$ with activity dropping off to $100 \mathrm{pCi} / \mathrm{g}$ at $27 \mathrm{~m}$. Below this depth there are two distinct smaller peaks $\left(\sim 10^{+3} \mathrm{pCi} / \mathrm{g}\right)$ at 30 and $35 \mathrm{~m}(98$ and $115 \mathrm{ft})$. Qualitatively the ${ }^{137} \mathrm{Cs}$ activity profile is similar to the gross beta profile but the values at the lower depths (30 and $35 \mathrm{~m}$ ) are not above the quantification limit for $\mathrm{Cs}$ and should be considered only qualitative. The peak ${ }^{137} \mathrm{Cs}$ activity is found at $14 \mathrm{~m}$ or at most $3 \mathrm{~m}(10 \mathrm{ft})$ below the bottom of the tank. Other beta emitters $\left({ }^{60} \mathrm{Co},{ }^{90} \mathrm{Sr}\right.$ and $\left.{ }^{99} \mathrm{Tc}\right)$ were also measured. The Sr data are very similar to the Cs data with the peak found at 12 to 14 meters depth and a large (three orders of magnitude) decrease by 20 meters depth. There are two Sr data points at 28-30 m depth near the contact between Hanford sediments and the underlying older PlioPleistocene contact that define a small secondary peak. The cobalt data differ from the Cs and Sr data in that the high activity plume stretches from the tank bottom all the way to $35 \mathrm{~m}$ depth which is about the bottom of the Plio-Pleistocene contact with Upper Ringold sediment. The Tc data show that it is the most mobile of the radionuclides studied. Measurable Tc is found from the tank bottom all the way to $\sim 47 \mathrm{~m}$ depth. The Tc concentration peaks at about 35 to $38 \mathrm{~m}$ depth.

The profiles for stable chemicals including $\mathrm{N}$ from nitrate and nitrite, sodium, and overall moisture content are also reported. The $\mathrm{N}$ and moisture content profiles are very similar to the Tc profile and suggest that these two components may be water coincident (i.e. exhibit 
essentially no adsorption and thus travel with the water). Sodium does not move as fast and shows a main peak from the tank bottom at $11-12 \mathrm{~m}$ down to $20 \mathrm{~m}$ and another peak at 30 to $32 \mathrm{~m}$ in the Plio-Pleistocene sediment. Ion exchange reactions are likely keeping the $\mathrm{Na}$ from being water coincident.

Total uranium was also measured and its profile is not similar to any of the others. There is one large peak and three smaller peaks in the profile, although in three of the four cases the peak is defined by only one data point. If the data are accurate and if the peaks represent $U$ from the tank as opposed to natural $U$ variations in the sediment from mineralogical changes, the bulk of the tank $U$ has reached a depth of $25 \mathrm{~m}$ but some has reached $50 \mathrm{~m}$ depth.

The new data for $\mathrm{T}-106$ suggest that mobile contaminants such as $\mathrm{Tc}$, and nitrate/nitrite have travelled with the leaking solution. Based on these "tracers" and moisture content for this one borehole placed where the leak was projected to be maximal, the T-106 solution has reached a depth of 37 to $40 \mathrm{~m}$ or a maximum of $29 \mathrm{~m}$ (95 ft) below the tank bottom. Obviously, one borehole does not assure that no deeper contamination may have occurred through preferred channeling at another location. Uranium, cobalt, sodium, and gross beta are somewhat less mobile and may have traveled (based on the penetration of their major peaks and not minor peaks) to $25,35,30$, and $30 \mathrm{~m}$, respectively or between 5 and $19 \mathrm{~m}(16$ and $62 \mathrm{ft})$ below the tank bottom. ${ }^{90} \mathrm{Sr}$ has reached a depth of $20 \mathrm{~m}$ [30 ft below the tank bottom] and ${ }^{137} \mathrm{Cs}$ has reached only $14 \mathrm{~m}$ [10 $\mathrm{ft}$ below the tank bottom]. Pu has a profile most similar to Cs for the major $\mathrm{Pu}$ peak. There are several profiles including the gross beta, ${ }^{90} \mathrm{Sr}, \mathrm{Pu}$, gross alpha(perhaps), and $U$ that show secondary smaller peaks down at the contacts of the PlioPleistocene with the younger Hanford and older Ringold sediments. How one factors these smaller peaks into the description of contaminant mobility is left to the reader. The contacts between sediment could act as zones where horizontal spreading is increased and zones where finer grained more adsorptive particles may reside.

In summary, the three extensive field studies of past tank leaks support the conceptual model that $\mathrm{Cs}$ is not as mobile as other contaminants and does not appear to migrate tens of meters from the tank bottoms over the time periods of a few years to up to about 30 years after suspected leak events. As mentioned in the past section, the REDOX metal or fission product bearing-waste composition found in SX tanks varies significantly from the bismuth phosphatetype wastes that were in tanks BX-102 and the combined bismuth phosphate and REDOX cladding wastes present in T-106 at the time of their leaks, such that it may not be useful to compare Cs behavior between SX tank farms with these two field studies of leaks. On the other hand Raymond and Shdo (1966) did study two leaks from the SX tank farm approximately two years after the suspected leaks and their data show migration of only a few meters over this period.

\subsection{Cs Migration Underneath Various Liquid Disposal Facilities}

Smith and Kasper (1983) discuss field measurements on the distribution of radionuclides 
beneath cribs 216-A-8 , 216-A-10, 216-A-30, 216-A-36B, 216-A-37-1, and 216-U-12. For 216-A-36B, in which high ammonia containing waste was disposed, the desorption Kd for Cs was $5.7 \mathrm{ml} / \mathrm{g}$.

Crib 216-A-8 received low-salt liquid waste and condensates from self-boiling tanks. Volatile organics also reached the crib as evidenced by an organic-rich layer ( $3-\mathrm{m}$ thick) below the crib bottom. The crib had received 1.2 billion liters of liquid waste by the end of 1980 that contained 642 curies of ${ }^{137} \mathrm{Cs}$ (decayed to $1-1-81$ ). The ${ }^{137} \mathrm{Cs}$ inventory disposed all resided within the upper 2 meters of soil beneath the crib bottom. The peak ${ }^{137} \mathrm{Cs}$ activity was 90,000 $\mu \mathrm{Ci} / \mathrm{g}$ soil.

Crib 216-A-10 received acidic ( $\mathrm{pH}^{-2}$ ) high-salt wastes from the PUREX process. The crib had received 2.9 billion liters of liquid waste by the end of 1980 . The total ${ }^{137} \mathrm{Cs}$ inventory disposed (decayed to 1-1-81) was 98 curies. Organics apparently were also disposed and have plugged the soil below the crib bottom for a distance of $4 \mathrm{~m}$. A distinct ${ }^{137} \mathrm{Cs}$ band with a concentration of $3,000 \mu \mathrm{Ci} / \mathrm{g}$ is found from the crib bottom to a depth of 13 more meters. The saturated paste $\mathrm{pH}$ of the sediments between 0 and $5 \mathrm{~m}$ below crib bottom is 4 which shows that the acid has significantly altered the soil to this depth.

Crib 216-A-30 received steam condensate and floor drainage from equipment cleaning. These liquids all were low salt and neutral $\mathrm{pH}$ solutions. 4.3 billion liters of liquid with a total ${ }^{137} \mathrm{Cs}$ inventory (decayed to 1-1-81) of 140 curies was disposed. All the ${ }^{137} \mathrm{Cs}$ was found to reside in the sediment within $2.3 \mathrm{~m}$ of the crib bottom.

Crib 216-A-36B received ammonia scrubber wastes (high salt, basic $\mathrm{pH}$ ). A total of 94 million liters of liquid with a total inventory of 431 curies of ${ }^{137} \mathrm{Cs}$ (decayed to 1-1-81) was disposed in the crib. Core samples show that ${ }^{137} \mathrm{Cs}$ has migrated $14 \mathrm{~m}$ below the bottom of the crib. Because the bulk of the $\mathrm{Cs}$ had been disposed only four years earlier than the sampling the $\mathrm{Cs}$ migration rate can be estimated as $3.5 \mathrm{~m} / \mathrm{yr}$ during active crib disposal. Desorption $\mathrm{Kd}$ values for ${ }^{137} \mathrm{Cs}$, calculated by leaching contaminated sediment with groundwater, averaged 26 $\mathrm{ml} / \mathrm{g}$. Smith and Kasper (1983) warn that further disposal of ammonia-rich liquid (0.3 M $\mathrm{NH}_{4} \mathrm{OH}$ ) could lower the ${ }^{137} \mathrm{Cs}$ desorption $\mathrm{Kd}$ to $3 \mathrm{ml} / \mathrm{g}$.

Crib 216-U-12 received stack drainage from 291-U-1, process condensate from 224-U building and in 1965 a one-time slug of contaminated water (highly acidic) from 244-WR vault. A total of 130 million liters of liquid were discharged to the crib with a total inventory of ${ }^{137} \mathrm{Cs}$ $<0.07$ curies (decayed to 1-1-81). In 1980 cores through the crib bottom showed a distinct ${ }^{137} \mathrm{Cs}$ plume from the crib bottom to $7.7 \mathrm{~m}$ deeper in the profile. The maximum concentration of ${ }^{137} \mathrm{Cs}$ was $0.020 \mu \mathrm{Ci} / \mathrm{g}$. The sediment below the crib was significantly impacted by the acidic waste disposal in 1965 and showed a saturated paste $\mathrm{pH}$ value of 3.9 for sediment $6.7 \mathrm{~m}$ directly below the crib bottom and a value of 6.1 for sediment $33.2 \mathrm{~m}$ below the crib bottom.

Van Luik and Smith (1982) report on borehole scintillation and gamma spectroscopy logging 
of boreholes in and around cribs 216-S-1 and 216-S-2. Active liquid discharges (a high salt acidic waste, $\mathrm{pH} \sim 2.1$ ) to these two cribs ended in 1956 with about 160 million liters disposed in the combined facility. The total inventory of ${ }^{137} \mathrm{Cs}$ (decayed to $1-1-81$ ) is 1,400 curies. Borehole logs from 1959, 1967, and 1980 showed that little movement of ${ }^{137} \mathrm{Cs}$ occurred with most of the ${ }^{137} \mathrm{Cs}$ found within $10 \mathrm{~m}$ of the crib bottoms. The sediment ${ }^{137} \mathrm{Cs}$ peak concentration in 1980 was $2 \mu \mathrm{Ci} / \mathrm{g}$. Sediments deeper than $10 \mathrm{~m}$ below the crib bottom show ${ }^{137} \mathrm{Cs}$ activities $<0.01 \mu \mathrm{Ci} / \mathrm{g}$. The authors estimate that the in-situ $\mathrm{Kd}$ for ${ }^{137} \mathrm{Cs}$ is $300 \mathrm{ml} / \mathrm{g}$. During a monitor well deepening effort in June 1955, liquid waste flooded the well casing and reached the water table. At various times in the ensuing years detectable ${ }^{90} \mathrm{Sr},{ }^{137} \mathrm{Cs}$ and tritium were found in the groundwater.

Brown (1967) also studied Cs migration at the S-1 and S-2 cribs. These two facilities with dimensions $12 \mathrm{~m}$ wide by $30 \mathrm{~m}$ deep with a bottom elevation at $11 \mathrm{~m}$ were in service for 4 years (1952 through 1956) and received about 150 million liters of liquid waste with 2,000 curies of ${ }^{137} \mathrm{Cs}$. In 1956 after the cribs were taken out of service three boreholes in the crib were deepened and six new ones drilled in the vicinity of the facility. Sediment samples were analyzed and the boreholes cased to allow future well logging. In 1966 another five wells were drilled. The data show that $99.9 \%$ of the Cs remains bound to sediments below the two cribs within 5 to 10 meters of the bottom. Ten years after the cribs were in operation small amounts of Cs were found at deeper depths apparently adsorbed to lenticular lenses as far down as 46 meters. The estimated ${ }^{137} \mathrm{Cs}$ activities on these deeper sediments is a few nanocuries/gram compared to up to 10 microcuries/g in the sediment right below the crib bottoms. Thus the amount of Cs that migrated is very small and sediment concentrations are four orders of magnitude lower at depth when found at all. The authors feel that the waste may have reached these depths by water channeling down the well casings followed by some horizontal spreading at distinct sediment boundaries. An alternative explanation is that the percolating waters contain very low concentrations of ${ }^{137} \mathrm{Cs}$ that are preferentially adsorbed by select minerals at the observed depth locations based of gamma borehole logging.

Contaminated sediments from beneath the cribs with $\sim 0.5 \mu \mathrm{Ci} / \mathrm{g}{ }^{137} \mathrm{Cs}$ were leached with groundwater and only $15 \%$ of the Cs was removed after 550 column volumes ( 1375 pore volumes) of leaching. For comparison $34 \%$ of the ${ }^{90} \mathrm{Sr}$ was leached from the sediments. The leached Cs re-absorbed on clean sediment taken from the underlying water table to yield a $\mathrm{Kd}$ value of $300 \mathrm{ml} / \mathrm{g}$.

Neutron probe measurements versus time appeared to show drainage of water from the vadose zone under the cribs to the water table with time. Rates dropped from $1.5 \mathrm{~m} / \mathrm{yr}$ right after the cribs were taken out of service to $0.5 \mathrm{~m} / \mathrm{yr}$ seven years after the cribs were taken out of service.

Rhodes (1956) measured the ${ }^{137} \mathrm{Cs}$ content in a well (207-S-11) which monitors the S-cribs. There was no indication that $\mathrm{Cs}$ was reaching the groundwater but there was evidence that ${ }^{90} \mathrm{Sr}$ was reaching the groundwater. 
Smith (1980) reports on the distribution of ${ }^{137} \mathrm{Cs}$ in sediments around a reverse well (216-B-5) drilled to $92 \mathrm{~m}$ and perforated between 74 and $92 \mathrm{~m}$ below ground surface. The water table at this site was around $91-92 \mathrm{~m}$ at the time of active disposal. The reverse well was used in 19451947 and 31 million liters of alkaline low salt $\left[<0.15 \mathrm{M} \mathrm{Na}\left(\mathrm{NO}_{3}, \mathrm{~F}\right)\right]$ was pumped into the well. The total inventory of ${ }^{137} \mathrm{Cs}$ disposed (decayed to 1-1-81) was 37 curies. Monitoring wells were placed around the facility in 1979 and measurable ${ }^{137} \mathrm{Cs}$ was found as far away as 8 $\mathrm{m}$, but a nearby source of ${ }^{137} \mathrm{Cs}$, the BY-cribs, might be the source of much of the Cs.

Fecht et al. (1977) present scintillation probe profiles for 200-W Area monitoring wells surrounding crib facilities. In the vicinity of the SX-Tank Farm they suggest that liquid (but not necessarily ${ }^{137} \mathrm{Cs}$ has reached the groundwater table from facilities $216-\mathrm{S}-1 / \mathrm{S}-2,216-\mathrm{S}-7$ and 216-S-9. These finding should be considered when addressing the potential sources of Cs surrounding the SX-109 tank. These crib facilities are directly east of the SX Tank Farm.

One can conclude from all this available information that $C s$ is not very mobile if the liquid in which it is being carried is more dilute than that in tank supernates and drainable liquid. The very leading edge of solution from a tank leak plume should interact and be diluted by the existing vadose zone sediment pore water such that there should be some retardation in Cs migration until the volume of leak plume water has had an opportunity to completely control the sediment pore water chemistry. The volume that may have leaked from any tank in the SX Tank Farm or other tank farms is smaller than the water that would be needed to completely destroy the buffering capacity of all the sediment above the water table, if the flow path was not some isolated preferred pathline such as a fracture, clastic dike, open borehole or loosely consolidated annulus around a borehole or monitoring well. Regardless of the chemistry of the leaking tank liquor it is unlikely that the Cs in the leak plume could migrate all the way to the water table without significant adsorption occurring in sediments away from the tank bottom and closer to the water table, unless one of these preferred isolated paths were carrying the leaking solution. This does not rule out low concentrations (the very early leading edge of a breakthrough curve) of ${ }^{137} \mathrm{Cs}$ reaching the water table. The transport modeling described in Ward et al. (1997) will further elaborate on this issue.

\subsection{Field Experiment - Sisson and Lu Test}

In 1980 an single well injection field test was performed with subsequent monitoring of the spread of water and radionuclides via wells that surrounded the injection well. The test was performed in the shallow Hanford sediments in the south-east corner of 200-E. See Sisson and $\mathrm{Lu}$ (1984) for details. The injection point was 15 feet below ground surface and 32 monitoring wells surround the central injection point to a depth of 60 feet. Eleven separate injection tests were performed. In all of them a dilute mixed salt solution was used that contained about $6 \mathrm{mM}$ of $\mathrm{Ca}$, chloride and nitrate and trace amounts of $\mathrm{Ba}$ and $\mathrm{Rb}$ (both -0.01 $\mathrm{mM}$ ) with radiotracers ${ }^{134} \mathrm{Cs}$ and ${ }^{85} \mathrm{Sr}$. Each injection lasted one week and between 800 and 1,500 gallons of this solution were continually injected at a rate of 2.5 to $3.9 \mathrm{gal} / \mathrm{hr}$. Monitoring of water content and gamma tracer content occurred during the injections and for 
up to three months after the last injection. The gamma scans were measured in each monitoring well at 1 -foot intervals to obtain vertical profiling. ${ }^{134} \mathrm{Cs}$ levels were above detection only in monitoring wells within 3 feet of the injection well and at depths from 13 to

16 feet from ground surface (recall that the injection point source was at 15 feet). ${ }^{85} \mathrm{Sr}$ migration was at least twice as far as the limited Cs migration. In 1995 several of the monitoring wells were probed with a state-of-the-art RLS unit (Radionuclide Logging System) that contains a high purity Germanium detector with very high resolution. In only one well at a 3-ft distance from the injection point at depths between 15 and $17 \mathrm{ft}$ was any ${ }^{134} \mathrm{Cs}$

detectable. See Fayer et al. (1995) for details. It would thus appear that Cs is not very mobile in Hanford sediments when dilute solutions containing $\mathrm{Cs}$ are injected. This agrees with the conclusions of Section 4 and field observations described in Section 6.2.

\subsection{Ammonia Discharges at Hanford}

Because Cs adsorption onto sediments can be limited by competition from small hydrated cations such as ammonium and potassium we reviewed information on the presence of these two cations in fuel processing and waste contents in tanks.

Agnew (1995) shows that ammonium bearing chemicals were an integral part of the REDOX process to adjust the oxidation-reduction potential of the $\mathrm{Pu}$ and $\mathrm{U}$. Ammonium bisulfite was used after the fuel was dissolved and just prior to the hexone solvent extraction step to separate the $\mathrm{U}$ and $\mathrm{Pu}$ from the fission products (see figure 7 in Agnew 1995). Further, Agnew (1995) states that radiolysis of nitrate and nitrite can lead to the formation of ammonium/ammonia in the tanks.

As shown in Tables 3.2, 3.3, and 3.7 Agnew predicts small amounts (tens of millimolar concentrations) of ammonium/ammonia in the REDOX waste compositions and a few millimolar or less in REDOX cladding wastes and bismuth phosphate wastes. Further, Agnew et al. (1996) project the contents expected in the tanks today and show small amounts of both ammonia and potassium are present in the supernate liquors for SX tanks that still contain drainable liquid. By inference the other SX tanks that are currently dried out would have had these constituents present when they also contained drainable liquid.

English and Mercer(1984) estimate the amount of chemicals discharged to the ground at Hanford. Approximately 2 million $\mathrm{kg}$ of ammonia/ammonium ion were discharged. Aside from sodium nitrate, and sodium phosphate this represents the largest inventory of all other chemicals. The ammonia/ammonium is associated with cribs' liquid discharges in A-8, -21, $24,-27,-36 \mathrm{~A}, \mathrm{~B} ; \mathrm{B}-7 \mathrm{~A},-8,-9,-11 \mathrm{~A}, \mathrm{~B} ;-14$ through $-36,-38$ through -62 in 200 East Area and $\mathrm{T}-3,-5,-6,-14$ through $-18,-21$ through- 24 , and -26 through -32 . There is no mention of ammonia release to the cribs surrounding the S or SX Tank Farms.

Klem (1988) shows that several processes used chemicals containing ammonium/ammonia. These include PUREX (A Plant in 200-E) that used ammonium fluoride and nitrate; B Plant 
that used ammonium nitrate, silicofluoride, sulfate, and sulfite; and Sr recovery which used anhydrous ammonia. In 200-W the REDOX process (S Plant) used ammonium fluoride and nitrate; T-Plant used ammonium nitrate, fluorosilicate, sulfate and sulfite to reprocess fuel; and $U$ Plant used ferrous ammonium sulfate.

Jungfleisch (1988) mentions that process condensate from 242-A has higher concentrations of ammonium ion when PUREX clad removal waste and PUREX ammonia scrubber feed are evaporated. By 1990 only the 242-A evaporator and 2724-W laundry generated liquid wastes with much ammonium ion. The former generates waste at 18 to $250 \mathrm{ppm} \mathrm{NH}_{4}^{+}$and $\mathrm{pH}$ about 9 to 9.5 and the latter (laundry facility is no longer operating) released waste water with 0.05 to $0.4 \mathrm{ppm}$ ammonium ion with $\mathrm{pH}$ between 6 and 7 .

Therefore, there may been some ammonium cations in the REDOX leaking solutions that would compete quite favorably with $\mathrm{Cs}$ for adsorption sites on Hanford sediments, but given the very large concentrations of $\mathrm{Na}$ in the REDOX solutions this variable is likely the dominating control on the adsorption of $\mathrm{Cs}$ onto the Hanford sediments. 


\subsection{CONCLUSIONS AND RECOMMENDATIONS}

In this report we provide an analysis of the chemistry of tank supernates with emphasis on the REDOX waste stream disposed in SX tanks, Cs aqueous chemistry, available data on Cs adsorption processes onto various mineral types, adsorption of $\mathrm{Cs}$ onto Hanford sediments, and information on Cs migration from other Hanford tank leaks and from intentional liquid waste disposal facilities. The data in this report was used to help guide the vadose zone transport analysis of the SX Tank Farm presented in Ward et al. (1997). The goal of the vadose zone transport modelling is to attempt to predict the depth and extent of the ${ }^{137} \mathrm{Cs}$ plume under the SX Tank farm and to compare the predictions to the Cs distribution based on the Rust Geotechnical gamma logging [DOE 1996], specifically in the vicinity of the greatest leak [SX109].

In solution, $\mathrm{Cs}$ is present as the monovalent cation and shows very little tendency to form aqueous complexes with inorganic or organic ligands. Cs shows no tendency to polymerize or to form true colloids. Cs is expected to sorb primarily by ion exchange. The degree of adsorption is dependent on the types and concentrations of other cations in solution that can compete for sorption sites. Ions of similar size $\left[\mathrm{NH}_{4}, \mathrm{~K}\right.$ and to a lesser extent $\mathrm{Na}$ ] effectively compete with each other for sorption sites on soils. Even though there was some ammonium and potassium cations in the REDOX leaking solutions that would compete quite favorably with Cs for adsorption sites on Hanford sediments, the very large concentrations of $\mathrm{Na}$ in the REDOX solutions likely controls the adsorption of Cs onto the Hanford sediments. The same is likely true for other tank waste streams including those that leaked from BX-102 and T-106 tanks that contained other types of process wastes. There are a few minerals, which are present in Hanford sediments that strongly and selectively adsorbed Cs onto specific structural sites with unique steric and geometric attributes. These micaceous 2:1 layer silicate minerals exist as a small mass fraction of Hanford subsurface sediments beneath the tank farms. Study of these particular minerals with REDOX supernates is highly recommended to understand the chemical processes that undoubtedly control the Cs adsorption observed for non-tank waste solutions at Hanford. The key question to answer is whether the very high ionic strength, $\mathrm{pH}$ and aluminum content of REDOX tank liquors can significantly impede these highly selective adsorption sites from sequestering $C s$.

The liquid disposed in SX tanks apparently self-concentrated to a significant extent based on the comparison of the initial waste composition (Table 3.2) versus the measured values for supernate and predicted values for tanks SX-101 through SX -106 shown in Tables 3.4 and 3.3 , respectively. The two historical actual measurements of tank supernate shown in Table 3.4 exhibit a very good cation-anion balance suggesting that the analyses are accurate. If so, the solution composition exhibits chemistry well beyond that studied in past laboratory $\mathrm{Kd}$ experiments and for the field investigations at the BX-102 and T-106 tank leaks. However as discussed in Section 5.0 we were unable to prepare a simulant that kept all the mass shown in Table 3.4 in solution. It appears that the historical data on supernate compositions may not be accurate, despite the good cation-anion balance reported. The very high $\mathrm{Al}, \mathrm{Na}$ and nitrate 
contents measured in the past were not sustained in our tests. Besides being unable to dissolve all the sodium nitrate, the $\mathrm{Al}$ especially seems to remain reactive with time and elevated temperatures resulting in the precipitation of very fine grained (high surface area) material that has been identified as bayerite, an $\mathrm{Al}$ hydroxide.

Fresh REDOX waste is predominately a $4 \mathrm{M}$ sodium-nitrate-nitrite-aluminate-hydroxide solution. This is similar to bismuth phosphate and PUREX waste liquids. But after selfboiling or other concentrating processes, the residual REDOX liquid exhibits a much higher ionic strength and perhaps higher basicity (free hydroxide content) in the range of 8-10 $\mathrm{M} \mathrm{Na}$ and perhaps 0.5 to $1 \mathrm{M}$ free hydroxide. These ionic strengths and hydroxide values exceed those used for any sediment-contaminant adsorption studies performed at Hanford or available in general literature. The comparison of the T-106 tank leak with SX Tank Farm leak(s) in terms of chemical composition of leaking liquid is not close enough to expect that the adsorption reactions between contaminants, especially $\mathrm{Cs}$ would be quantitatively similar. The chemical composition of the supernatant solution in T-106 at the time of the leak was much lower in $\mathrm{Na}$ and hydroxide content than the REDOX supernate. It is quite possible that the migration of Cs from the SX tanks is faster than that observed for the T-106 tank leak.

None of the available $\mathrm{Kd}$ tests were run with liquids that contained more than $4 \mathrm{M}$ sodium and $\mathrm{pH}$ values were never above 12 (free hydroxide $-0.01 \mathrm{M}$ ). The data that are available may be adequate to estimate $\mathrm{Kd}$ values for $\mathrm{Cs}$ in very fresh REDOX liquid that has not self-

concentrated, but the data are not adequate to estimate $\mathrm{Kd}$ values for the higher ionic strength, high soluble $\mathrm{Al}$, and higher $\mathrm{pH}$ solution that forms through self-boiling and other processes. Dependent upon when the SX tank leaks actually occurred, the chemical composition of the draining liquid would vary and thus $\mathrm{Cs}$ adsorption would also vary given its sensitivity to $\mathrm{Na}$ concentration. The extremely high $\mathrm{pH}$ and $\mathrm{Al}$ condition might also impact the Cs adsorption and perhaps dissolve bulk sediment or severely etch the fine particulates that likely perform most of the adsorption.

The preliminary batch and flow-through column adsorption tests described in Section 5.0 have not been successful at bounding the probable fate of Sr and Cs radionuclides in REDOX waste tanks in the SX Tank Farm. About the only conclusion that can be offered, without further empirical testing using high ionic strength/high $\mathrm{pH} / \mathrm{high} \mathrm{Al}$-bearing solutions, is that the Cs $\mathrm{Kd}$ values could be higher (as found in the scouting studies) or lower than those reported in the available literature that did not have $\mathrm{Al}$ as a key variable. If the $\mathrm{Al}$ precipitation is the key to the higher than expected $\mathrm{Cs}$ adsorption and if the $\mathrm{Al}$ in the REDOX liquor is rapidly removed by the sediments surrounding the tank, then perhaps the Cs Kd would be much lower beyond the zone of $\mathrm{Al}$ precipitation. As shown for the less concentrated T-106 liquid simulants, the Cs Kd value ranges from 0.5 to $12 \mathrm{ml} / \mathrm{g}$ across a range of solution compositions, with a more realistic range of 2 to $6 \mathrm{ml} / \mathrm{g}$ for the simulant most representative of the T-106 tank liquor (see Table 4.3 Solution II). Without more empirical adsorption data on REDOX solutions interacting with Hanford sediments with emphasis on the Al chemistry, all we can offer is that the $\mathrm{Kd}$ for $\mathrm{Cs}$ may be lower than this range. Conversely, in the presence of high solution $\mathrm{Al}$ 
that tends to form precipitates in the sediment, the Cs adsorption was found to yield $\mathrm{Kd}$ values from 20 to $60 \mathrm{ml} / \mathrm{g}$ in the scouting studies.

The three extensive field studies of past tank leaks support the conceptual model that Cs is not as mobile as other contaminants and does not appear to migrate tens of meters from the tank bottoms. But as mentioned, the REDOX metal or fission product bearing-waste composition found in SX tanks varies significantly from the bismuth phosphate-type wastes that were in Tank BX-102 and the combined bismuth phosphate and REDOX cladding wastes present in T106 at the time of the leaks, such that it may not be useful to compare Cs behavior under SX Tank Farm with these past leaks.

Once the solution carrying the $\mathrm{Cs}$ has been diluted by vadose zone pore water and chemical reaction with the sediment, $\mathrm{Cs}$ is not very mobile. The very leading edge of solution from a tank leak plume should interact and be diluted by the existing vadose zone sediment pore water such that there should be some retardation in Cs migration until the volume of leak plume water has had an opportunity to completely control the sediment pore water chemistry. The volume that may have leaked from any tank in the SX Tank Farm or other tank farms is smaller than the volume that would be needed to completely control all the sediment above the water table, provided that the flow path was not some isolated preferred pathline such as a fracture, clastic dike, open borehole or loosely consolidated annulus around a borehole. Regardless of the chemistry of the leaking tank liquor it is unlikely that the Cs in the leak plume could migrate all the way to the water table without significant adsorption occurring in sediments away from the tank bottom and closer to the water table, unless one of these preferred isolated paths were carrying the leaking solution. This does not rule out low concentrations (the very early leading edge of a breakthrough curve) of ${ }^{137} \mathrm{Cs}$ reaching the water table.

Should matrix dissolution in the very near field around the tanks be important, especially for REDOX waste bearing tanks such as SX Tanks, the migration of Cs (and other contaminants thought to interact with sediments) could be expected to increase. At some point away from the tanks, the tank leak liquor would be expected to be "neutralized" by the sediments large buffering capacity to consume free hydroxide and one should see a re-precipitation of the silica and aluminum to form amorphous coatings/gel that could lower permeability as well as coprecipitate (physically trap) or adsorb other soluble components such as Cs. The precipitation of Al hydroxide was observed in all of the scouting tests and appears to enhance the adsorption of Cs. Thus it is difficult to say that the fate of Cs should follow a monotonically increasing adsorption (Kd) as the distance from the tank increases. It appears that the fate of Cs may be controlled by a complicated mix of parameters such as competing cations, $\mathrm{pH}$, and presence of fresh precipitates such as $\mathrm{Al}$ hydroxides. The net effect may cause the Kd to vary widely, with complicated increases and decreases, as a function of distance from the tank. The measurement of the adsorption properties of Sr and Cs from the evolving REDOX solution in our scoping studies was difficult (see Section 5). The observed $\mathrm{Kd}$ for ${ }^{137} \mathrm{Cs}$ (range of 20 to $60 \mathrm{ml} / \mathrm{g}$ dependent on whether the solution is filtered or only 
gravity settled), is much larger than expected and does not agree with recent computer predictions and field gamma logging measurements of Cs in vadose zone sediments underlying the SX Tank Farm. Sr is not soluble in the REDOX solution as long as Al precipitation is occurring. The literature review and past analytical measurements of tank waste phases also supports this conclusion. Cs is essentially soluble but upon contact with sediment and further precipitation of $\mathrm{Al}$ bearing material there appears to be a higher than expected sorption (Kd). More detailed and complete solution and solid (both sediment and reaction products) characterization using techniques such as ICP-MS, SEM-EDS, XRD and newer molecular and surface techniques would be needed to help interpret the complicated reactions.

There does not appear to be any indication that matrix dissolution products (high $\mathrm{Si}, \mathrm{Al}$ and $\mathrm{pH})$ have reached the groundwater below SX tanks and further one might expect that massive dissolution would manifest itself in the near vicinity of the tanks as more porous material with perhaps copious gel-like coatings. It is possible that the high ${ }^{137} \mathrm{Cs}$ activities found in several SX-Tank Farm sediments (inferred from recent gamma logs through cased boreholes at the 75foot level is an indication of how far the matrix dissolution impact has reached. If there was a significant accumulation of precipitated Al hydroxide in the 75-foot zone perhaps it would adsorb large amounts of Cs and appear as highly concentrated material in the gamma logs. This would imply a zone of reaction of about 20-25 feet below the tank bottoms. We recommend that additional laboratory testing be performed to better evaluate this sediment matrix dissolution and $\mathrm{Al}$ precipitation issue. 


\subsection{REFERENCES}

Abendroth R. P. 1970. "Behavior of a Pyrogenic Silica in Simple Electrolytes," J. Coll. Interface Sci. 34: 591-596.

Agnew, S. F. 1995. Hanford Defined Wastes: Chemical and Radionuclide Compositions. LA-UR-94-2657, Rev. 2. Los Alamos National Laboratory, Los Alamos, New Mexico.

Agnew, S. F., J. Boyer, R. A. Corbin, T. B. Duran, J. R. FitzPatrick, K. A. Jurgensen, T. P. Ortiz, and B. L. Young. 1996. Hanford Tank Chemical and Radionuclide Inventories: HDW Model Rev.3. LA-UR-96-858, Los Alamos National Laboratory, Los Alamos, New Mexico.

Ames, L. L. and B. F. Hajek. 1966a. Statistical Analysis of Cesium and Strontium Sorption on Soils. BNWL-CC-539, Pacific Northwest Laboratory, Richland, Washington.

Ames, L. L. and B. F. Hajek. 1966b. An Experimental Design for the Preliminary Study of Geochemical Processes. BNWL-CC-573, Pacific Northwest Laboratory, Richland, Washington.

Ames, L. L. and D. Rai. 1978. Radionuclide Interactions with Soil and Rock Media. EPA 520/6-78-007A, Environmental Protection Agency, Las Vegas, Nevada.

Anderson, K. and B. Allard. 1983. Sorption of Radionuclides on Geologic Media. Report No. SKBF-KBS-TR-83-07, Svensk Kärnsbränsteförjning, Stockholm.

Atlantic Richfield. 1973. 241-T-106 Tank Leak Investigation. ARH-2874, Atlantic Richfield Hanford Company, Richland, Washington.

Baker, V. R. and R. O. Bunker. 1985. "Cataclysmic Late Pleistocene Flooding from Glacial Lake Missoula: A Review." Quanternary Sci. Rev. 4:1-41.

Baker, V. R., B. N. Bjornstad, A. J. Busacca, K. R. Fecht, E. P. Kiver, U. L. Moody, J. G. Rigby, O. F. Stradling, and A. M. Tallman. 1991. "Quanternary Geology of the Columbia Plateau". In Quanternary Nonglacial Geology; Conterminous U.S., v. K-2 of The Geology of North America. (Ed., R. B. Morrison), Geological Society of America, Boulder, CO.

Barney, G. S. 1978. "Variables Affecting Sorption and Transport of Radionuclides in Hanford Subsoils." RHO-SA-87, Rockwell Hanford Operations, Richland, Washington.

Barney, G. S. 1982a. "Radionuclide Sorption of Columbia River Basalt Interbed Materials." RHO-SA-198 P, Rockwell Hanford Operations, Richland, Washington. 
Barney, G. S. 1982b. EY1981 Annual Report-Radionuclide Sorption on Basalt Interbed Materials. RHO-BW-ST-35 P, Rockwell Hanford Operations, Richland, Washington.

Barnhisel, R. I. and P. M. Bertsch. 1989. "Chlorites and Hydroxy-Interlayered Vermiculite and Smectite". In Minerals in Soil Environments, Second Edition. (Eds., J. B. Dixon and S. B. Weed), pp. 729-788, Soil Science Society of America, Madison, WI.

Beard, S. J., G. L. Ritter, J. J. Shefcik, and P. W. Smith. 1965. Waste Management Program Chemical Processing Department. RL-SEP-894, General Electric Hanford Atomic Products Operation, Richland, Washington.

Bell, T. E. 1986. Microstructure in Mixed-Layer Illite/Smectite and its Relationship to the Reaction of Smectite to Ilite. Clays Clay Miner. 34: 146-154.

Bertsch, P. M. 1987. "Conditions for $\mathrm{Al}_{13}$ Polymer Formation in Partially Neutralized Aluminum Solutions". Soil Sci. Soc. Am. J. 51: 825-828.

Bertsch, P. M. 1989. "Aqueous Polynuclear Aluminum Species". In The Environmental Chemistry of Aluminum. (Ed., G. Sposito), pp. 87-111, CRC Press, Boca Raton, FL.

Bjornstad, B. N. 1984. Suprabasalt Stratigraphy Within and Adjacent to the Reference Repository Location. SD-BWI-DP-039, Rockwell Hanford Operations, Richland, WA.

Brady, P. V. and J. V. Walther. 1989. "Controls on Silicate Dissolution Rates in Neutral and Basic pH Solutions at $25^{\circ} \mathrm{C} "$. Geochim. Cosmochim. Acta 53:2823-2830.

Breeuwsma, A. and J. Lyklema. 1971. "Interfacial Electrochemistry of Hematite $\left(\alpha-\mathrm{Fe}_{2} \mathrm{O}_{3}\right)^{\text {". }}$ Disc. Faraday Soc. 52:324-333.

Brevick, C. H. 1995. Historical Tank Content Estimate for the Southwest Quadrant of the Hanford 200 West Area. WHC-SD-WM-ER-352, Rev. Oa, Westinghouse Hanford Company, Richland, Washington.

Brevick, C. H., L. A. Gaddis and W. H. Pickett. 1994. Historical Tank Content estimate for the Northeast Quadrant of the Hanford 200 East Areas. WHC-SD-WM-ER-349, Rev. 0, Westinghouse Hanford Company, Richland, Washington.

Brouwer, E., B. Baeyens, A. Maes, and A. Cremers. 1983. "Cesium and Rubidium Ion Equilibria in Illite Clay". J. Phys. Chem. 87:1213-1219.

Brown, D. J. 1967. "Migration Characteristics of Radionuclides through Sediments Underlying the Hanford Reservation." in Disposal of Radioactive Wastes into the Ground, pp 215-228, IAEA Proceedings SM-93, International Atomic Energy Agency, Vienna, Austria. 
Caggiano, J. A. 1996. Assessment Groundwater Monitoring Plan for Single Shell Tank Waste Management Area S-SX. WHC-SD-EN-AP-191, Rev. 0, Westinghouse Hanford Company, Richland, Washington.

Casey, W. H., H. R. Westrich, and G. W. Amold. 1988. "Surface Chemistry of Labradorite Feldspar Reacted with Aqueous Solutions at $\mathrm{pH}=2,3$, and 12". Geochim. Cosmochim. Acta. 52: $2795-2807$.

Casey, W. H., H. R. Westrich, G. W. Amold, and J. F. Banfield. 1989. "The Surface Chemistry of Dissolving Labradorite Feldspar". Geochim. Cosmochim. Acta. 53: 821-832.

Choquette, M., M. A. Berube, and J. Locat. 1991. "Behavior of Common Rock-Forming Minerals in a Strongly Basic NaOH Solution". Canadian Mineralogist. 29:163-173.

Churms, S. C. 1966. "The Effect of $\mathrm{pH}$ on the Ion-Exchange Properties of Hydrated Alumina. Part I. Capacity and Selectivity". J. S. Afr. Chem. Inst. 19:98-107.

Clark, R. M. 1990. "Water Supply" in Standard Handbook of Environmental Engineering, R. A. Corbitt, Ed. McGraw Hill, New York, pp. 5.1-5.225.

Comans, R. N. J. and D. E. Hockley. 1992. "Kinetics of Cesium Sorption on Illite". Geochim. Cosmochim. Acta. 57:1157-1164.

Comans, R. N. J., M. Haller, and P. De Preter. 1991. "Sorption of Cesium on Illite: NonEquilibrium Behavior and Reversibility". Geochim. Cosmochim. Acta. 55:433-440.

Conaway, J. G., R. J. Luxmoore, J. M. Matuszek, and R. O. Patt. 1997. Tank Waste Remediation System Vadose Zone Contamination Issue: Independent Expert Panel Status Report. DOE/RL-97-49, Rev. 0, Department of Energy, Richland, Washington.

Cremers, A., A. Elsen, P. De Preter, and A. Maes. 1988. "Quantitative Analysis of Radiocaesium Retention in Soils". Nature 335:247-249.

Davis, J. A. and D. B. Kent. 1990. "Surface Complexation Modeling in Aqueous Geochemistry". In Mineral-Water Interface Geochemistry. (Eds., M. F. Hochella and A. F. White), pp. 177, Mineralogical Society of America, Washington, D.C.

De Haan, F. A. M., G. H. Bolt, and B. G. M. Pieters. 1965. "Diffusion of Potassium-40 into an Illite During Prolonged Shaking". Soil Sci. Soc. Am. Proc. 29:528-530.

De Preter, P., L. Van Loon, and A. Cremers. 1991. "Solid/Liquid Distribution of Radiocesium in Boom Clay. A Quantitative Interpretation". Radichim. Acta 52/53:299-302. 
Dixon J. B. and S. B. Weed. 1989. Minerals in Soil Environments, Second Edition. Soil Science Society of America, Madison, WI.

DOE. 1996. Vadose Zone Characterization Project at the Hanford Tank Farms- SX Tank

Earm. DOE/ID/12584-268, U. S. Department of Energy, Grand Junction, Colorado.

Dumont, F. and A. Watillon. 1971. "Stability of Ferric Oxide Hydrosols". Disc. Faraday Soc. 52:352-360.

Elprince, A. M., C. I. Rich, and D. C. Martens. 1977. "Effect of Temperature and Hydroxy Aluminum Interlayers on the Adsorption of Trace Radioactive Cesium by Sediments near Water-Cooled Nuclear Reactors". Water Resour. Res. 13:375-379.

English, C. J. and B. W. Mercer. 1984. An Inventory of Chemical Wastes and Disposal Sites at the Hanford Site. PNL-XXXX(draft document apparently never published), Pacific Northwest Laboratory, Richland, Washington.

Evans, D. W., J. J. Alberts, and R. A. Clark, III. 1983. "Reversible Ion-Exchange Fixation of Cesium-137 Leading to Mobilization from Reservoir Sediments". Geochim. Cosmochim. Acta 47:1041-1049.

Fanning, D. S., V. Z. Keramidas, and M. A. El-Desoky. 1989. "Micas". In Minerals in Soil Environments, Second Edition. Soil Science Society of America, Madison, WI.

Fayer, M. J., R. E. Lewis, R. E. Engelman, A. J. Pearson, C. J. Murray, J. L. Smoot, R. R. Randall, W. H. Wegener, and A. H. Lu. 1995. Re-Evaluation of a Subsurface Injection Experiment for Testing Flow and Transport Models. PNL-10860, Pacific Northwest Laboratory, Richland, Washington.

Fecht, K. R., G. V. Last, and K. R. Price. 1977. Evaluation of Scintillation Probe Profiles Erom 200 Area Crib Monitoring Wells Volume III. ARH-ST-156, Atlantic Richfield Hanford Company, Richland, Washington.

Ferrel, R. E. and R. E. Grim. 1967. "The Influence of Alkaline Solutions on the Alteration of the Clay Minerals". In Proc. $15^{\text {th }}$ National Conference on Clays and Clay Minerals. (Ed., S. W. Bailey), pp. 293-304. Pergamon Press, New York, NY.

Francis, C. W. and F. S. Brinkley. 1976. "Preferential Adsorption of ${ }^{137} \mathrm{Cs}$ to Micaceous Minerals in Contaminated Freshwater Sediment". Nature 260:511-513.

Freeman-Pollard, J. R., J. A. Caggiano, S. J. Trent, and ENSEARCH Environmental/Hart Crowser. 1994. Engineering Evaluation of the GAO/RCED-89-157. Tank 241-T-106 Vadose Zone Investigation. BHI-00061, Rev. 00, Bechtel Hanford, Inc., Richland, Washington. 
Goulding, K. W. T. 1983. "Thermodynamics and Potassium Exchange in Soils and Clay Minerals". In Advances in Agronomy. (Eds., S. S. Virmani and I. B. Edwards), pp. 215264. Academic Press, Inc.

Greenland, D. J. and M. H. B. Hayes. 1978. The Chemistry of Soil Constituents. John Wiley \& Sons, New York, NY.

Grütter, A., H. R. von Gunten, and E. Rössler. 1986. "Sorption, Desorption, and Isotope Exchange of Cesium $\left(10^{-9}-10^{-3} \mathrm{M}\right)$ on Chlorite". Clays Clay Miner. 34:677-680.

Grütter A., H. R. von Gunten, E. Rössler, and R. Keil. 1994. "Sorption of Strontium on Unconsolidated Glaciofluvial Deposits and Clay Minerals; Mutual Interference of Cesium, Strontium and Barium". Radiochim. Acta 64:247-252.

Grütter A., H. R. von Gunten, M. Kohler, and E. Rössler. 1990. "Sorption, Desorption and Exchange of Cesium on Glaciofluvial Deposits". Radiochim. Acta 50:177-184.

Hajek, B. F. and L. L. Ames. 1966. "Trace Strontium and Cesium Distribution Coefficients: Batch and Column Determinations". BNWL-SA-843, Pacific Northwest Laboratory, Richland, Washington.

Hayden, P. L. and A. J. Rubin. 1974. "Systematic Investigation of the Hydrolysis and Precipitation of Aluminum(II), Chapter 9." In Aqueous-Environmental Chemistry of Metals. (Ed., A. J. Rubin), pp. 317-381. Ann Arbor Science, Ann Arbor, MI.

Helferrich, F. 1962. Ion Exchange. McGraw-Hill Book Co., New York, NY.

Jackson, M. L. 1963. "Interlayering of Expansible Layer Silicates in Soils by Chemical Weathering". Clays Clay Miner. 11:29-46.

Jungfleisch, F. 1988. Preliminary Evaluation of Hanford Liquid Discharges to Ground. WHC-EP-0052, Westinghouse Hanford Company, Richland, Washington.

Kaplan, D. I. and R. J. Seme. 1995. Distribution Coefficient Values Describing Iodine, Neptunium, Selenium, Technetium, and Uranium Sorption to Hanford Sediments. PNL10379, SUP. 1, Pacific Northwest Laboratory, Richland, Washington.

Kepak, F. 1971, "Adsorption and Colloidal Properties of Radioactive Elements in Trace Concentrations," in Chem. Rev., Vol. 71, pp. 357-370.

Kim, Y., R. T. Cygan, and R. J. Kirkpatrick. $1996 .{ }^{1133} \mathrm{Cs}$ NMR and XPS Investigation of Cesium Adsorbed on Clay Minerals and Related Phases". Geochim. Cosmochim. Acta 60:1041-1052. 
Kinniburgh D. G. and M. L. Jackson, 1981, "Cation Adsorption by Hydrous Metal Oxides," in Adsorption of Inorganics at Solid-Liquid Interfaces, pp. 91-160. M. A. Anderson and A. J. Rubin, eds., Ann Arbor Science, Ann Arbor, Michigan.

Klem, M. J. 1988. Inventory of Chemicals Used at Hanford Production Plants and Support Operations (1944-1980). WHC-EP-0172, Westinghouse Hanford Company, Richland, Washington.

Knoll, K. C. 1969. Reactions of Organic Wastes in Soils. BNWL-860, Pacific Northwest Laboratory, Richland, Washington. General Electric Hanford Works, Richland, Washington.

Le Roux, J., C. I. Rich, P. H. Ribbe. 1970. "Ion Selectivity by Weathered Micas as Determined by Electron Microscopy". Clays Clay Miner. 18:333-338.

Lindsay, W. L. 1979. Chemical Equilibria in Soils. John Wiley \& Sons, New York, NY.

McHenry, J. R. 1957. The Removal of Cesium-137 and Strontium-90 Erom Scavenged Bismuth Phosphate Solutions. HW-48141,

Mercer, B. W., L. L. Ames, and R. G. Parkhurst. 1968. Removal of ${ }^{137}$ Cs From Alkaline Condensate Wastes. BNWL-829, Pacific Northwest Laboratory, Richland, Washington.

Murdock, L. M. and C. I. Rich. 1972. "Ion Selectivity in Three Soil Profiles as Influenced by Mineralogical Characteristics". Soil Sci. Soc. Am. Proc. 37:167-171.

Nelson, J. L., B. W. Mercer, and W. A. Haney. 1960. Solid Fixation of High-Level Radioactive Waste By Sorption on Clinoptilolite-Scouting Studies. HW-66796, General Electric Hanford Works, Richland, Washington.

Raymond, J. R. and E. G. Shdo. 1966. Characterization of Subsurface Contamination in the SX Tank Farm. BNWL-cc-701, Pacific Northwest Laboratory, Richland, Washington.

Rhodes, D. W. 1956. Adsorption by Soil of Sr Erom 216-S Crib Waste. HW-42699, General Electric Hanford Works, Richland, Washington.

Rhodes, D. W., K. B. Holtzinger, J. R. McHenry. 1954. Adsorption of Radioactive Isotopes by Soil Erom a Bismuth Phosphate Waste. HW-32978, General Electric Hanford Works, Richland, Washington.

Rhodes, D. W. and J. L. Nelson. 1957. Disposal of Radioactive Liquid Wastes from the Uranium Recovery Plant. HW-54721, General Electric Hanford Works, Richland, Washington. 
Rich, C. I. and W. R. Black. 1964. "Potassium Exchange as Affected by Cation Size, pH, and Mineral Structure". Soil Sci. 97:384-390.

Righetto, L., G. Bidoglio, B. Marcandalli, and I. R. Bellabono, 1988, "Surface Interactions of Actinides with Alumina Colloids," Radio Chimica Acta, Vol. 44/45, pp. 73-75.

Routson, R. C., G. S. Bamey, and R. M. Smith. 1981a. "Hanford Site Sorption Studies for the Control of Radioactive Wastes: A Review." Nucl. Technol.54:100-106.

Routson, R. C., G. S. Barney, R. M. Smith, C. H. Delegard, and L. Jensen. 1981b. Eission Product Sorption Parameters for Hanford 200-Area Sediment Types. RHO-35, Rockwell Hanford Operations, Richland, Washington.

Routson, R. C., W. H. Price, D. J. Brown, and K. R. Fecht. 1979. High-Level Radioactive Waste Leakage From the 241-T-106 Tank on the Hanford Site. RHO-ST-14, Rockwell Hanford Operations, Richland, Washington.

Routson, R. C., W. H. Price, D. J. Brown, and K. R. Fecht. 1980. "High-Level Radioactive Waste Leakage From the 241-T-106 Tank on the Hanford Site." Nucl and Chem. Waste Manage 1:143-151.

Sawhney, B. L. 1970. "Potassium and Cesium Ion Selectivity in Relation to Clay Mineral Structure". Clays Clay Miner. 18:47-52.

Sawhney, B. L. 1972. "Selective Sorption and Fixation of Cations by Clay Minerals". Clays Clay Miner. 20:93-100.

Schindler, P., 1981, "Surface Complexes at Oxide-Water Interfaces," in Adsorption of Inorganics at Solid-Liquid Interfaces, M. A. Anderson and A. J. Rubin, eds., Ann Arbor Science, Ann Arbor, Michigan, pp. 1-50.

Schulz, W. W. 1978. "Removal of Radionuclides from Hanford Defense Waste Solutions." RHO-SA-51, Rockwell Hanford Operations, Richland, Washington.

Schulz, W. W. 1977. "Ozonation of Organic Complexants." In Process Technology and Process Development Quarterly Report -October 1976 thru December 1976. pp. 75-78, ARHLD-152 A, Atlantic Richfield Hanford Company, Richland, Washington.

Serne, R. J. 1973(unpublished) "Kd's for Simulated T-106 Tank Liquor for Selected Nuclides onto Hanford Sediments". excerpts can be found in Ames, L. L., and D. Rai (1978). Radionuclides Interactions with Soil and Rock Media. EPA 520/6-78-007A, Environmental Protection Agency, Office of Radiation Programs, Las Vegas, Nevada. 
Serne, R. J. , C. W. Lindenmeier, J. L. Conca, J. A. Campbell, V. L. LeGore, J. E. Amonette, K. J. Cantrell, and M. I. Wood. 1993. Solid-Waste Leach Characteristics and Contaminant-Sediment Interactions. Vol. 1: Batch Leach and Adsorption Tests and Sediment Characterization. PNL-8889, Pacific Northwest Laboratory, Richland, Washington.

Shade, J. W. 1974. Reaction of Hanford sediments with Synthetic Waste: A Reconnaissance Study. ARH-CD-176, Atlantic Richfield Hanford Company, Richland, Washington.

Shannon, R. D. 1976. "Revised Effective Ionic Radii and Systematic Studies of Interatomic Distances in Halides and Chalcogenides." Acta Cryst. A32:751-767.

Sisson, J. B. and A. H. Lu. 1984. Eield Calibration of Computer Models for Application to Buried Liquid Discharges: A Status Report. RHO-ST-46P, Rockwell Hanford Operations, Richland, Washington.

Smith, G. A. 1993. "Missoula Flood Dynamics and Magnitudes Inferred form

Sedimentology of Slack-water Deposits on the Columbia Plateau, Washington". Geological Society of America, Bulletin. v. 105.

Smith, R. M. 1980. 216-B-5 Reverse Well Characterization Study. RHO-ST-37, Rockwell Hanford Operations, Richland, Washington.

Smith, R. M. and R. B. Kasper. 1983. Serviceability of Cribs Affected by PUREX Stattup. RHO-HS-EV-18, Rockwell Hanford Operations, Richland, Washington.

Sposito, G. 1984. The Surface Chemistry of Soils. Oxford University Press, New York, NY.

Sposito, G. 1989. The Chemistry of Soils. Oxford University Press, New York, NY.

Sumner, M. E. and G. H. Bolt. 1962. "Isotopic Exchange of Potassium in an Illite under Equilibrium Conditions". Soil Sci. Soc. Am. Proc. 26:541-544.

Tallman, A. M., K. R. Fecht, M. C. Marratt, and G. V. Last. 1979. Geology of the Separations Areas, Hanford Site, South-Central Washington. Report No. RHO-ST-23, Rockwell Hanford Operations, Richland, WA.

Tamura, T. and D. G. Jacobs: 1960. "Structural Implications in Cesium Sorption". Health Phys. 2:391-393.

Tien, H. T. 1965. "Interaction of Alkali Metal Cations with Silica Gels". J. Phys. Chem. 69: $350-252$.

Tullock, R. J. and C. B. Roth. 1975. "Stability of Mixed Iron and Aluminum Hydrous 
Oxides on Montmorillonite". Clays Clay Miner. 23:27-32.

Van Luik, A. E. and R. M. Smith. 1982. 216-S-1 and S-2 Mixed Fission Product Crib Characterization Study, RHO-ST-39, Rockwell Hanford Operations, Richland, Washington.

Venkataramani, B., K. S. Venkateswarlu, and J. Shankar. 1978. "Sorption Properties of Oxides. III. Iron Oxides". J. Coll. Interface Sci. 67:187-194.

Ward, A. L., G. W. Gee, and M. D. White. 1997. A Comprehensive Analysis of Contaminant Transport in the Vadose Zone Beneath Tank SX-109. PNNL-11463, Pacific Northwest National Laboratory, Richland, Washington.

Weast, R. C. (editor). 1981. Handbook of Chemistry and Physics, 62nd Edition. CRC Press, Inc., Boca Raton, Florida.

Weiss, C. A., Jr., R. J. Kirkpatrick, and S. P. Altaner. 1990a. "Variations in Interlayer Cation Sites of Clay Minerals as Studied by ${ }^{133}$ Cs MAS Nuclear Magnetic Resonance Spectroscopy". Amer. Mineralogist 75:970-982.

Weiss C. A., Jr., R. J. Kirkpatrick, and S. P. Altaner. 1990b. "The Structural Environments of Cations Adsorbed onto Clays: ${ }^{133} \mathrm{Cs}$ Variable-Temperature MAS NMR Spectroscopic Study of Hectorite. Geochim. Cosmachim. Acta 54:1655-1669.

Weiss, R. L. and K. E. Schull. 1988a. Data Transmittal Package for 241-A-103 Waste Tank Characterization. SD-RE-TI-198, Westinghouse Hanford Company, Richland, Washington.

Weiss, R. L. and K. E. Schull. 1988a. Data Transmittal Package for 241-C-104 Waste Tank Characterization. WHC-SD-RE-TI-199, Westinghouse Hanford Company, Richland, Washington.

Weiss, R. L. and K. E. Schull. 1988c. Data Transmittal Package for 241-A-106 Waste Tank Characterization. WHC-SD-RE-TI-200, Westinghouse Hanford Company, Richland, Washington.

Weiss, R. L. and K. E. Schull. 1988d. Data Transmittal Package for 241-A-102 Waste Tank Characterization. WHC-SD-RE-TI-201, Westinghouse Hanford Company, Richland, Washington.

Weiss, R. L. and K. E. Schull. 1988e. Data Transmittal Package for 241-BX-105 Waste Tank Characterization. WHC-SD-RE-TI-202, Westinghouse Hanford Company, Richland, Washington.

Weiss, R. L. and K. E. Schull. 1988f. Data Transmittal Package for 241-C-103 Waste Tank 
Characterization. WHC-SD-RE-TI-203, Westinghouse Hanford Company, Richland, Washington.

Weiss, R. L. and K. E. Schull. 1988g. Data Transmittal Package for 241-C-105 Waste Tank Characterization. WHC-SD-RE-TI-204, Westinghouse Hanford Company, Richland, Washington.

Weiss, R. L. and K. E. Schull. 1988h. Data Transmittal Package for 241-C-106 Waste Tank Characterization. WHC-SD-RE-TI-205, Westinghouse Hanford Company, Richland, Washington.

Weiss, R. L. and K. E. Schull. 1988i. Data Transmittal Package for 241-BX-104 Waste Tank Characterization. WHC-SD-RE-TI-206, Westinghouse Hanford Company, Richland, Washington.

Womack, J. C. and D. J. Larkin. 1971. Investigation and Evaluation of 102-BX Tank Leak. ARH-2035, Atlantic Richfield Hanford Company, Richland, Washington. 
APPENDIX A

DETAILS ON ACCESSING THE TANK CHARACTERIZATION DATA BASE 


\section{APPENDIX A. DETAILS ON ACCESSING THE TANK CHARACTERIZATION DATA BASE}

A data base exists on the World Wide Web within the PNNL home page that contains archived analyses of the contents of many of the Hanford SST tanks. To reach the data base open your Internet browser and go to http:Ilwwi.pnl.gov. Once in the PNNL home page scroll down to the subheading Research Organizations. Within Research Organizations scroll down to a further subheading ( Environmental Technology) and finally double click under a final subheading \{ $\square$ Tank Waste Information\}. Upon clicking on this final subheading a new window appears called Tank Waste Information Network System (TWINS) Reference at which one must scroll down to the heading Hanford Tank Characterization Database Interface. After clicking on this heading a third new window appears called Hanford Tank Characterization Database Interface which explains how to query. NOTE: The complete address to access the Hanford Tank Characterization Database Interface is

http://twins.pnl.gov:8001/TCD/main.html

so that one does not have to go through all the PNNL homepage as described above. For first time user's once on the Hanford Tank Characterization Database Interface homepage one needs to click on the purple colored "Help" word found in the lower left hand corner of this homepage. This causes the screen to change to the Hanford Tank Characterization Database Interface Help page. On this page you click on either the words "Netscape Browser" or "Mosiac Browser" depending upon which type of browser software you have. This will bring up a new page of instructions with a title such as "Instructions For Configuring XXXX For Use With the TCD Web User Interface". After you follow these instructions you will be requested to download Excel Macros from the Hanford Tank Characterization Database Interface page. After you click on the download "icon" you will likely get a dialog box that you then click on save file (if the file name is not automatically named tcd plot.xls you should rename to such). You have now successfully initiated all the links needed to use the database. From now on when you get to the Hanford Tank Characterization Database Interface page you need only click on the Data Source Selection Forms "icon" to start the program to search for data on tanks.

In the box designated "Please Select a Subject Area/Table" you make a choice of what type of data you want. For our example we chose "Historical Analytical Data". You then click on the Build a Query Screen box and a new screen appears that allows you to choose which tank(s) you want to get information on and what constituents you are interested in obtaining. In our example we looked for all SX tanks and designated "All" for the constituents of interest. You then click on the "Submit Query" box and the program takes over. At the end of 
the search Excel should automatically open and a spreadsheet will appear with the data found within the large data base that meets your selection criteria, as long as the users has stored the tcd_plot.xls file in the C:lexcellxlstart directory. If the spreadsheet that appears is empty that means there were no data in the data base that met the desired search criteria. Currently under the Sample Analysis (Historical Analytical Data) option there is some data on SX-108 supernate solution taken in April 1961 and data on SX-111 supernate solution and solids taken in September 1974. These data are shown in Table 3.4. No other explanation as to where the original data can be found in hard copy is available in the data base. Under a different option, Sample Analysis [Tank Results (no QA)] is a large amount of data for SX-108 solids removed from the tank in August 1995 using an auger tool. The data come from two tank risers and includes analyses in duplicate from both the top and bottom of the auger samples from each riser. Both hot acid extraction and water soluble compositions are reported but we will not dwell on these data. They can be found in hard copy in a WHC report number WHC-SDWM-DP-151, Rev 1. We have also found a much larger amount of historical data on both supernates, solids and evaporator concentrates that were returned to the tanks for each of the twelve tanks in the S Tank Farm. These data show a much wider range in chemical compositions than those shown in Tables 3.2-3.4.

One computer expert that was instrumental in developing the Internet accessible data base is Steve Bobrowski-PNNL in ISB1 on telephone 509-375-2449. There also is a more formal help organization for the data base that can be reached via e:mail at: char_data_admin@twins.pnl.gov on the internet. 


\section{Distribution}

No. of

Copies

\section{OFFSITE}

2 Confederated Tribes and Bands of the Yakima Indian Nation

Environmental Restoration Waste

Management Program

P.O. Box 151

Toppenish, WA 98948

Attn: Wade Riggsbee

Russell Jim

2 Confederated Tribes of the Umatilla

Indian Reservation

P.O. Box 638

Pendleton, OR 97801

Attn: Bill Burke Tom Gilmore

Heart of America Northwest

Gerald Pollet

Heart of American Northwest, Suite 208

Seattle, WA 98101

Jacobs Engineering Group, Inc.

Phil Rogers

3250 W. Clearwater Ave.

Kennewick, WA 99336

2 Nez Perce Tribe

Nez Perce Tribal Department of

Environmental Restoration and Waste Management

Attn: Donna Powaukee

Stan Sobczyk
No. of

Copies

U.S. General Accounting Office

Chris Abraham

U.S. General Accounting Office

825 Jadwin Ave., MSIN \#A1-80

Richland, WA 99352

4 SX Expert Panel Members

John G. Conaway

Los Alamos National Laboratories

Mail Stop J561

P.O. Box 1663

Los Alamos, NM 87545

Robert Luxmoore

295 Solomon Hollow Rd

Harriman, TN 37748

John Matuszek

JMM Consulting Services

82 McGuffy Lane

Delmar, NY12054-4206

Ralph Patt

1655 S. Eim St \#405

Canby, OR 97013

\section{ONSITE}

17 DOE Richland Operations Office

C. E. Clark

B. L. Foley

A5-15

M. J. Furman

H0-12

C. C. Haass

$\mathrm{H} 0-12$

J. B. Hall

A5-15 
R. D. Hildebrand

R. A. Holten

J. E. Kinzer

E. M. Mattlin

J. K. McClusky

R. W. Lober

E. J. Rasmussen

D. S. Shafer

K. M. Thompson

A. K. Wright

Public Reading Room (2)

3 Bechtel Hanford, Inc.

K. R. Fecht

B. H. Ford

A. J. Knepp

$3 \quad$ CH2M Hill Hanford

J. V. Borgese

M. P. Connelly

V. J. Rohay

3 Fluor Daniel Hanford

E. A. Fredenburg

F. A. Ruck

J. D. Williams

1. Fluor Daniel Northwest

F. M. Mann

4 Lockheed Martin Hanford

R. J. Brown

B. G. Erlandson

D. A. Myers

R. D. Wojtasek
H9-03

H9-09

H9-11

H6-12

H6-23

S7-40

B4-43

$\mathrm{H} 0-12$

S7-50

A5-15

S7-54

S7-51

A5-58

S7-54

H0-12

S7-55

$\mathrm{H} 2-53$

H0-02

H0-19

T4-08

RI-51

G3-21

G3-21
$2 \quad$ Mactec
J. R Brodeur
B1-42
J. F. Bertsch
B1-42

1 Numatec Hanford Company

J. W. Shade

H5-27

1 U.S. Environmental Protection Agency

D. R. Sherwood

B5-01

6 Washington State Department of Ecology

S. L. Dahl

B5-18

D. N. Goswami B5-18

M. N. Jaraysi B5-18

S. Leja B5-18

Scott McKinney (Olympia) B5-18

$\begin{array}{ll}\text { C. O. Ruud B5-18 } & \end{array}$

4 Waste Management Federal Services Hanford

M. G. Gardner

H1-12

D. J. Moak

H1-11

J. C. Sonnichsen

M. I. Wood

H6-26

H6-06 
No. of

Copies

Pacific Northwest National

Laboratory

D. S. Burke

P8-37

K. J. Cantrell

K6-81

C. J. Chou

K6-81

J. L. Devary

K6-96

P. E. Dresel

K6-96

R. M. Ecker

K6-91

M. J. Fayer

K9-33

G. W. Gee

K9-33

R E. Gephart

K9-76

M. J. Hartman

K6-96

F. N. Hodges

K6-81

G. R. Holdren

K6-81

D. G. Horton

K6-81

D. I. Kaplan

K6-81

C. T. Kincaid

K9-33

K. M. Krupka

K6-81

V. G. Johnson (5)

K6-96

G. V. Last

K6-81

C. W. Lindenmeier

K6-81

S. P. Luttrell (5)

K6-96

S. V. Mattigod

K6-81

B. P. McGrail

K6-81

R. B. Mercer

K6-96

S. M. Narbutovskih

K6-81

S. P. Reidel

K6-81

R J. Serne (10)

K6-81

R. M. Smith

K6-96

P. D. Thorne

K9-33

B. A. Williams

K6-81

J. M. Zachara (5)

K8-96

Information Release Office (7)

K1-06 